\title{
镍催化醇衍生物构筑碳-碳键的偶联反应研究进展
}

\author{
吴 良 ${ }^{a}$ 魏瀚林 $a$ 陈建中 $*, b$ 张万斌 $*, a, b$ \\ ( ${ }^{a}$ 上海交通大学药学院 变革性分子前沿科学中心 上海市手性药物分子工程重点实验室 上海 200240) \\ $\left({ }^{b}\right.$ 上海交通大学化学化工学院 上海 200240)
}

\begin{abstract}
摘要 过渡金属催化构筑碳-碳键的交叉偶联反应由于其高效性、高选择性而得到了研究人员的广泛关注. 近年来, 含 $\mathrm{C}\left(\mathrm{sp}^{3}\right)-\mathrm{O}$ 键的亲电试剂由于其商业易得或容易合成、反应选择性高、环境友好等优点而被用来替代有机卤化物，应用 到构建 $\mathrm{C}\left(\mathrm{sp}^{3}\right)-\mathrm{C}$ 键的交叉偶联反应中. 一系列高效催化体系得以陆续报道, 其中镍催化剂由于其储量丰富、价格便宜 以及独特的催化活性和选择性而被逐步应用到此类反应中, 并取得了显著的成果. 综述了镍催化醇衍生物参与的偶联 反应的最新研究进展, 主要包括镍催化甲醇或伯醇衍生物参与的偶联反应, 镍催化仲醇衍生物参与的偶联反应, 镍催 化叔醇衍生物参与的偶联反应, 以及镍催化缩醛和 $N, O$ - 缩醛衍生物参与的偶联反应等.
\end{abstract}

关键词＼cjkstart镍催化剂; 醇衍生物; 交叉偶联反应; 立体专一性合成; 不对称催化

\section{Development of Nickel-Catalyzed Cross-Coupling of Alcohol Derivatives to Construct Carbon-Carbon Bonds}

\author{
Wu, Liang ${ }^{a} \quad$ Wei, Hanlin $^{a} \quad$ Chen, Jianzhong*,b Zhang, Wanbin ${ }^{*, a, b}$ \\ ( ${ }^{a}$ Shanghai Key Laboratory for Molecular Engineering and Chiral Drugs, Frontiers Science Center for Transformative \\ Molecules, School of Pharmacy, Shanghai Jiao Tong University, Shanghai 200240) \\ ( ${ }^{b}$ School of Chemistry and Chemical Engineering, Shanghai Jiao Tong University, Shanghai 200240)
}

\begin{abstract}
Transition metal-catalyzed cross-coupling reactions for building carbon-carbon bonds have received extensive attention due to their high efficiency and selectivity. In recent years, electrophiles which containing $\mathrm{C}\left(\mathrm{sp}^{3}\right)-\mathrm{O}$ bonds have been used to replace organic halides in cross-coupling reactions for the construction of $\mathrm{C}\left(\mathrm{sp}^{3}\right)-\mathrm{C}$ bonds, due to their advantages of commercial availability or facile synthesis, high reaction selectivity, and environmental friendliness. Among those reported highly efficient catalysts, nickel catalysts have been gradually applied to such reactions and achieved remarkable advances due to their earth-abundant, cheap, unique catalytic activities and selectivity. Because of the small radius of the nickel atom, $\mathrm{C}\left(\mathrm{sp}^{3}\right)-\mathrm{Ni}$ can inhibit and/or manipulate $\beta$-H elimination reactions, which reduces the formation of by-products. Nickel has several variable valence states and can flexibly participate in redox-neutral coupling reactions and reductive cross-coupling reactions. The latest research progress in nickel-catalyzed coupling reactions employing alcohol derivatives as electrophiles is reviewed. It is separated into four sections including nickel-catalyzed cross-coupling reactions involving methanol or primary alcohol derivatives, nickel-catalyzed cross-coupling reactions involving secondary alcohol derivatives, nickel-catalyzed cross-coupling reactions involving acetal and $\mathrm{N}, \mathrm{O}$-acetal derivatives, and nickel-catalyzed cross-coupling reactions involving tertiary alcohol derivatives.
\end{abstract}

Keywords Ni catalyst; alcohol derivatives; cross-coupling reactions; stereospecific synthesis; asymmetric catalysis

碳一碳键是有机分子中最为广泛存在的化学键之一. 因此，碳一碳键形成反应是合成天然产物、药物分子及精 细化学品的重要基础反应之一 ${ }^{[1]}$. 在有效构筑碳-碳键 的方法中，过渡金属催化的偶联反应由于其高效性、高
选择性、广泛适用性而受到了有机化学家们的高度关注 和深入研究, Richard Heck、Ei-ichi Negishi 以及 Akira Suzuki三位化学家因在该领域的卓越成就，获得了 2010 年诺贝尔化学奖. 如今, 高效的过渡金属催化的偶联反

\footnotetext{
* Corresponding authors. E-mail: 0091109001@sju.edu.cn; wanbin@sjtu.edu.cn Received June 10, 2021; revised June 22, 2021; published online July 19, 2021. Project supported by the Shanghai Post-Doctoral Excellence Program (No. 2020272) and the National Natural Science Foundation of China (Nos. 21620102003, 21772119, 21831005).

上海市 “超级博士后” 激励计划(No. 2020272)和国家自然科学基金(Nos. 21620102003, 21772119, 21831005)资助项目.
} 
应已广泛应用于制药、电子工业和先进材料等领域，可 以使人们造出更多复杂的有机分子.

经过几十年的不断发展, 目前通过偶联反应形成 $\mathrm{C}\left(\mathrm{sp}^{2}\right)-\mathrm{C}\left(\mathrm{sp}^{2}\right)$ 键的研究已取得很多优秀结果 ${ }^{[2]}$. 相比而 言, 通过烷基 $C\left(\mathrm{sp}^{3}\right)$ - $X$ ( $X$ 为卤素、氧或氮衍生物等) 键的活化来构建 $\mathrm{C}\left(\mathrm{sp}^{3}\right)-\mathrm{C}$ 键的交叉偶联反应则更具挑 战性 ${ }^{[3]}$. 首先, 过渡金属与含 $\mathrm{C}\left(\mathrm{sp}^{3}\right)-\mathrm{X}$ 键的烷基卤化 物、醇衍生物等发生氧化加成的速率相对缓慢; 其次, 得到的烷基金属中间体容易发生 $\beta-\mathrm{H}$ 消除等副反应. 因 此, 寻找合适的金属催化剂至关重要, 近年来金属锦因 储量丰富、价格便宜、对环境友好、符合现代化学可持 续发展要求等优点, 开始被应用于许多反应中, 例如不 对称加成反应、不对称催化氢化、偶联反应、 $\mathrm{C}-\mathrm{H}$ 活 化等 ${ }^{[4,5]}$, 并取得了显著成果. 特别是在交叉偶联反应 中, 镍表现出了独特的催化活性. 由于镍原子半径较小, 在偶联反应中 $\mathrm{C}\left(\mathrm{sp}^{3}\right)-\mathrm{Ni}$ 不易发生 $\beta-\mathrm{H}$ 消除反应, 减少 了副产物的生成. 最重要的是镍的价态变化丰富, 目前 已经分离鉴定的镍化合物氧化态包括 $\mathrm{Ni}(0) 、 \mathrm{Ni}(\mathrm{I})$ 、 $\mathrm{Ni}(\mathrm{II}) 、 \mathrm{Ni}(\mathrm{III}) 、 \mathrm{Ni}(\mathrm{IV})$, 使得其在催化交叉偶联反应中, 既可能存在 $\mathrm{Ni}(0) / \mathrm{Ni}(\mathrm{II})$ 双电子转移过程, 也可能存在 $\mathrm{Ni}(\mathrm{I}) / \mathrm{Ni}(\mathrm{II}) / \mathrm{Ni}(\mathrm{III})$ 单电子转移过程. 这也为开发全新的 反应类型和探索新的催化循环机理, 尤其是为解决稀有 贵金属催化体系中存在的难题提供了更多的可能手段.

含烷基 $\mathrm{C}\left(\mathrm{sp}^{3}\right)-\mathrm{O}$ 的亲电试剂由于其广泛易得、反 应选择性高、环境友好等优点而被用来替代一般的有机 卤化物. 近年来, 金属镍催化的醇衍生物参与的偶联反 应得到了显著的发展 ${ }^{[6]}$, 常用的醇衍生物有简单的醇、 醚、酯、氨基甲酸酯类以及磺酸酯类化合物等(Scheme $1)$.

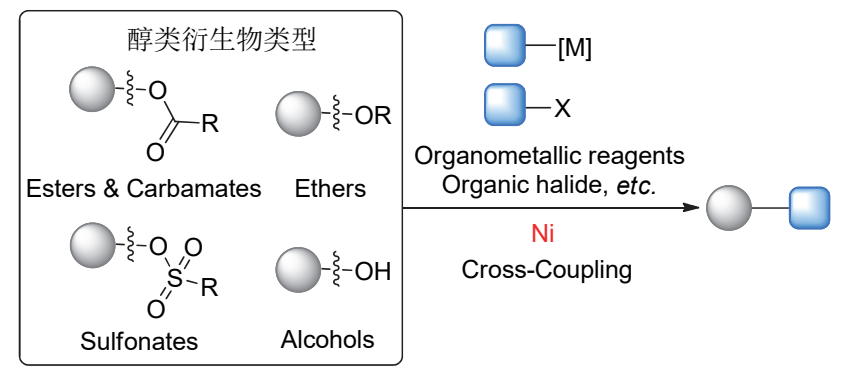

图式 1 醇衍生物参与的交叉偶联反应

Scheme 1 Cross-coupling reaction involving alcohol derivatives
目前已经报道的镍催化的含烷基 $\mathrm{C}\left(\mathrm{sp}^{3}\right)-\mathrm{O}$ 醇衍生 物参与的偶联反应综述有: 2015 年 Jarvo 等[6]]报道的镍 催化茮基醚及酯的立体专一性交叉偶联反应，Reisman 等 ${ }^{[1 b]}$ 报道的过渡金属催化的有机金属试剂参与的对映 选择性和立体专一性的交叉偶联反应构建碳一碳键，以 及 Watson 等[6g,6i]报道的烷基醇衍生物参与的立体专一 性交叉偶联反应. 这几篇综述都重点总结了醇衍生物与 有机金属试剂的交叉偶联反应，未对其与烷基卤化物等 的还原交叉偶联做出阐述. 同时在这几篇综述涉及醇衍 生物的反应都是从手性原料出发, 通过立体专一性转化 得到手性产物，未对该领域的非手性合成以及不对称催 化方面做出总结. 本文将全面总结通过镍催化烷基 $\mathrm{C}\left(\mathrm{sp}^{3}\right)-\mathrm{O}$ 亲电试剂的偶联反应构筑 $\mathrm{C}\left(\mathrm{sp}^{3}\right)-\mathrm{C}$ 键这一 领域. 将从镍催化甲醇或伯醇衍生物参与的偶联反应、 镍催化仲醇衍生物参与的偶联反应、镍催化叔醇衍生物 参与的偶联反应以及镍催化缩醛和 $N, O$ - 缩醛衍生物参 与的偶联反应等方面进行阐述和总结.

\section{1 镍催化甲醇或伯醇衍生物参与的偶联反应}

\section{1 甲醇或伯醇衍生物与有机金属试剂等的偶联反应}

近年来金属镍催化的烷基 $\mathrm{C}\left(\mathrm{sp}^{3}\right)-\mathrm{O}$ 亲电试剂(醇 衍生物)参与的交叉偶联反应得到了显著的发展, 亲核 试剂一般采用有机金属试剂, 例如有机镁试剂 $(\mathrm{RMgX})$ 、 有机锌试剂 $(\mathrm{RZnX})$ 、有机嗍试剂 $\left(\mathrm{RB}(\mathrm{OH})_{2}\right)$ 等.

过渡金属催化的烯丙基取代反应作为一类重要的 形成 $\mathrm{C}-\mathrm{C}$ 键和 $\mathrm{C}-\mathrm{X}$ 键 (如 $\mathrm{C}-\mathrm{O} 、 \mathrm{C}-\mathrm{N}$ 和 $\mathrm{C}-\mathrm{S}$ 键等) 的反应，现已被广泛应用于天然产物和具有重要生物活 性药物的合成中 ${ }^{[7]}$. 在这类反应中通常需要经过 $\pi$-烯丙 基金属配合物中间体的过程. 在进行烯丙基官能化反应 中亲核试剂通常分为两类: (1)稳定或“软” 亲核试剂, 在 此定义的亲核试剂的共轭酸的 $\mathrm{p} K_{\mathrm{a}}$ 小于 $25 ;$; (2)不稳定或 “硬” 亲核试剂的反应，通常包含有机金属试剂. 软亲核 试剂通常会直接攻击 $\pi$-烯丙基金属络合物的碳原子，而 硬亲核试剂一般先通过转金属化与 $\pi$-烯丙基金属作用 得到一类金属络合物中间体，随后通过还原消除来构建 新的碳一碳键(Scheme 2).

烯丙醇衍生物是一类常用的烯丙基底物, 广泛应用 于与有机金属试剂的镍催化交叉偶联反应中. 1989 年,

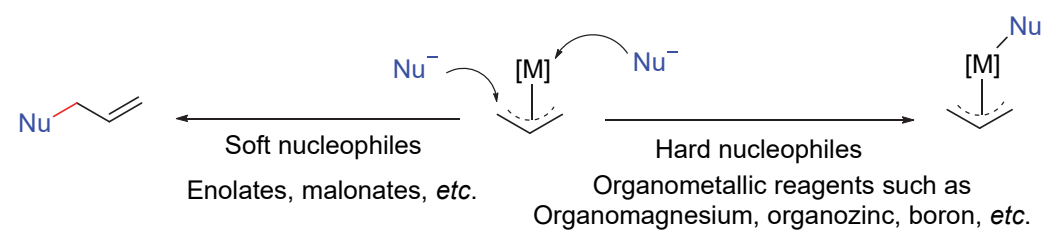

图式 2 稳定与不稳定亲核试剂比较

Scheme 2 Stabilized vs unstabilized nucleophiles 
Yamamoto 课题组 ${ }^{[8]}$ 报道了非手性的镍催化烯丙醇与有 机锌试剂的偶联反应. 随后, Nedden 课题组 ${ }^{[9]}$ 报道了一 例镍催化的直链烯丙醇衍生物与芳基镁试剂的不对称 偶联反应，当以 Chiraphos 为手性配体时，能以 $75 \%$ 的 收率得到支链和直链产物比为 $67: 33$ 的混合产物, 以 及 $89 \%$ 的对映选择性. 2009 年, Woodward 课题组 ${ }^{[10]}$ 报道 了一类 Baylise-Hillman 衍生的烯丙基底物与三甲基铝 试剂的不对称偶联反应, 以轴手性二茂铁衍生物为手性 配体, 能够得到高对映选择性的产物, 但是收率和区域 选择性不能令人满意(Scheme 3 ).

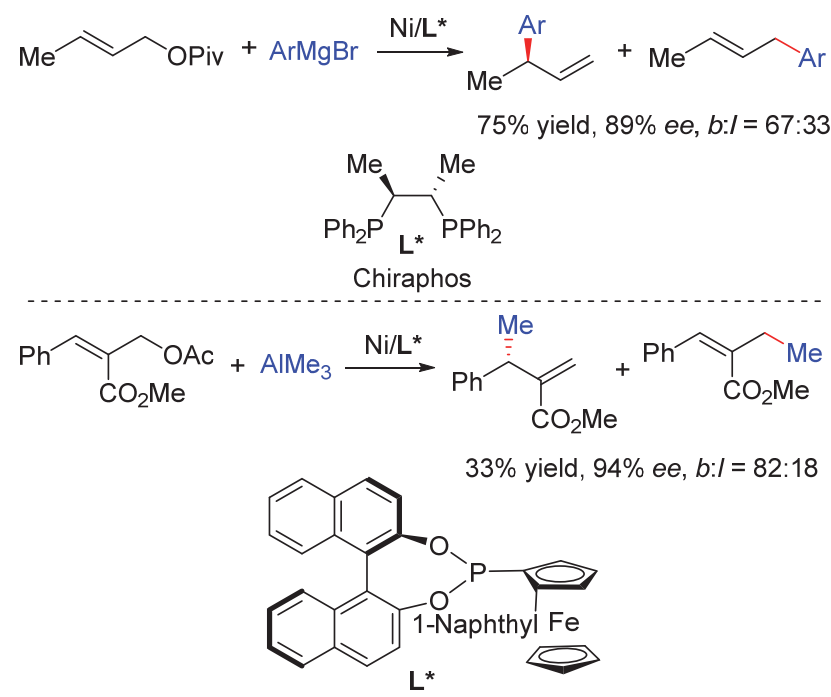

图式 3 镍催化直链烯丙醇衍生物与芳基镁试剂及三甲基铝 的不对称偶联反应

Scheme 3 Nickel-catalyzed asymmetric coupling of linear allyl alcohol derivatives with aryl magnesium and $\mathrm{AlMe}_{3}$ reagents

2008 年, Oshima 课题组 ${ }^{[11]}$ 报道了利用镍为催化剂, 催化 Boc 保护的烯丙醇与高烯丙醇的交叉偶联反应, 在 温和条件高效地合成了一系列 1,5-己二烯衍生物. 该小 组根据实验结果推测了反应机理, 首先, 镍对 Boc 保护 的烯丙醇底物氧化加成得到中间体 $\mathbf{1}$, 随后脱羧得到烷 氧基( $\pi$-烯丙基)镍中间体 2 , 然后与高烯丙醇底物进行 配体交换, 经过逆烯丙基化过程 3, 得到中间体 4. 最后 还原消除得到偶联产物, 同时再生最初的零价镍催化剂 (Scheme 4).

2010 年, Jamison 课题组 ${ }^{[12]}$ 报道了镍催化烯丙醇衍 生物与简单烯烃的偶联反应, 此方法广泛适用于一系列 的烯丙醇衍生物以及一些未活化的末端烯烃, 例如乙烯 和丙烯, 可高效获得具有重要合成价值的 1,4-二烯类化 合物. 该小组 ${ }^{[13]}$ 提出了可能的催化反应机理: 首先 $\mathrm{Ni}^{0}$ 络合物与烯丙基底物反应得到相应的烯丙基镍络合物 5, 随后与烯烃底物作用生成 6 . 烯烃部分迁移插入得到 中间体 7. 在 $\mathrm{P}(\mathrm{OPh})_{3}$ 的作用下进行 $\beta-\mathrm{H}$ 消除和还原消除
经过中间体 8 得到 1,4-二烯产物并再生催化剂(Scheme $5)$.
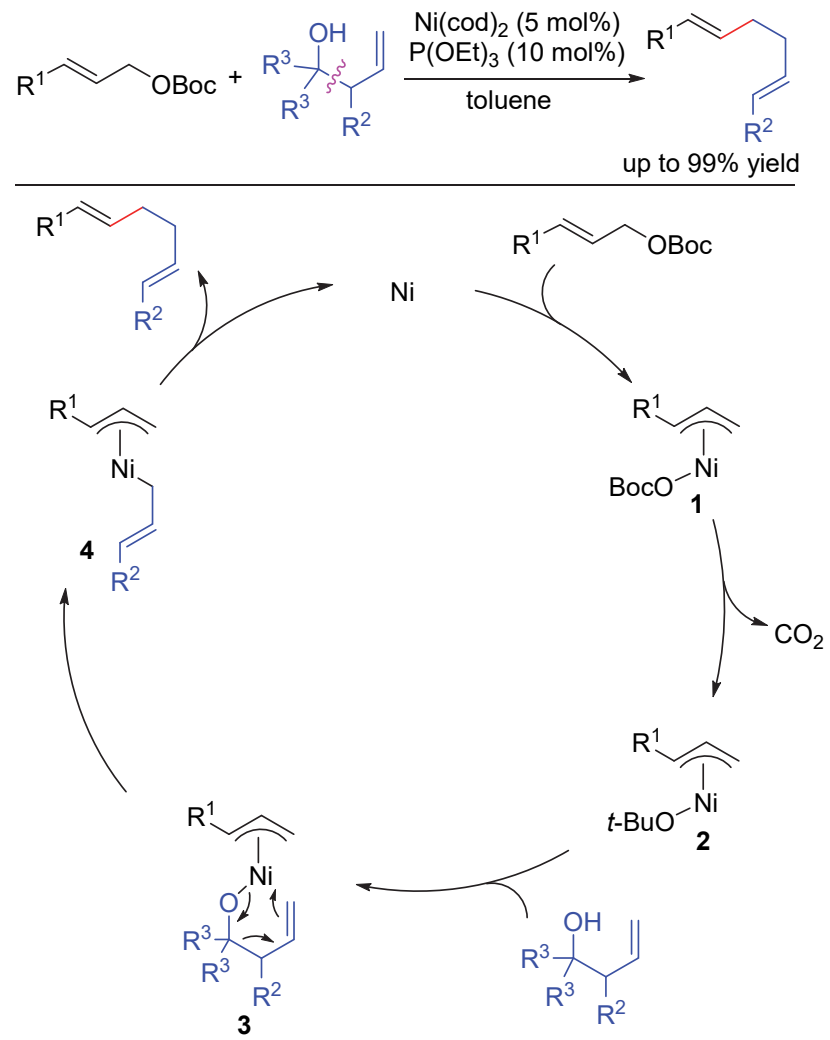

图式 4 镍催化烯丙醇衍生物与高烯丙醇的偶联反应

Scheme 4 Nickel-catalyzed coupling of allyl alcohol derivatives with homoallyl alcohols

2019 年, Molander 课题组 ${ }^{[14]}$ 实现了自由基介导的 镍/光氧化还原双催化的烯丙醇衍生物与 4-烷基-1,4-二 氢吡啶衍生物的交叉偶联反应. 反应条件温和，官能团 容忍性优异，能够以高区域选择性得到线性的 $E$ 构型产 物. 当烯丙醇作为反应底物时，加入二碳酸二甲酯 (DMDC)作为活化剂, 原位生成碳酸酯, 从而促进反应 的进行. 动力学同位素效应实验结果表明, 镍催化剂对 烯丙基亲电试剂的氧化加成是该反应的速率决策步骤 (Scheme 6).

2020 年, Engle 课题组 ${ }^{[15]}$ 报道了镍催化烯丙醇衍生 物与烯丙胺衍生物及二甲基锌的偶联反应. 这种转化是 通过弱配位的单齿氮杂杂环导向基团实现，这些基团是 合成中有用的结构单元，包括邻苯二甲酰亚胺、吡啶酮、 喹诺酮、哒嗪酮、吡唑、三唑、四唑和苯并噁唑等. 该 反应条件温和，与多种烯丙基亲电试剂兼容. 机理研究 揭示了弱配位导向基团解离的重要性，在反应过程中能 够促进烯丙基部分之间的偶联以及 $\mathrm{C}\left(\mathrm{sp}^{3}\right)-\mathrm{C}\left(\mathrm{sp}^{3}\right)$ 的还 原消除(Scheme 7). 


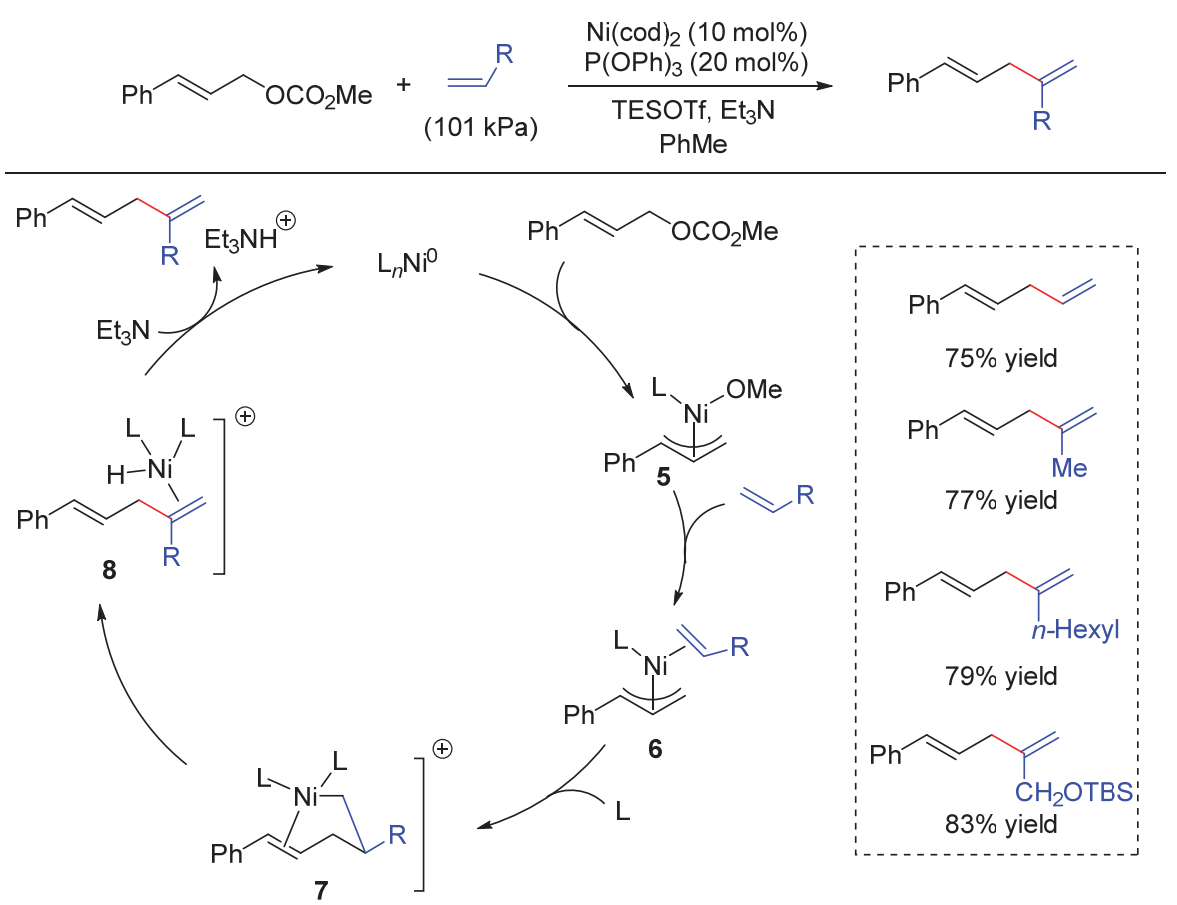

图式 5 镍催化烯丙醇衍生物与简单烯烃的偶联反应及机理

Scheme 5 Nickel-catalyzed coupling of allyl alcohol derivatives with simple alkenes and mechanism

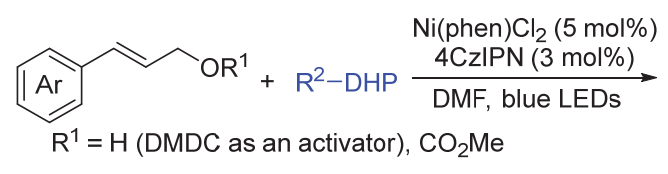

$$
\text { Ar } \mathrm{R}^{2}
$$

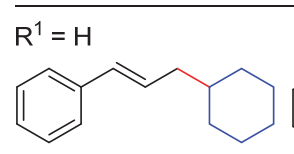

$82 \%$ yield

$\mathrm{R}^{1}=\mathrm{CO}_{2} \mathrm{Me}$<smiles>C(=Cc1ccccc1)CC1CCCCC1</smiles>

$85 \%$ yield

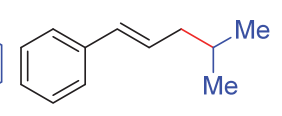

$66 \%$ yield<smiles>CC(C)CC=Cc1ccccc1</smiles>

$83 \%$ yield<smiles>OCC/C=C/c1ccccc1</smiles>

$57 \%$ yield<smiles>C(=Cc1ccccc1)CCOCc1ccccc1</smiles>

$71 \%$ yield

图式 6 镍催化烯丙醇衍生物与烷基-1,4-二氢吡啶的偶联反 应

Scheme 6 Nickel-catalyzed coupling of allyl alcohol derivatives with alkyl 1,4- dihydropyridines

2016 年, Morken 课题组 ${ }^{[16]}$ 报道了镍催化环状硫酸 酯与芳基镁试剂的不对称交叉偶联反应，通过去对称化 过程, 高收率和高对映选择性地构建了一个手性中心. 在对反应结果及机理实验进行研究后, 推测手性镍络合 物使环状硫酸酯开环是该反应立体化学的决定步骤, 环 状硫酸酯的构象有两类 $\mathbf{1 0}$ 和 $\mathbf{1 1}$, 参与反应的环状硫酸 酯的构象为 10 , 在催化循环中活性中间体 9 对 10 进行

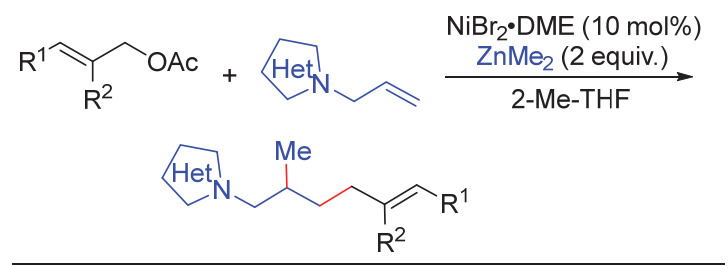

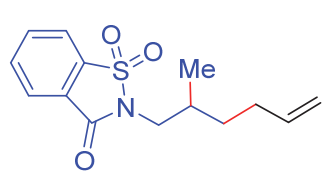

$78 \%$ yield<smiles>CC(CC/C=C/c1ccccc1)Cn1cnccc1=O</smiles>

$15 \%$ yield<smiles>CC(CC/C=C/c1ccccc1)Cn1cncn1</smiles>

$48 \%$ yield<smiles>CC(CC/C=C/c1ccccc1)CN1C(=O)c2ccccc2C1=O</smiles>

$87 \%$ yield<smiles>CC(CC/C=C/c1ccccc1)Cn1cccn1</smiles>

$80 \%$ yield<smiles>CC(CC/C=C/c1ccccc1)Cn1nc2ccccc2n1</smiles>

$97 \%$ yield
图式 7 镍催化烯丙醇衍生物与烯丙胺衍生物及二甲基锌的 偶联反应

Scheme 7 Nickel-catalyzed coupling of allyl alcohol derivatives with allyl amine derivatives and $\mathrm{ZnMe}_{2}$

$\mathrm{S}_{\mathrm{N}} 2$ 类型的氧化加成通过过渡态 $\mathbf{T S}$, 得到中间体 $\mathbf{1 2}$, 随 后还原消除得到 13 , 再与格氏试剂作用得到目标产物 并再生催化剂(Scheme 8). 

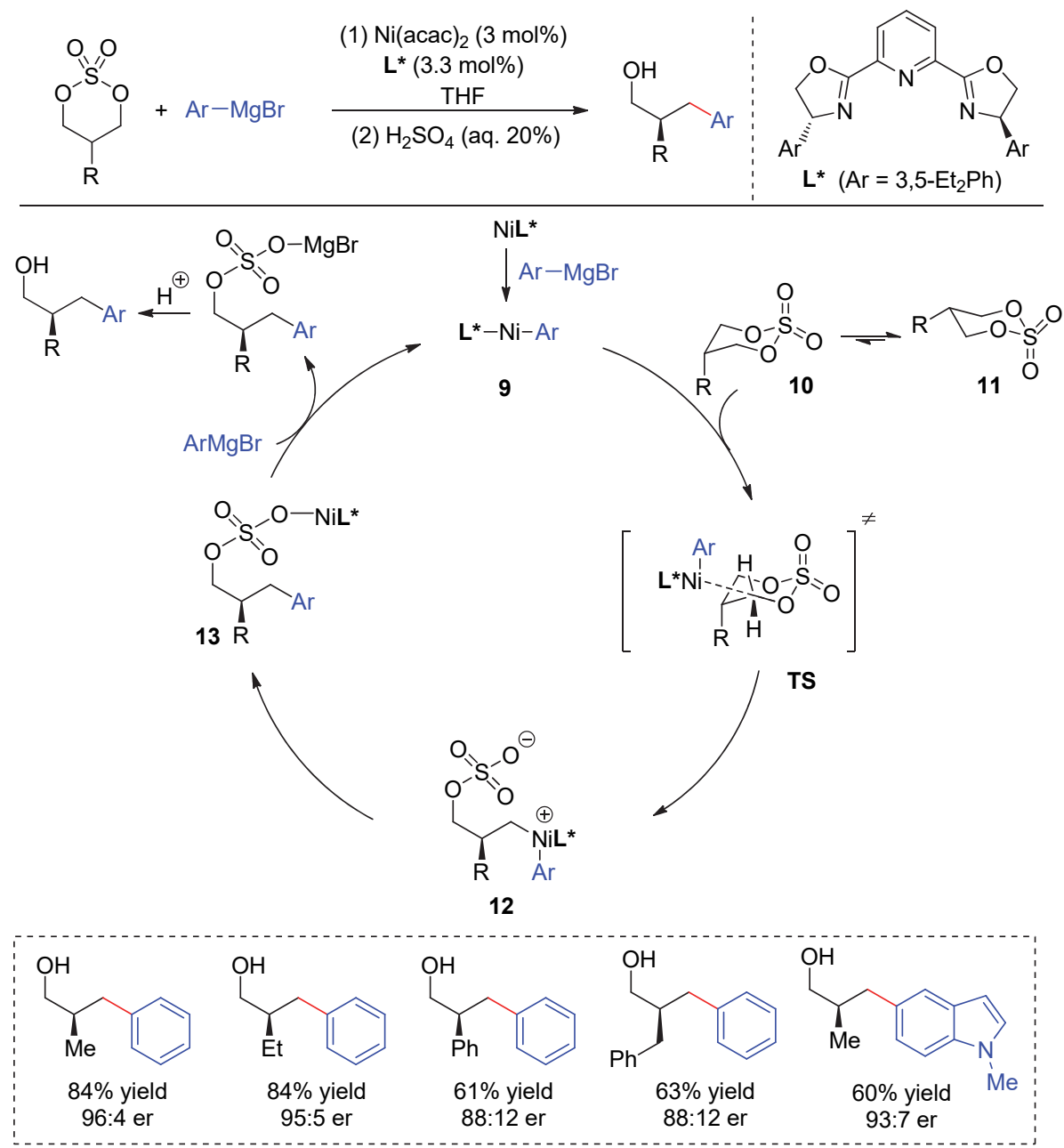

图式 8 镍催化环状硫酸酯与有机镁试剂的不对称偶联反应及机理

Scheme 8 Nickel-catalyzed asymmetric coupling of cyclic sulfates with organomagnesium reagents and mechanism

简单醚官能团相对较为稳定，如果能实现其高效的 转化反应, 则简单醚可以在合成策略中发挥更为关键的 作用. 2008 年施章杰课题组 ${ }^{[17]}$ 报道了镍催化的茮基烷基 醚与有机镁试剂的交叉偶联反应. 通过 $\mathrm{C}\left(\mathrm{sp}^{3}\right)-\mathrm{O}$ 键的 活化, 以优异的化学选择性得到目标产物, 研究发现当 底物中同时存在 $\mathrm{C}\left(\mathrm{sp}^{2}\right)-\mathrm{O}$ 与苄位 $\mathrm{C}\left(\mathrm{sp}^{3}\right)-\mathrm{O}$ 键时, 可以 通过加入不同的双膦配体来调控反应的选择性, 单一地 得到苄位甲基化产物。随后利用苄醇替代茮基烷基醚, 同样实现了其与烷基及芳基镁试剂的交叉偶联反应, 得 到优异的收率 ${ }^{[18]} .2011$ 年该小组 ${ }^{[19]}$ 利用镍催化剂实现了 $\alpha$-新戊氧基酮与芳基硼酸的交叉偶联反应，高收率地得 到一系列 $\alpha$-芳基酮类化合物(Scheme 9).

\section{2 甲醇或伯醇衍生物与有机卤化物等的还原偶联反}

应

上节中总结了有机金属试剂与烷基 $\mathrm{C}\left(\mathrm{sp}^{3}\right)-\mathrm{O}$ 亲电 试剂的氧化还原中性交叉偶联反应. 以下介绍在还原剂 作用下多组分亲电试剂之间的还原交叉偶联反应. 还原 交叉偶联反应避免了对空气、水敏感的有机金属试剂的

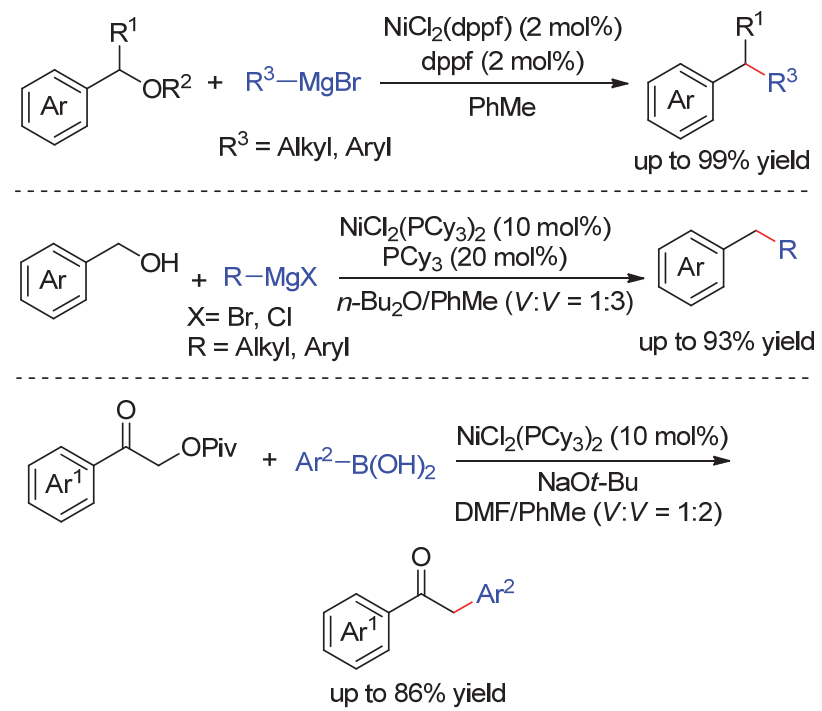

图式 9 镍催化苄醚/醇及 $\alpha$-新戊氧基酮与有机金属试剂的偶 联反应

Scheme 9 Nickel-catalyzed coupling of benzylic ethers/alcohols and $\alpha$-pivaloxyl ketones with organometallic reagents 
使用, 反应条件更温和, 官能团耐受性更佳, 具有更优 势的应用前景. 而烷基 $\mathrm{C}\left(\mathrm{sp}^{3}\right)-\mathrm{O}$ 亲电试剂参与的还原 交叉偶联反应是目前十分具有挑战性的偶联反应之一 (Scheme 10).

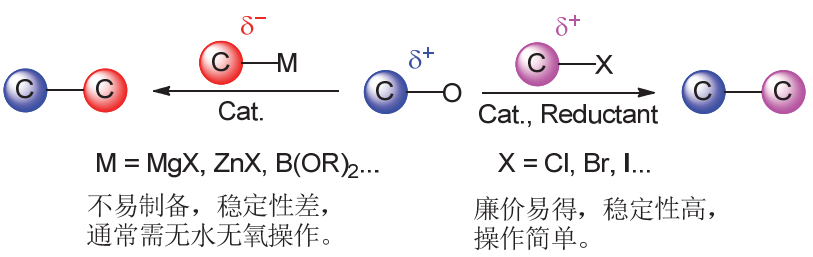

图式 10 氧化还原中性偶联反应与还原偶联反应比较

Scheme 10 Redox-neutral coupling reactions vs reductive coupling reactions

\subsection{1 磺酸酯类化合物作为甲基亲电试剂}

烷基磺酸酯, 特别是一级烷基醇的磺酸酯, 容易与 碘离子等进行原位卤素交换, 形成高活性的烷基碘物种 来参与偶联反应. 基于卤素交换, 很多镍催化烷基卤化 物参与的交叉偶联反应, 也能推广到烷基磺酸酯底物. 该类型的研究论文很多, 甚至一篇烷基卤化物偶联反应 的研究论文往往夹杂一个或两个烷基磺酸酯底物. 因此 在本综述中关于烷基磺酸酯卤素交换参与偶联反应仅 做举例说明.

甲基通常用来调节候选药物的性质, 并会对材料的 功能性产生重要的影响[20]. 考虑到这一重要性, 2014 年

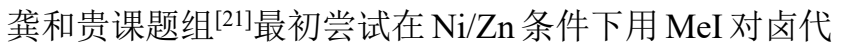
烷进行甲基化, 遗憾的是未能观察到所需的 $\mathrm{C}\left(\mathrm{sp}^{3}\right)-\mathrm{Me}$ 产物, 这可能是因为在反应过程中优先形成了 $\mathrm{Me}-\mathrm{ZnI}$ 或乙烷, 使得反应无法进行. 为了避免这些可能的竞争 反应，该小组选择使用反应性较低的 MeOTs 作为甲基 源, 以镍作为催化剂与 $\mathrm{B}_{2} \mathrm{pin}_{2} / \mathrm{MeOLi}$ 结合使用, 实现了 一系列伯烷基溴、仲烷基溴以及芳基酰氯化合物的甲基 化反应(Scheme 11).

在这一甲基化反应中, 因为需要保持低浓度的 $\mathrm{MeX}(\mathrm{X}=\mathrm{Br}$ 或 $\mathrm{Cl}$, 由氯化镍或烷基溴转化而来), 因此 $\mathrm{MeOTs}$ 缓慢转换为 $\mathrm{MeX}$ 的过程至关重要. 该小组 ${ }^{[22]}$ 提 出了双重氧化机理, 首先 $\mathrm{L}_{n}-\mathrm{Ni}-\mathrm{Br}$ 在反应条件下生成 活性的 $\mathrm{L}_{n}-\mathrm{Ni}^{\mathrm{I}}-\mathrm{Bpin}$ 物种 14, 随后与由 MeOTs 转化而来 的更具亲电活性的 $\mathrm{MeX}$ 反应, 得到三价镍 $\mathrm{Me}-\mathrm{Ni}^{\mathrm{III}}\left(\mathrm{L}_{n}\right)$ (Bpin)X 中间体 15, 消除 Bpin-X生成体积较小的一价镍 $\mathrm{Me}-\mathrm{Ni}^{\mathrm{I}}\left(\mathrm{L}_{n}\right)$ 物种 16, 接着与位阻更大的烷基溴作用得到 一个关键 $\mathrm{Me}-\mathrm{Ni}^{\mathrm{III}}\left(\mathrm{L}_{n}\right)(\mathrm{Br})$ - 烷基中间体 17 , 最后还原消 除得到甲基化产物, 释放出一价镍进入下一个循环 (Scheme 12).

2017 年, 该课题组 ${ }^{[23]}$ 同样利用 $\mathrm{Ni} / \mathrm{Zn}$ 催化体系, 实 现了芳基卤化物/甲苯磺酸酯类化合物的甲基化反应, 反应的官能团的耐受性非常出色. 反应活性较低的芳基

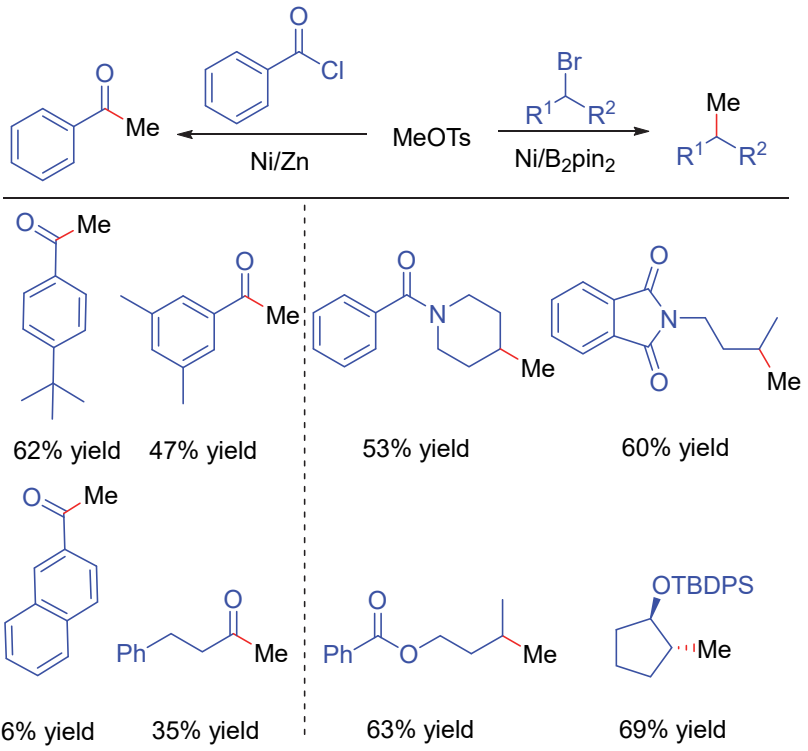

图式 11 镍催化对甲苯磺酸甲酯与烷基卤化物及酰氯的甲基 化反应

Scheme 11 Nickel-catalyzed methylation of methyl $p$-tosylate with alkyl halides and acid chlorides

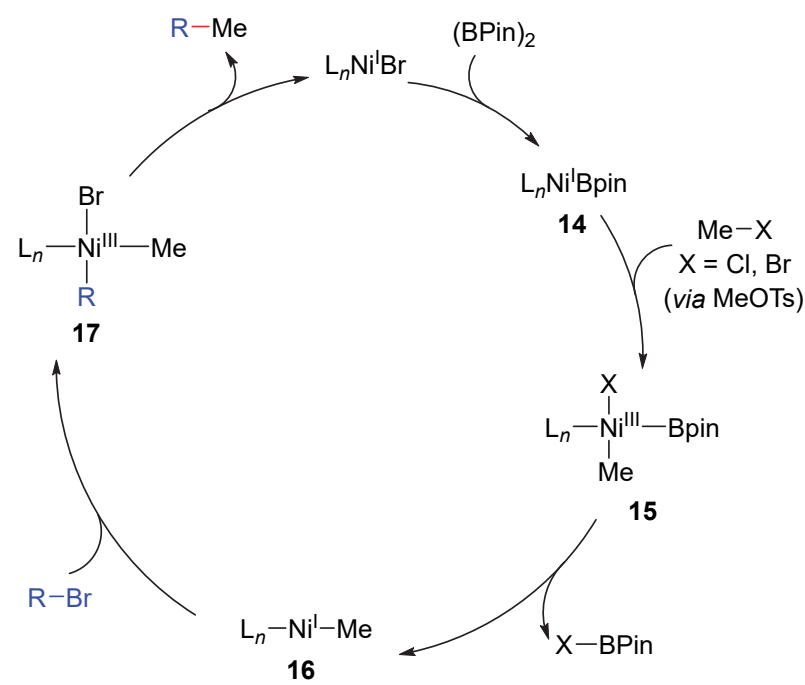

图式 12 镍催化还原甲基化可能的机理

Scheme 12 Possible mechanism of nickel-catalyzed reductive methylation

甲苯磺酸酯类化合物需要使用 $1,1^{\prime}$-双(二苯基膦基)二茂 铁(dppf)作为配体，对于空间位阻较大的 2,6-二甲基苯 基甲苯磺酸酯在标准条件下也可实现甲基化反应. 初步 的机理研究排除了原位生成 MeZnX 的可能性; 因此, 也就排除了 Ni/Bipy 催化的芳基卤化物甲基化的 Negishi 型机理(Scheme 13).

2019 年, Komeyama 课题组 ${ }^{[24]}$ 报道了镍和钴组合催 化的烷基甲苯磺酸酯类化合物与烷基卤化物之间的还 原交叉偶联反应，该反应能够在温和的条件下进行，并 


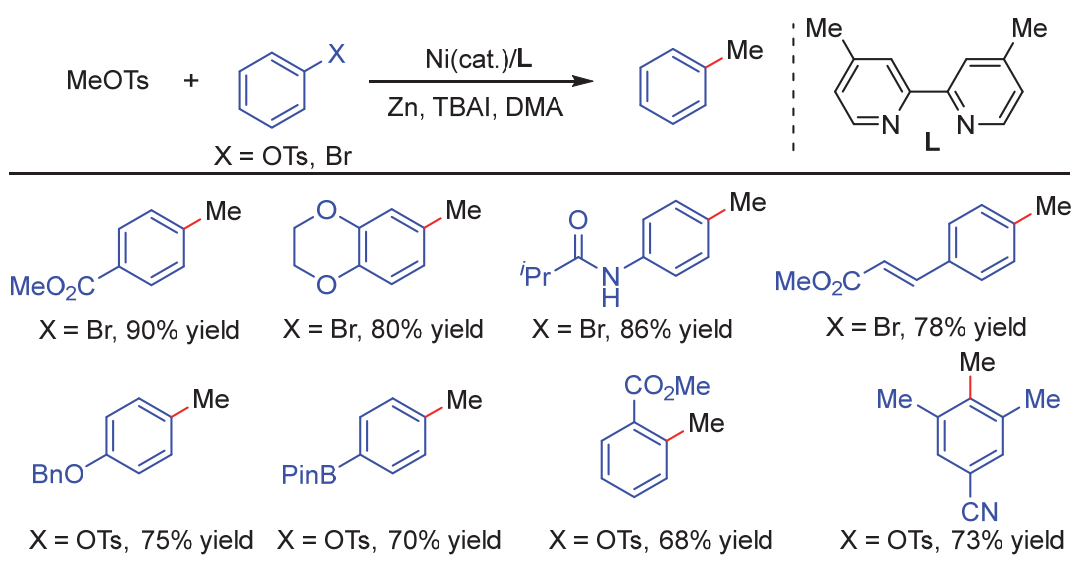

图式 13 镍催化对甲苯磺酸甲酯与芳基卤化物/甲苯磺酸酯的甲基化反应

Scheme 13 Nickel-catalyzed methylation of methyl $p$-tosylates with aryl halides/tosylates

且具有良好的官能团耐受性. 初步机理研究表明, 烷基 自由基可能来自烷基卤化物以及烷基甲苯磺酸酯类化 合物. 此外，该交叉偶联可用于组蛋白脱乙酰基酶抑制 剂 Vorinostat 的高效合成(Scheme 14).

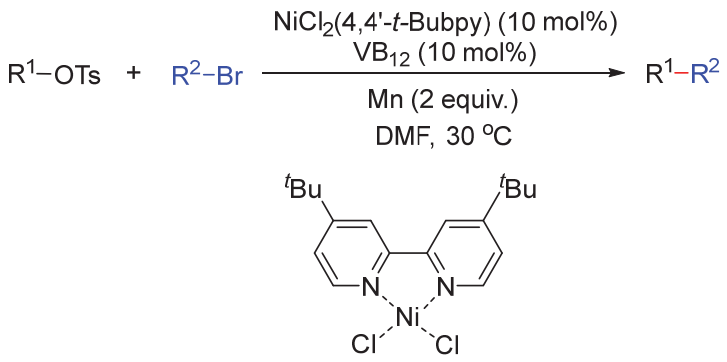

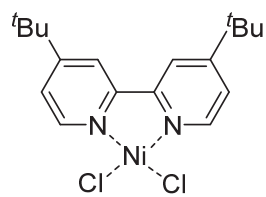

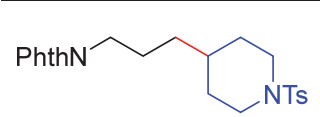

$60 \%$ yield
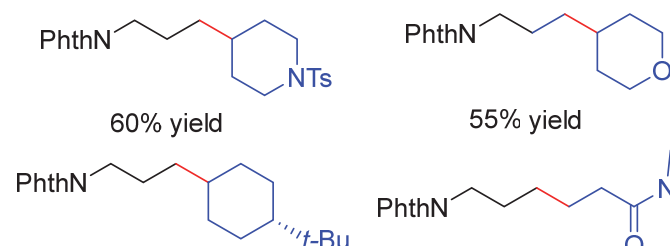

$55 \%$ yield

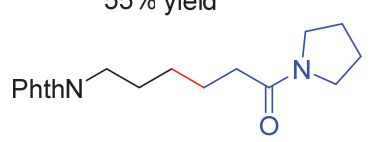

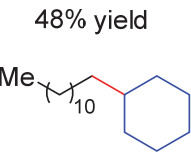

$65 \%$ yield

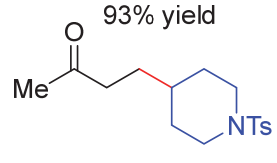

$84 \%$ yield
图式14 镍/钴催化烷基甲苯磺酸酯与芳基卤化物的甲基化反 应

Scheme 14 Nickel/Cobalt catalyzed methylation of alkyl tosylates with alkyl halides

2018 年, MacMillan 课题组 ${ }^{[25]}$ 以三(三甲基甲硅烷 基)硅烷醇作为有效的卤素篗取剂, 利用光氧化还原催 化剂和镍作为组合催化剂, 实现了 $\mathrm{C}\left(\mathrm{sp}^{3}\right)-\mathrm{C}\left(\mathrm{sp}^{3}\right)$ 亲电 交叉偶联反应。在这项研究中, 该小组实现了在各种脂 肪族药物基团上偶联一些小烷基亲电试剂，包括甲基甲 苯磺酸甲酯和环烷基溴化物等, 提供了合成复杂分子的 新策略，丰富了合成手段.
该小组 ${ }^{[25]}$ 提出了可能的催化机理：首先光催化剂 $\mathrm{Ir}^{\mathrm{III}}$ 在可见光下激发, 得到寿命更长 $(\tau=2.3 \mu \mathrm{s})$ 的激发态 *IrII 络合物. 该物质是一种强的单电子氧化剂 $\left(E_{1 / 2}^{\mathrm{red}}\left[{ }^{*} \mathrm{Ir}^{\mathrm{III}} / \mathrm{Ir}^{\mathrm{II}}\right]=+1.21 \mathrm{~V}\right.$ vs SCE in $\left.\mathrm{CH}_{3} \mathrm{CN}\right)$, 随后通过 单电子转移被超级硅烷醇的去质子化反应所产生的硅 烷醇盐还原，从而提供还原的催化剂 $\operatorname{Ir}{ }^{\mathrm{II}[26]}$. 以甲硅烷氧 基为中心的自由基经历键异构化产生甲硅烷基，它可以 迅速㩲取烷基澳 18 的溴原子, 从而得到脂肪族自由基 19 ${ }^{[27]}$. 同时活性光催化剂 $\mathrm{Ir}^{\mathrm{II}}$ 能够通过单电子转移过程, 使催化剂 $\mathrm{L}_{n} \mathrm{Ni}^{\mathrm{II} X}$ 还原得到 $\mathrm{L}_{n} \mathrm{Ni}^{0}$ 物种 $\left(E_{1 / 2}^{\mathrm{red}}\left[\mathrm{Ir}^{\mathrm{III}} / \mathrm{Ir}^{\mathrm{II}}\right]=\right.$ $-1.37 \mathrm{~V}$ vs $\mathrm{SCE}$ in $\mathrm{CH}_{3} \mathrm{CN}, E_{1 / 2}^{\text {red }}\left[\mathrm{Ni}^{\mathrm{II}} / \mathrm{Ni}^{0}\right]=-1.2 \mathrm{~V}$ vs $\mathrm{SCE}$ in $\mathrm{DMF})^{[28]}$. $\mathrm{L}_{n} \mathrm{Ni}^{0}$ 物种捕获自由基 $\mathbf{1 9}$, 得到烷基$\mathrm{Ni}^{\mathrm{l}} \mathrm{L}_{n}$ 物种 20 ${ }^{[29]}$, 随后对 $\mathrm{MeBr}$ (由 MeOTs 原位生成)进行 氧化加成得到物种 $\mathbf{2 1}$, 还原消除得到偶联产物以及 $\mathrm{L}_{n} \mathrm{Ni}^{\mathrm{I}} \mathrm{X}$, 随后通过单电子转移得到 $\mathrm{L}_{n} \mathrm{Ni}^{0}$ 物种, 同时 $\mathrm{Ir}^{\mathrm{II}}$ 转化成 $\mathrm{Ir}^{\mathrm{III}}$, 使得两个催化循环都能运转起来 [30] (Scheme 15).

\subsection{2 其他酯类化合物作为伯烷基亲电试剂}

2012 年, 龚和贵课题组 ${ }^{[31]}$ 开发了一种用于烷基卤 化物烯丙基化的有效镍催化方法. 具有各种取代基团的 烯丙基底物和卤代烷都能有效地转化为相应的烯丙基 化产物. 该反应可能的机理为: 首先零价 $\mathrm{Ni}^{0}$ 氧化加成 到碳酸烯丙酯上得到烯丙基- $\mathrm{Ni}^{\mathrm{II}}$ 物种 $22, \mathrm{Zn}$ 的单电子还 原得到烯丙基 $-\mathrm{Ni}^{\mathrm{I}}$ 物种 23 , 随后与烷基卤化物作用产生 烷基自由基和第二个烯丙基- $\mathrm{Ni}^{\mathrm{II}}$ 复合物. 烷基自由基和 $\mathrm{Ni}^{\mathrm{II}}$ 中间体键合生成烷基- $\mathrm{Ni}^{\mathrm{III}}$-烯丙基物种 $\mathbf{2 4}$, 最后还原 消除得到偶联产物，释放出一价镍 $\mathrm{Ni}^{\mathrm{I}}$ ，被 $\mathrm{Zn}$ 还原得到 零价 $\mathrm{Ni}^{0}$, 进入下一个循环(Scheme 16).

2014 年, Martin 课题组 ${ }^{[32]}$ 开发出了一种新型的镍催 化烯丙酯类化合物与 $\mathrm{CO}_{2}$ 的差样化还原偶联反应. 通过 配体的调控可以选择性地得到直链或者支链羧基化产 


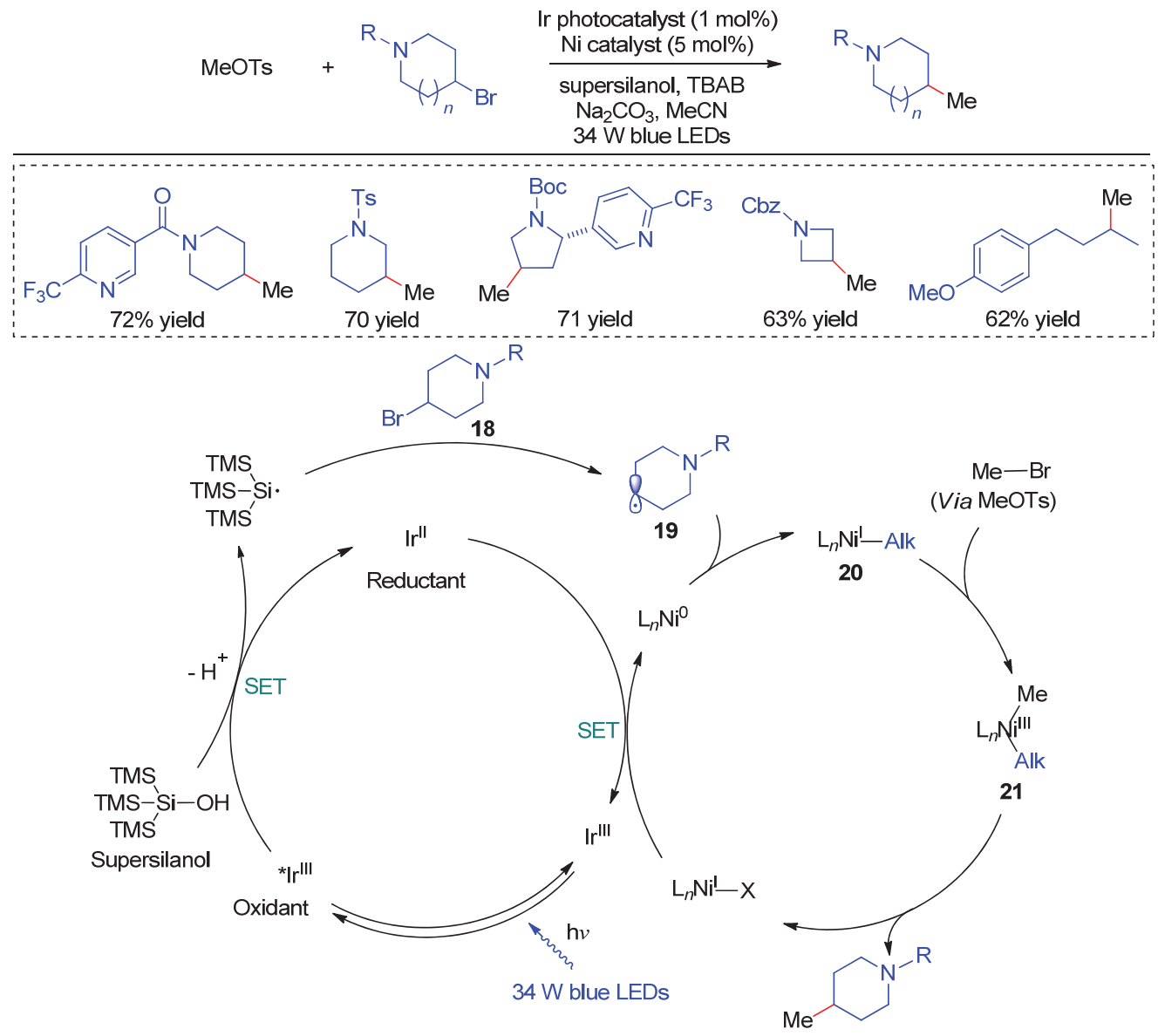

图式 15 镍-光反应催化剂协同催化烷基卤代烷的交叉偶联反应及机理

Scheme 15 Dual nickel-photoredox catalyzed cross-coupling of alkyl halides and mechanism
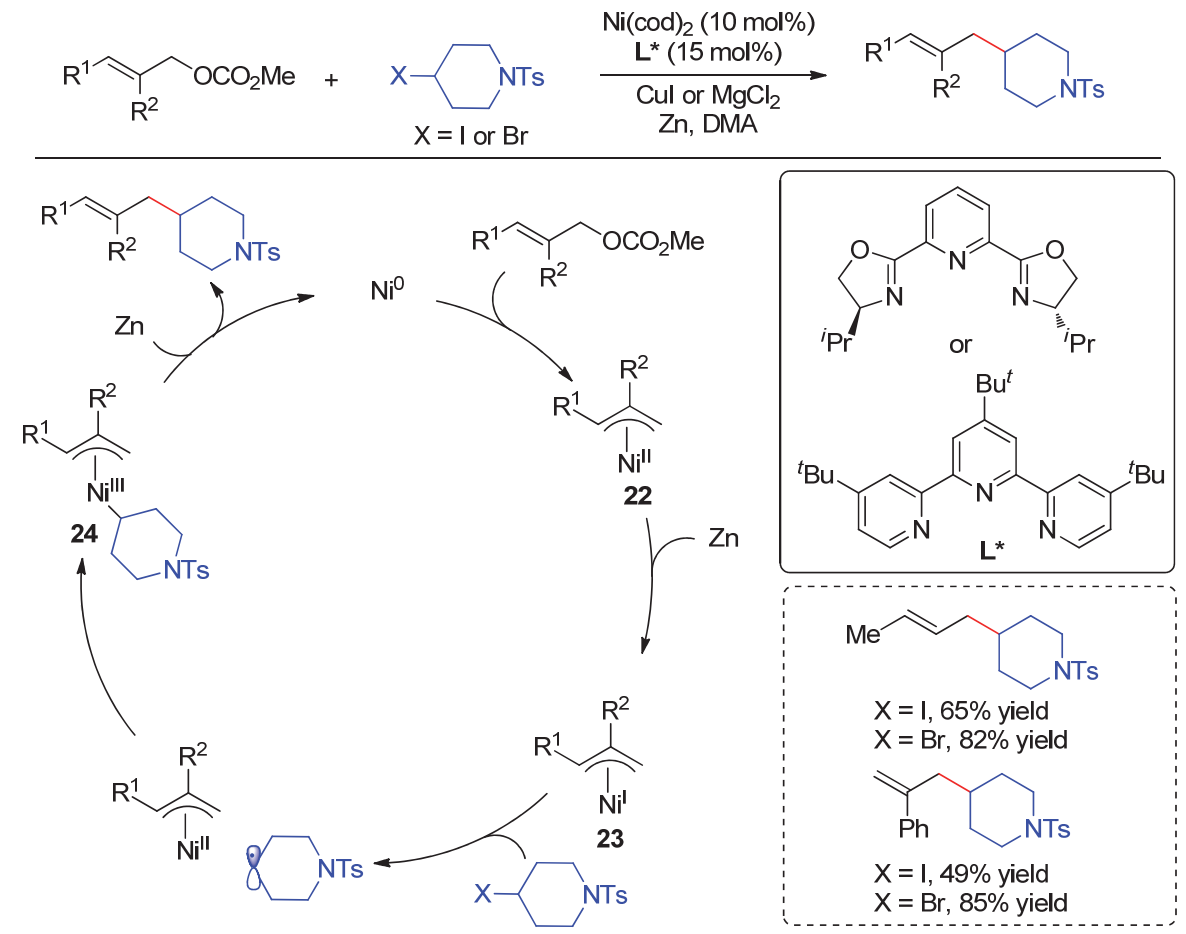

图式 16 镍催化烯丙醇衍生物与烷基卤化物的偶联反应及机理

Scheme 16 Nickel-catalyzed coupling of allyl alcohol derivatives with alkyl halides and mechanism 
物, 当以 $\mathrm{Mn}$ 为还原剂 $\mathrm{L1}$ 为配体时, 能够高选择性地得 到直链羧基化产物, 当以 $\mathrm{Zn}$ 为还原剂 $\mathbf{L} 2$ 为配体时, 能 够高选择性地得到支链羧基化产物. 该小组通过反应活 性催化剂的捕获以及相关的机理实验, 提出了配体决定 选择性的反应模式(Scheme 17).

2017 年, 龚和贵课题组 ${ }^{[33]}$ 报道了镍催化烯丙基碳 酸酯与未活化叔卤代烷烃的还原交叉偶联反应，通过 $\mathrm{C}\left(\mathrm{sp}^{3}\right)-\mathrm{O}$ 的活化, 高效地实现了全碳中心的构建. 对 于 $\mathrm{C}(1)$ 或 $\mathrm{C}(3)$ 位取代的烯丙基碳酸酯底物, 该反应表现 出出色的区域选择性, 专一地得到烯丙基碳末端烷基化 产物. 这一偶联反应的官能团兼容性优良, 并得到具有 高 $E$ 构型选择性的产物. 初步的机理研究表明, 叔烷基 自由基参与了该反应过程(Scheme 18).

2015 年 Weix 课题组 ${ }^{[34]}$ 以苠醇为原料, 利用 $\mathrm{Ms}_{2} \mathrm{O}$ 原位生成磺酸酯类化合物, 通过酞菁钴 $(\mathrm{Co}(\mathrm{Pc}))$ 作用生 成苄基自由基，随后与芳基卤化物偶联. 该小组推测的 反应机理为: 首先 $\mathrm{Ni}^{0}$ 对芳基卤化物氧化加成得到芳基 镍物种 25 , 使用 $\mathrm{Co}(\mathrm{Pc})$ 实现苄基自由基的生成, 然后对
物种 25 进行单电子氧化加成得到 26, 还原消除得到产 物以及一价镍物种 27,27 还原进入下一个循环(Scheme 19).

2018 年, 舒兴中课题组 ${ }^{[35]}$ 合成了一类以草酸酯作 为离去基团的苄酯类化合物，通过镍催化，实现了其与 烷基溴化物的还原交叉偶联反应. 将官能团例如氯、醇、 醛、胺、酰胺、硼酸酯、醚、酯、杂环、膦酸酯和小环 化合物等引入苄酯底物，反应都能顺利进行，并且得到 中等至良好的收率. 这种合成方法可以应用于复杂生物 活性化合物的后期精准修饰. 初步机理实验表明，该反 应可能涉及自由基过程(Scheme 20). Jarvo 课题组 ${ }^{[36]}$ 则 实现了此类苄基酯和芳基卤化物的还原交叉偶联反应， 官能团耐受性好，能够以最高 $94 \%$ 的收率得到二芳基甲 烷类衍生物

2019 年，龚和贵课题组 ${ }^{[37]}$ 报道了镍催化氯甲酸苄 酯衍生物与芳基碘化物的还原交叉偶联反应，高收率地 生成了一系列的二芳基甲烷产物. 初步的机理研究表 明，在镍催化的条件下，茮基 $\mathrm{C}\left(\mathrm{sp}^{3}\right)-\mathrm{O}$ 键断裂得到茮

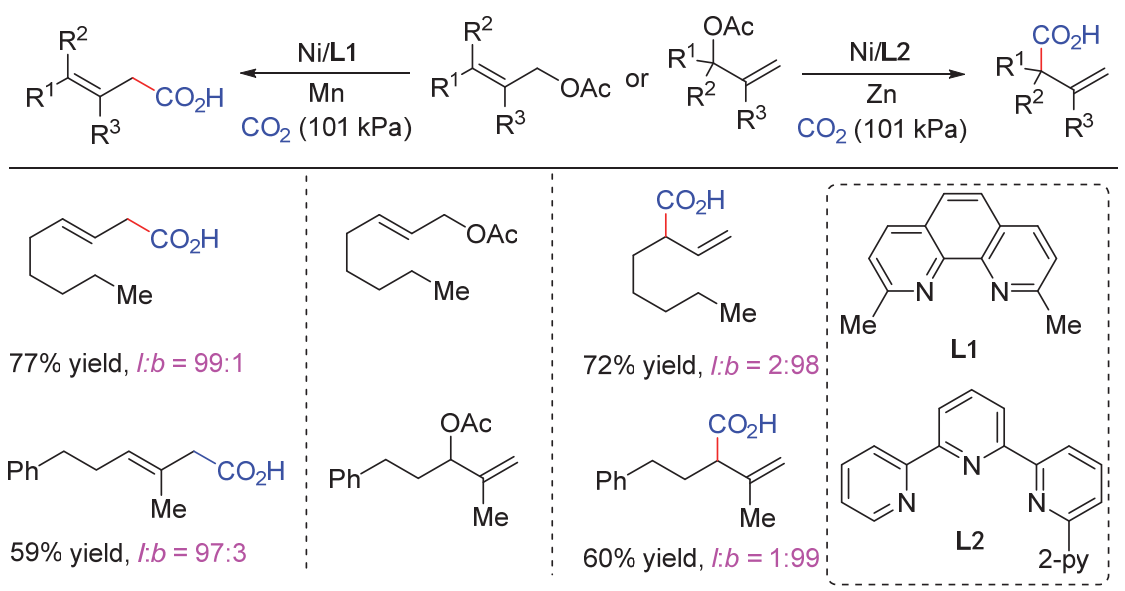

图式 17 镍催化配体控制的烯丙基酯与 $\mathrm{CO}_{2}$ 的差样化还原羧基化反应

Scheme 17 Nickel-catalyzed ligand-controlled differential reductive carboxylation of allyl esters with $\mathrm{CO}_{2}$

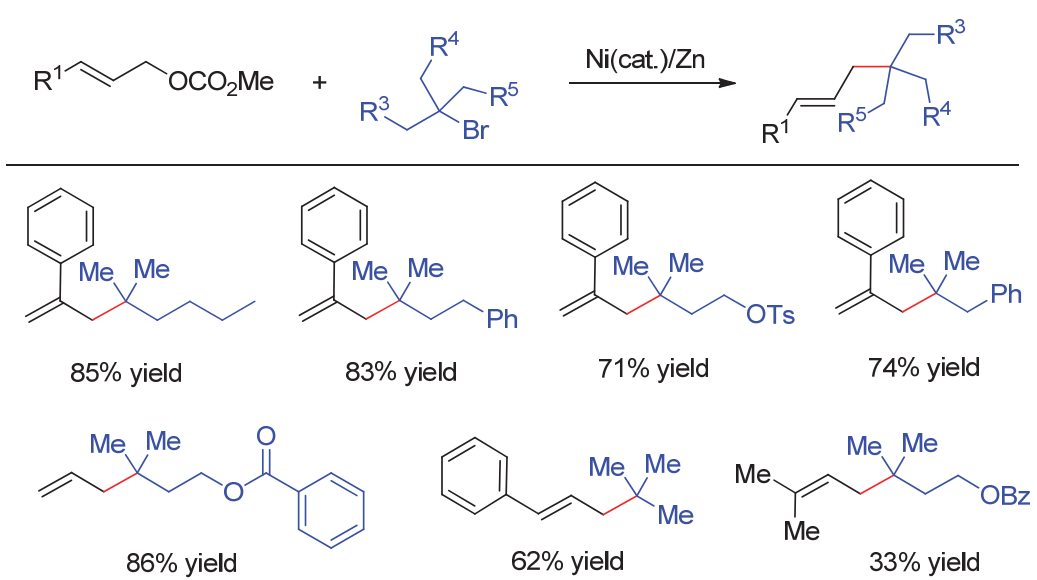

图式 18 镍催化烯丙基碳酸酯与叔卤代烷烃的还原偶联反应

Scheme 18 Nickel-catalyzed reductive coupling of allylic carbonates with tertiary alkyl halides 


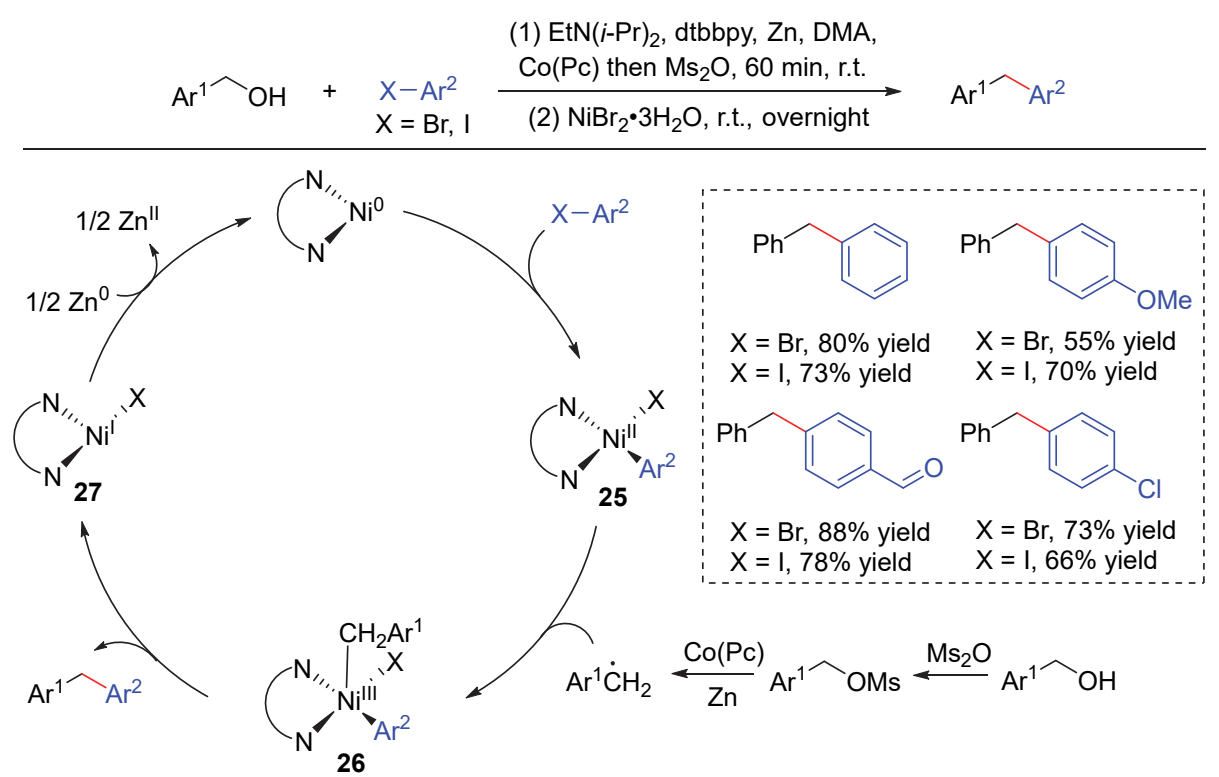

图式 19 镍/ $\mathrm{Co}(\mathrm{Pc})$ 催化苄醇与芳基卤化物还原偶联反应及机理

Scheme $19 \mathrm{Nickel} / \mathrm{Co}(\mathrm{Pc})$-catalyzed reductive coupling of benzyl alcohols with aryl halides and mechanism

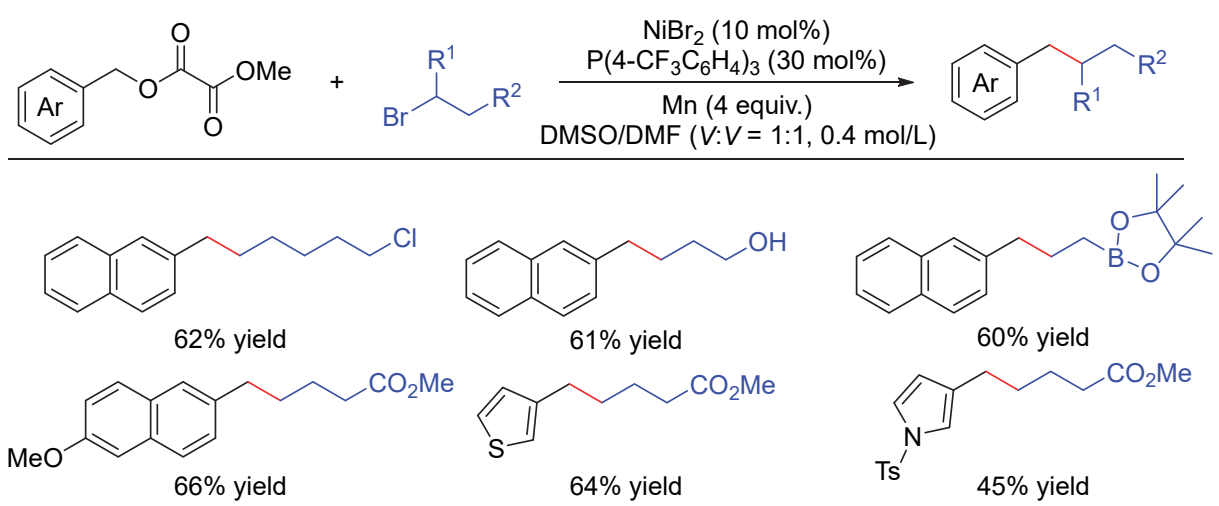

图式 20 镍催化草酸苠基酯与烷基溴化物的还原偶联反应

Scheme 20 Nickel-catalyzed reductive coupling of benzyl oxalates with alkyl bromides

基自由基，随后进行还原偶联反应得到目标化合物，这 项工作为还原交叉偶联反应提供了一种新的反应底物
类型(Scheme 21).

2021 年，舒兴中课题组 ${ }^{[38]}$ 报道了一例苄醇与芳基

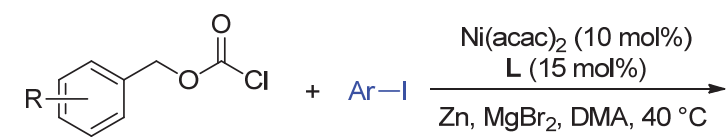<smiles>[R][C]1CCCCC1CCc1ccccc1</smiles><smiles>COc1ccnc(-c2cc(OC)ccn2)c1</smiles><smiles>CCOc1ccc(Cc2ccccc2)cc1</smiles>

$93 \%$ yield<smiles>O=Cc1ccc(Cc2ccccc2)cc1</smiles>

$83 \%$ yield<smiles>c1ccc(Cc2ccc3sccc3c2)cc1</smiles>

$93 \%$ yield

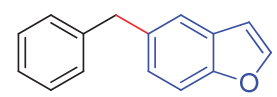

$92 \%$ yield<smiles>COc1ccc(Cc2ccc(C#N)cc2)cc1</smiles>

图式 21 镍催化氯甲酸苄酯与芳基碘化物的还原偶联反应

Scheme 21 Nickel-catalyzed reductive coupling of benzyl chloroformates with aryl iodides 
亲电试剂的动态动力学还原交叉偶联反应. 该方法具有 广泛的底物范围, 出色的官能团兼容性以及独特的化学 选择性. 为高区域选择性地合成广泛存在于制药和功能 性有机材料中的联芳甲烷类衍生物提供了更优势的合 成方法. 正是由于其出色的化学选择性, 该方法能够应 用于生物活性分子以及肽链等的精准修饰. 该反应的成 功取决于草酸二甲酯(DMO)原位活化醇, 随后与镍作用 得到自由基 ${ }^{[39]}$. 与 Weix 和 Ukaji 的方法相比, 不需要额 外的共催化剂, 更加绿色环保(Scheme 22).

\subsection{3 醚类化合物作为伯烷基亲电试剂}

有机卤化物的甲基化是一种十分有价值的转化，但 通常需要苛刻的反应条件或试剂. 2020 年, Doyle 课题 组 ${ }^{[40]}$ 报道了镍/光氧化还原催化剂组合催化的原甲酸三 甲酯与(杂)芳基氯化物的甲基化反应，其中原甲酸三甲 酯作为甲基源，具有十分重要的工业化前景(Scheme 23). 机理研究表明, $\mathrm{Ni}^{\mathrm{III}}$ 中间体 $\mathbf{2 8}$ 在光照的条件下, 提 供一个氯自由基，随后与原甲酸三甲酯通过氢转移得到 自由基 29, 再与 $\mathrm{L}_{n} \mathrm{Ni}^{\mathrm{II}}-\mathrm{Ar}$ 反应得到中间体 30 , 最后还

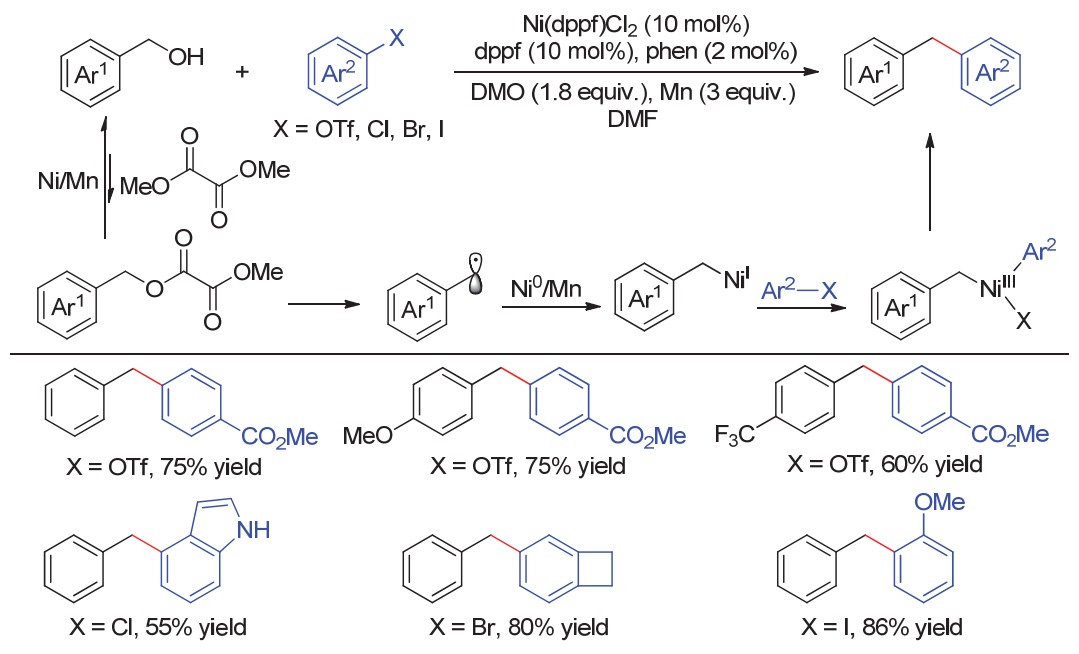

图式 22 镍催化苄醇与芳基亲电试剂的还原偶联反应

Scheme 22 Nickel-catalyzed reductive coupling of benzyl alcohols with aryl electrophiles

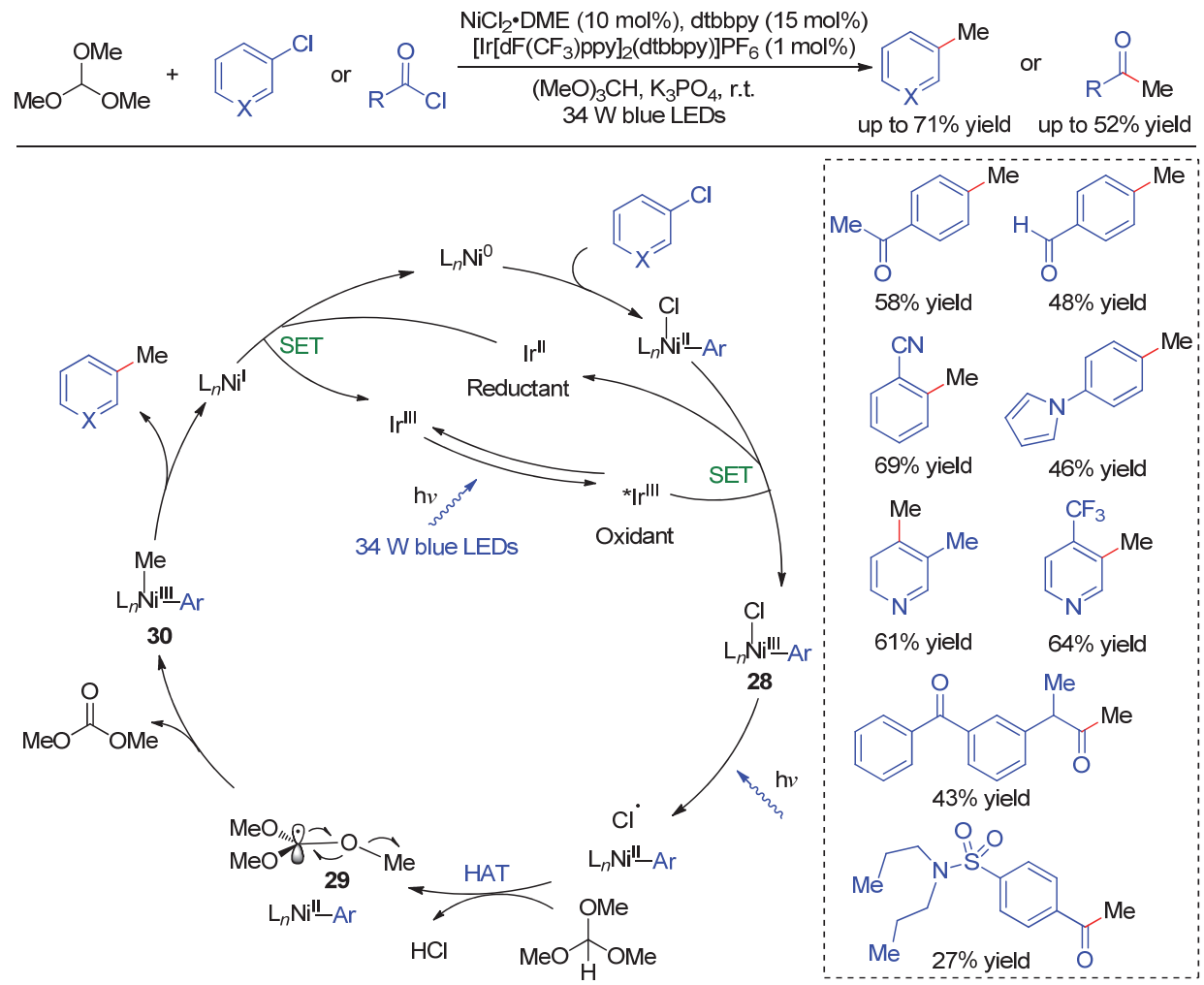

图式 23 镍/光氧化还原催化的原甲酸三甲酯与有机氯化物的偶联反应及机理

Scheme 23 Nickel/photoredox-catalyzed coupling of trimethyl orthoformates with organic chlorides and mechanism 
原消除得到甲基化产物(Scheme 23).

\subsection{4 醇类化合物作为伯烷基亲电试剂}

相较于酯类和醚类化合物, 在醇化合物中 $\mathrm{C}\left(\mathrm{sp}^{3}\right)$ $\mathrm{O}$ 键的断裂需要更苛刻的条件. 为了解决这一问题, 2018 年 Ukaji 课题组 ${ }^{[41]}$ 利用低价态的 Ti 化合物为共催 化剂, 实现了茮醇与芳基卤化物的还原交叉偶联反应, 最高获得 $93 \%$ 的收率. 在前人工作的基础上 ${ }^{[42]}$, 该小组 推测可能的反应机理为: 首先 $\mathrm{Ni}^{0}$ 对芳基卤化物氧化加 成得到芳基镍物种 31 , 使用 $\mathrm{TiCl}_{4}$ (lutidine)实现茮基自 由基的生成, 然后对物种 31 进行单电子氧化加成得到 32, 最后还原消除得到产物和一价镍物种 33, 33 还原进
入下一个循环(Scheme 24). 最近, Rahaim 课题组 ${ }^{[43]}$ 以氯 代三甲基硅烷( $\mathrm{TMSCl}$ )为作为添加剂, 同样能够以最高 $99 \%$ 的收率实现这一反应.

2018 年, 舒兴中课题组 ${ }^{[44]}$ 报道了镍和 Lewis 酸协同 催化的烯丙醇与芳基卤化物的还原交叉偶联反应. 该反 应可耐受多种官能团，包括醇、酚、苯胺、硅烷和喼酸 盐等. 在多数情况下, 高选择性地生成线性 $(E)$-芳基烯 烃产物. 初步的机理研究表明，该反应可能始于芳基镍 中间体 34, 然后在 Lewis 酸和还原剂存在的条件下与烯 丙醇反应得到还原偶联产物(Scheme 25).

2017 年, Martin 课题组 ${ }^{[45]}$ 开发了镍催化可切换反应

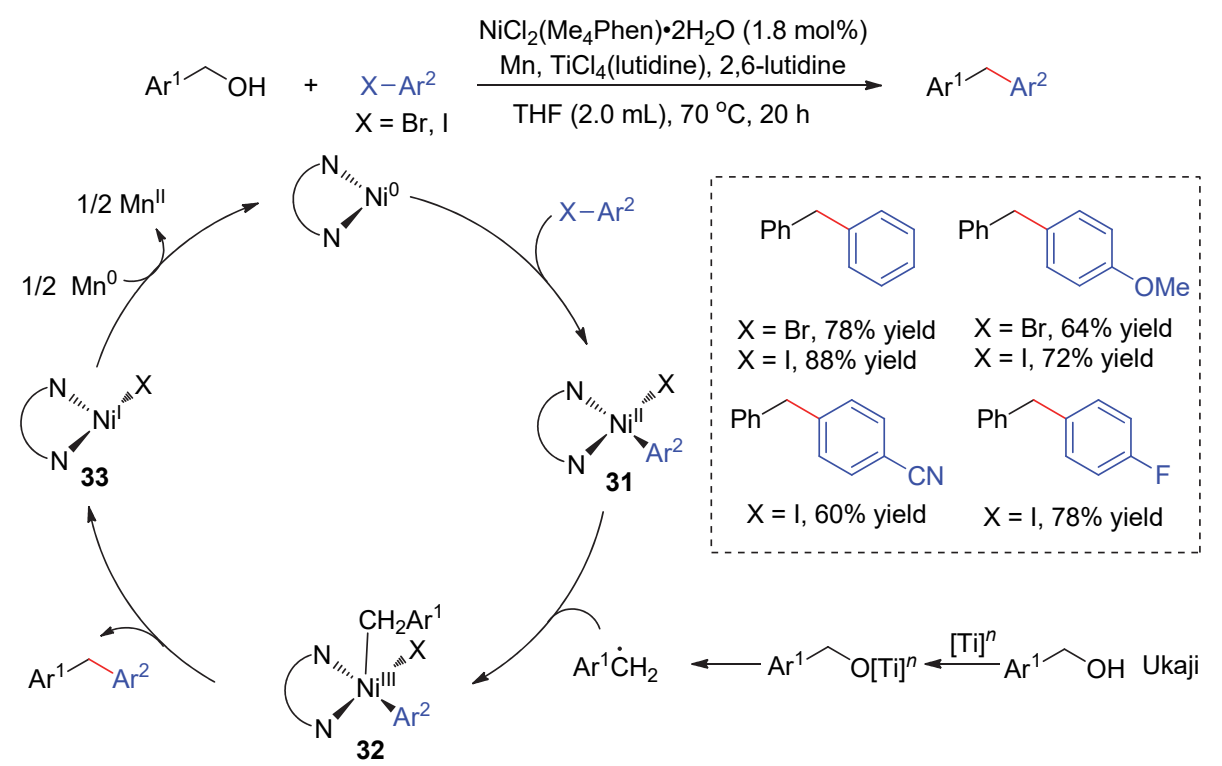

图式 24 镍/ $/ \mathrm{TiCl}_{4}$ (lutidine)催化苄醇与芳基卤化物还原偶联反应及机理

Scheme 24 Nickel/ $\mathrm{TiCl}_{4}$ (lutidine)-catalyzed reductive coupling of benzyl alcohols with aryl halides and mechanism

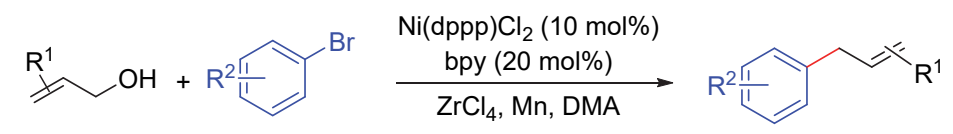
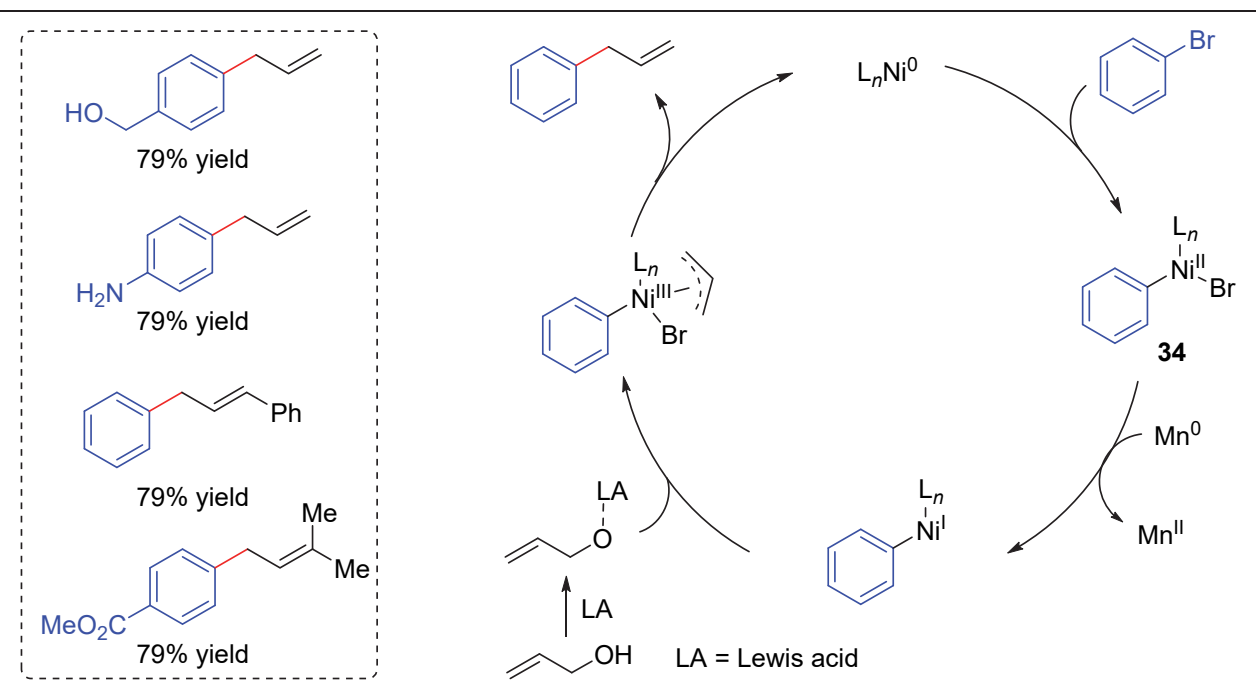

图式 25 镍和 Lewis 酸协同催化烯丙醇与芳基卤化物的还原偶联反应及机理

Scheme 25 Dual nickel and Lewis acid catalyzed reductive coupling of allylic alcohols with aryl halides and mechanism 
位点的烯丙醇的还原羧基化反应, 其区域选择性仅由配 体主链的几何形状决定. 当 $\mathbf{L 3}$ 为配体时得到直链产物, 当 L4 为配体时得到支链产物. 在底物拓展中观察到不 管是直链还是支链烯丙醇参与反应, 都能实现优异的位 点选择性, 表明该反应的位点选择性与底物结构无关. 二氧化碳在反应中起到双重作用, 既促进了 $\mathrm{C}-\mathrm{OH}$ 的 裂解, 又可作为碳源. 该方法的特点是反应条件温和, 不需要化学计量的有机金属试剂, 广泛的底物适用性和 精准的区域选择性(Scheme 26).

\section{2 镍催化仲醇衍生物参与的偶联反应}

\section{1 仲醇衍生物与有机金属试剂的偶联反应}

\section{1 .1 仲醇衍生物与有机镁试剂的偶联反应}

最近几十年来, 镍催化仲醇衍生物尤其是烯丙醇参 与的与有机镁试剂的不对称交叉偶联反应得到越来越
多的研究. 1980 年, Consiglio 课题组 ${ }^{[46]}$ 首次以环状烯丙 醇衍生物为原料，利用镍与双齿手性膦 4,5-双(二苯基膦 甲基)-2,2-二甲基-1,3-二氧戊环(DIOP)为催化剂，能够 以 $16 \%$ 的对映选择性得到偶联产物. 以环状烯丙基苯基 醚衍生物为原料, 再次对手性配体进行篮选, Chiraphos 或轴向手性 2,2'-双 (二苯基膦)-6,6'-二甲基-1,1'-联苯 (BIPHEMP)作为配体，可分别得到 51\%和 $84 \%$ 的对映选 择性 ${ }^{[47]}$. 随后 Uemura 课题组 ${ }^{[48]}$ 利用二茂铁衍生的膦啞唑啉为手性配体，环状烯丙基甲基醚衍生物为原料, 能够将对映选择性提高至 $88 \%$. 遗憾的是在类似的反应 条件下, 链状烯丙基甲基醚衍生物参与反应，只能以 $47 \%$ 的收率, $47 \%$ 的 $e e$ 值得到产物 ${ }^{[49]}$ (Scheme 27).

1997 年, RajanBabu 课题组 ${ }^{[50]}$ 发表了 Ni/Chiraphos 催化的非环状二苯基烯丙基醚的不对称烷基化反应. 研 究发现甲醚底物的手性控制优于苯醚底物，而 $\mathrm{EtMgBr}$
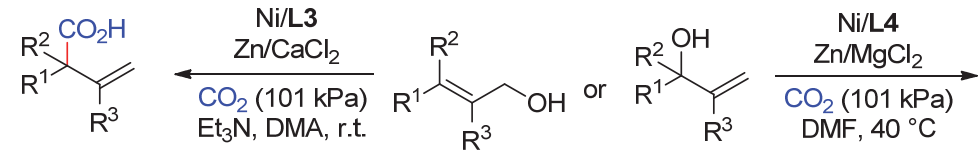<smiles>[R]C([R])=C([R])CC(=O)O</smiles>

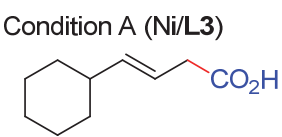

$68 \%$ yield $(99: 1, l: b)$

Condition B (Ni/L4)

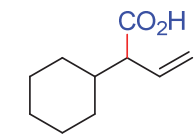

$67 \%$ yield $(82: 18, l: b)$

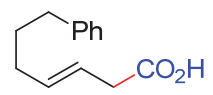

$61 \%$ yield $(99: 1, l: b)$

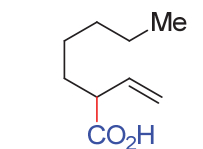

$81 \%$ yield $(99: 1, l: b)$

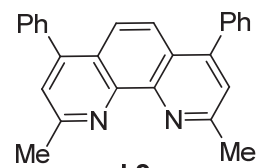

L3<smiles>Cc1cc(C)nc(-c2cccc(-c3cc(C)cc(C)n3)n2)c1</smiles>

图式 26 可切换位点的烯丙醇和二氧化碳的还原羧基化反应

Scheme 26 Switchable site reductive carboxylation of allylic alcohols with $\mathrm{CO}_{2}$

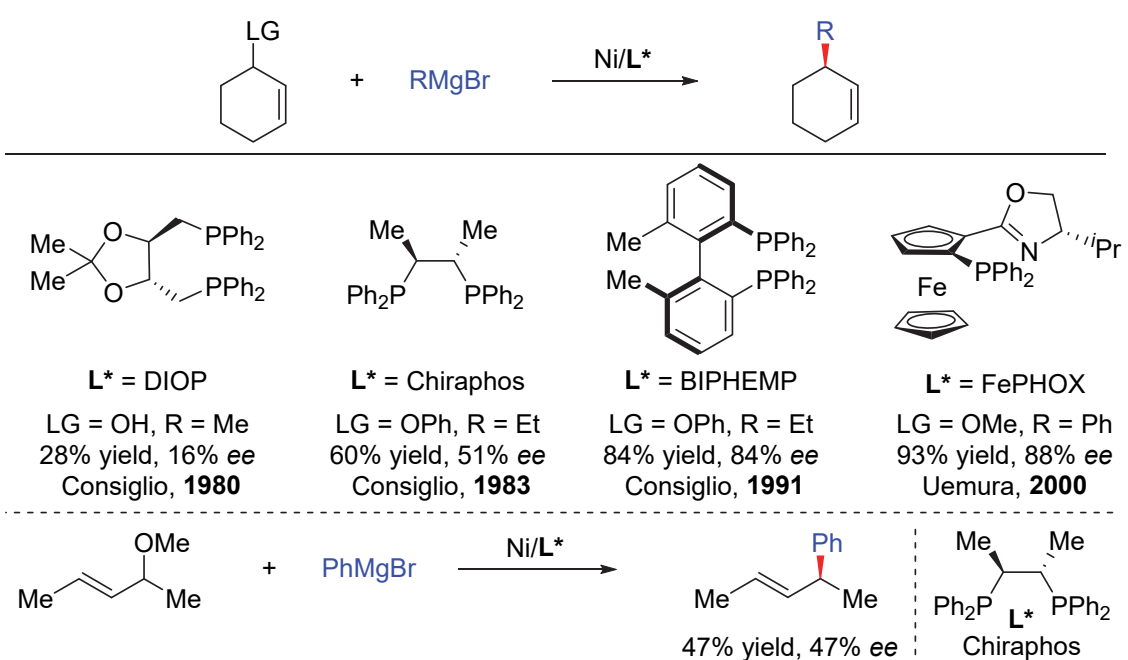

图式 27 开创性的镍催化的烯丙基醇衍生物与有机镁试剂的偶联反应

Scheme 27 Seminal nickel-catalyzed coupling of allylic alcohol derivatives with organomagnesium reagents 
提供的 $e e$ 值略高于 $\mathrm{MeMgBr}$. 在完全反应之前淬灭体 系, 回收的原料具有 79\%的 $e e$ 值, 因此推测在烯丙基醚 的氧化加成步骤具有动力学拆分效应. 1998 年, Hoveyda 课题组 ${ }^{[51]}$ 同样实现了此类反应(Scheme 28).

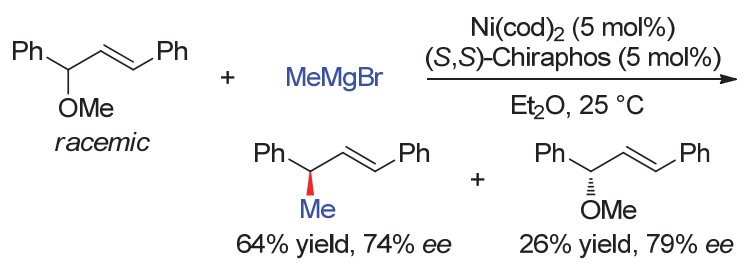

图式 28 镍催化烯丙基甲基醚与有机镁试剂的偶联反应 Scheme 28 Nickel-catalyzed coupling of allyl ether derivatives with organomagnesium reagents

近年来立体专一性交叉偶联反应由于其独特的性 质而得到了广泛的研究. 该类反应由手性化合物作为反 应原料, 在产物立体化学方面受底物控制, 并在得到复 杂产物的同时保留立体化学信息. 因为原料中已经含有 立体中心，立体专一性的交叉偶联反应不需要手性催化 剂的参与. 因此, 当我们无法找到合适手性催化剂或者 手性催化剂比较昂贵, 无法通过不对称催化反应获得高 对映选择性的产物时, 立体专一性反应是一个很好的选 择 ${ }^{[52]}$. 由于醇通常是对空气和湿气稳定的, 并且毒性 低，对映体富集的醇相较于手性烷基卤化物，更容易制 备. 因此, 近年来以镍为催化剂, 利用手性醇衍生物替 代传统的手性卤代烷来构建手性中心的方法得到了高 速发展.

2011 年, Jarvo 课题组 ${ }^{[53]}$ 报道了第一例镍催化仲苄 基醚与甲基镁试剂的立体专一性交叉偶联反应. 作者通 过优化配体, 加速氧化加成并减少 $\beta$ - $\mathrm{H}$ 消除, 从而提高 反应活性. 这一交叉偶联在实现芐基立体中心反转的同 时立体化学得到了很好地保持, 为对映体富集的 1,1-二 芳基烷烃化合物的合成提供了新的方法(Scheme 29).

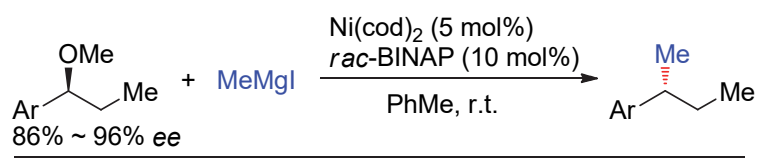

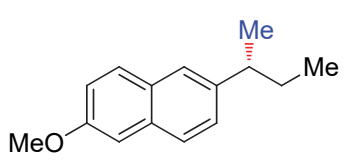

$70 \%$ yield, $85 \%$ ee<smiles>CC[C@H](C)c1cc2ccccc2o1</smiles>

$92 \%$ yield, $87 \%$ ee

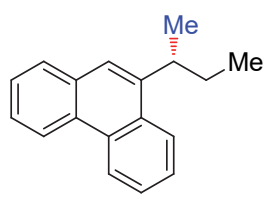

$71 \%$ yield, $90 \%$ ee

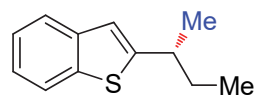

$87 \%$ yield, $95 \%$ ee
图式 29 立体专一性的镍催化苄基醚与甲基镁试剂的偶联反 应

Scheme 29 Stereospecific nickel-catalyzed coupling of benzyl ethers with methyl magnesium reagents
在以上工作的基础上，该小组 ${ }^{[54]}$ 利用了此类对映 体富集的仲甲基醚作为亲电试剂，镍为催化剂，实现了 其与含有 $\beta$ - $\mathrm{H}$ 的长链烷基镁试剂、芳基镁试剂的交叉偶 联反应，取得了令人满意的结果(Scheme 30).

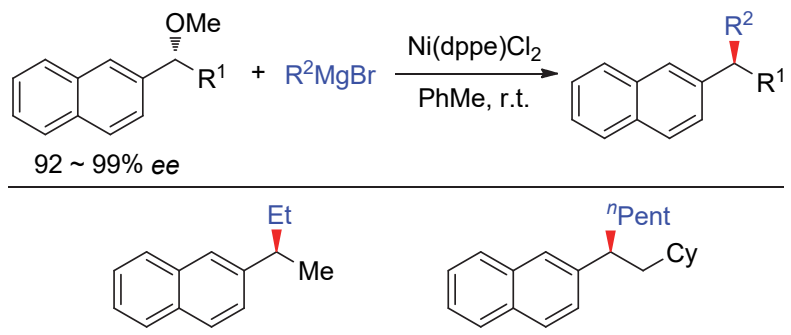

$80 \%$ yield, $91 \%$ ee, $99 \%$ es $\quad 91 \%$ yield, $97 \%$ ee, $99 \%$ es<smiles>ClCC[C@H](CCCc1ccccc1)c1ccc2ccccc2c1</smiles><smiles>CC(C)(C)[C@H](CCl)c1ccc2ccccc2c1</smiles>

$88 \%$ yield, $97 \%$ ee, $99 \%$ es $40 \%$ yield, $90 \%$ ee, $93 \%$ es<smiles>c1ccc([C@H](CC2CCCCC2)c2ccc3ccccc3c2)cc1</smiles><smiles>COc1ccc(C(CC2CCCCC2)c2ccc3ccccc3c2)cc1</smiles>

$67 \%$ yield, $91 \%$ ee, $92 \%$ es $86 \%$ yield, $97 \%$ ee, $97 \%$ es<smiles>Fc1ccc([C@H](CC2CCCCC2)c2ccc3ccccc3c2)cc1</smiles>

$82 \%$ yield, $87 \%$ ee, $88 \%$ es<smiles>c1csc([C@@H](CC2CCCCC2)c2ccc3ccccc3c2)c1</smiles>

$76 \%$ yield, $93 \%$ ee, $94 \%$ es

图式 30 立体专一性的镍催化苄基醚与有机镁试剂的偶联反 应

Scheme 30 Stereospecific nickel-catalyzed coupling of benzyl ethers with organomagnesium reagents

Jarvo 小组之前的工作都是利用含䒺基的底物，形 成大 $\pi$ 键，促进反应的进行. 为了将底物范围拓展到简 单的芳烃底物，该小组设计用2-甲氧基乙基醚替代原来 的甲基，在反应中镁盐的加入能够与此基团螯合，活化 $\mathrm{C}$ - $\mathrm{O}$ 键进行氧化加成，从而加快交叉偶联反应的速率， 由于此类导向基团在反应的过程中会离去，无需后续的 脱导向基团的步骤，是一类很好的无痕导向基团. 基于 此, 该小组 ${ }^{[55]}$ 以镍为催化剂, 实现了对映体富集的二苄 基醚与甲基镁试剂以及芳基镁试剂的交叉偶联反应，分 别得到光学纯的二芳基以及三芳基产物(Scheme 31).

2014 年，该小组 ${ }^{[56]}$ 又开发了镍催化的芳基取代的 四氢呋喃、四氢吡喃等与有机镁试剂的立体专一性开环 交叉偶联反应. 当存在多个立体中心时, 开环发生在苄 位，其立体中心会发生翻转，但不会影响或不受其他立 


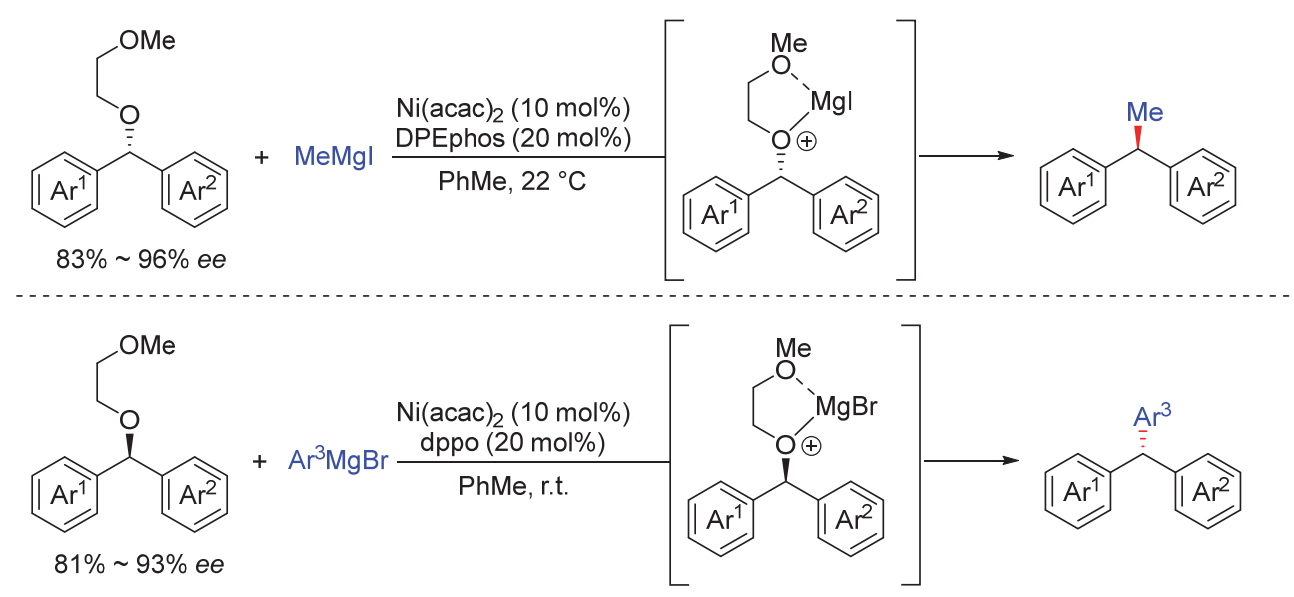

图式 31 无痕导向基团参与的立体专一性的镍催化交叉偶联反应

Scheme 31 Traceless directing group for stereospecific nickel-catalyzed cross-coupling reactions

体中心影响. 该小组也证明了此反应具有很高的立体专 一性, 其中产物的 $d r$ 值与起始氧杂环的 $d r$ 值相匹配. 次 年, 该小组 ${ }^{[57]}$ 实现了此类反应的克级放大反应, 并阐述 了其在制药工业中的应用前景. 在相关机理控制实验以 及密度泛函理论(DFT)计算的基础上，该小组 ${ }^{[58]}$ 提出了 可能的催化循环机理: 从活性催化剂 $\mathrm{L}_{n} \mathrm{Ni}^{0}$ 物种 35 启动, 首先 35 对底物进行氧化加成, 裂解苄基 $\mathrm{C}-\mathrm{O}$ 键, 生成 茮位立体中心翻转的两性离子 $\eta^{3}-\mathrm{Ni}^{\mathrm{II}}$ 物种 36.36 与有机 镁试剂转金属化得到中间体 37. 最后还原消除经过中 间体 38 得到偶联产物, 同时释放出活性催化剂 35 (Scheme 32).

\subsection{2 仲醇衍生物与有剂锌试剂的偶联反应}

2013 年, Jarvo 课题组 ${ }^{[59]}$ 首次报道了镍催化仲苄基 酯的立体专一性 Negishi 交叉偶联反应. 该小组对一系 列能够促进与二甲基锌的交叉偶联的无痕导向基团进 行评估考察, 发现商业可得的 2-(甲硫基)乙酸衍生的酯 能够给出最高的收率和最优异的立体专一性转化. 他们 利用该方法成功实现了视黄酸受体激动剂和脂肪酸酰 胺水解酶抑制剂的高效合成(Scheme 33). 在相似条件 下，该小组 ${ }^{[56]}$ 利用对映体富集的内酯经过与二甲基锌 的 Negishi 交叉偶联，成功制得对映体富集的羧酸，该

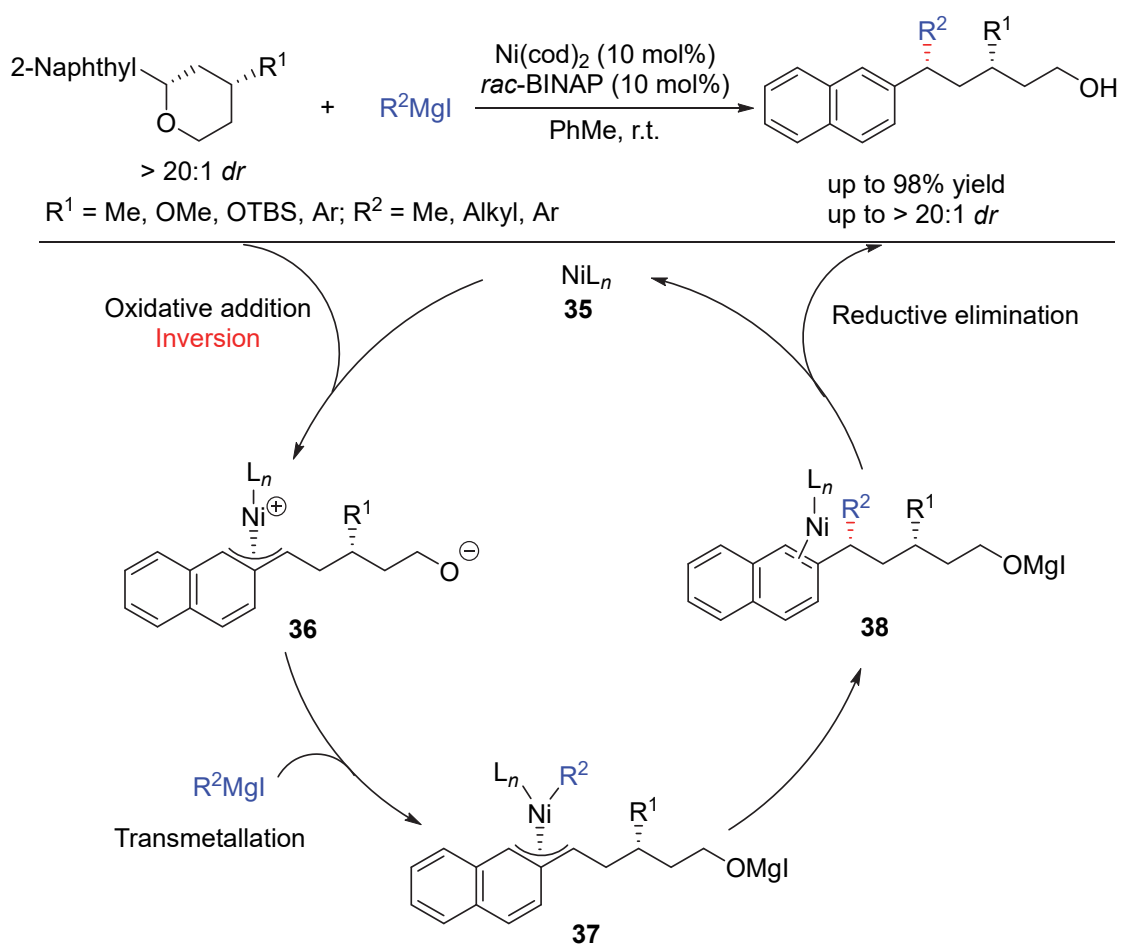

图式 32 立体专一性的镍催化取代四氢吡喃等与有机镁试剂的偶联反应及机理

Scheme 32 Stereospecific nickel-catalyzed coupling of substituted tetrahydropyrans with organomagnesium reagents and mechanism 


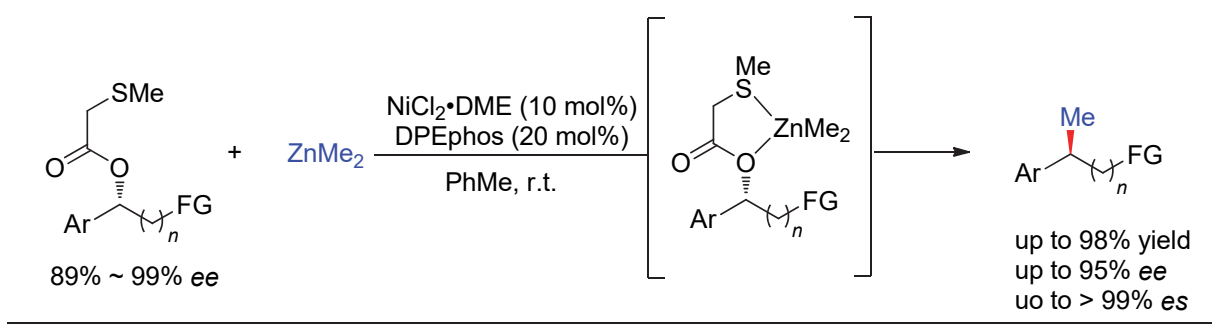<smiles>CCC(C)c1ccc2ccccc2c1</smiles>

$81 \%$ yield, $98 \%$ ee, $>99 \%$ es<smiles>[BH3-]O[C@@H]([Mg])c1cc2ccccc2o1</smiles>

$75 \%$ yield, $90 \%$ ee, $98 \%$ es

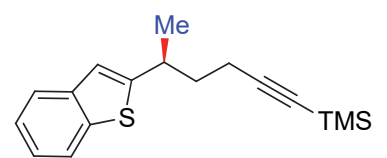

$81 \%$ yield, $96 \%$ ee, $99 \%$ es

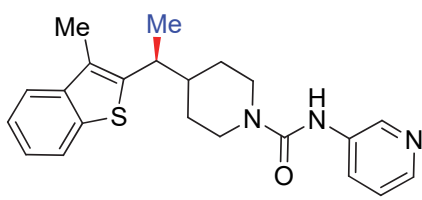

Fatty acid amide hydrolase inhibitor<smiles>CC(c1ccc2c(c1)C(C)(C)CCC2(C)C)c1ccc2cc(C(=O)O)ccc2c1</smiles>

Retinoic acid receptor agonist

图式 33 立体专一性的镍催化仲苄基酯与二甲基锌的偶联反应

Scheme 33 Stereospecific nickel-catalyzed coupling of secondary benzylic esters with ZnMe

方法在两步合成抗血脂异常剂中得到了成功应用 (Scheme 34).
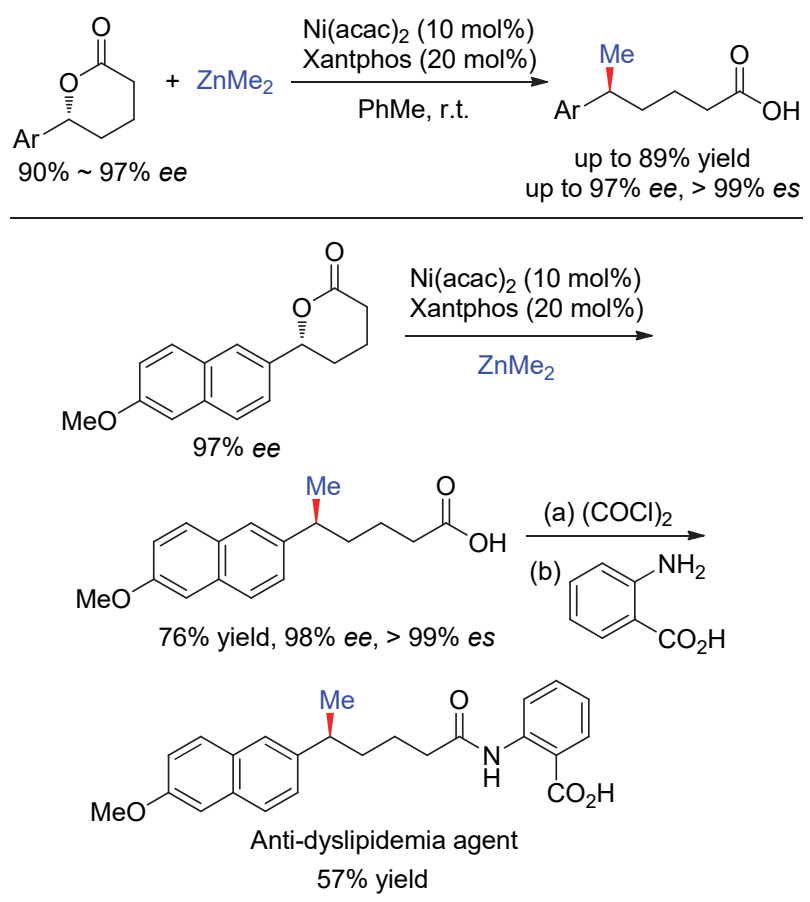

图式 34 立体专一性的镍催化内酯与二甲基锌的偶联反应

Scheme 34 Stereospecific nickel-catalyzed coupling of lactones with $\mathrm{ZnMe}_{2}$

同年, $\mathrm{Fu}$ 课题组 ${ }^{[60]}$ 首次开发了镍催化外消旋苄基亲 电试剂与芳基锌试剂的手性汇聚不对称 Negishi 交叉偶 联反应, 高收率和高对映选择性地得到 1,1-二芳基烷烃 类衍生物(up to $98 \%$ yield, $95 \% e e$ ). 在反应中首先形成
甲磺酸芰酯(未分离), 然后直接与芳基锌试剂、LiI 和手 性镍催化剂作用得到偶联产物，反应条件温和且适用于 一系列官能团, 例如芳基碘化物、噻吩和 $N$-Boc-吲哚等. 利用该方法能够实现 $(S)$-舍曲林四氢䒺酮的高效不对称 合成, 它是 Zoloft 的重要前体. 机理研究表明, 茮基碘 化物可能是反应的活性物种(Scheme 35).

2017 年, 王中夏课题组 ${ }^{[61]}$ 报道了镍催化烯丙醇衍 生物与芳基氯化锌和烯基氯化锌的交叉偶联反应. $(E)-$ 3-苯基丙-2-烯-1-醇和 1-芳基-丙-2-烯-1-醇与芳基或烯基 氯化锌的反应能够给出线性交叉偶联产物; 1-苯基或者 1-甲基取代的 $(E)$-3-苯基丙-2-烯-1-醇与芳基或烯基氯化 锌反应则得到 3-芳基/烯基取代的 $(E)$-(丁-1-烯基)苯类化 合物等. 该小组推测反应历经的是 $\mathrm{Ni}^{0} / \mathrm{Ni}^{\mathrm{II}}$ 催化循环, 同 时锂、镁和锌离子在催化过程中的起着重要的作用 (Scheme 36).

\subsection{3 仲醇衍生物与有机硼试剂的偶联反应}

有机硼试剂较其它金属有机试剂, 具有对空气和水 稳定，操作存储简便，反应时官能团耐受性好等优点， 因此有机硼试剂参与的金属有机催化反应得到了广泛 的关注. 其中, 镍催化的有机硼试剂与醇衍生物的交叉 偶联反应作为最基本的转化之一, 逐渐成为有机化学家 研究和应用的焦点反应之一。

环氧丙烷是复杂分子中重要的骨架结构, 易于从烯 烃和含羰基化学原料合成. 同时环氧丙烷的反应活性较 高，易于与各种亲核试剂反应从而生成开环产物. 基于 此, 环氧化合物的开环偶联反应得到了有机化学家的关 注, 并取得了一定的进展. 2011 年, Doyle 课题组 ${ }^{[62]}$ 首次 


$\mathrm{Ar}^{2} \mathrm{Znl}$
$\begin{aligned} & \text { racemic } \\ & \begin{array}{l}\text { (2) } \mathrm{NIBr}_{2} \cdot \mathrm{DME}^{*}(13 \mathrm{~mol}) \\ \mathrm{Lil}, \mathrm{CH}_{2} \mathrm{Cl}_{2} / \mathrm{THF}\end{array}\end{aligned}$<smiles>COc1ccc(C(C)c2ccccc2)cc1</smiles>

$88 \%$ yield, $88 \%$ ee<smiles>COc1ccc(C(CCC#N)c2ccccc2)cc1</smiles>

$75 \%$ yield, $94 \%$ ee<smiles>CCC(c1ccc(OC)cc1)c1ccc2ccccc2c1</smiles>

$79 \%$ yield, $91 \%$ ee<smiles>CCCC(c1ccc(OC)cc1)c1ccsc1</smiles>

$93 \%$ yield, $94 \%$ ee<smiles></smiles>

图式 35 镍催化外消旋苠醇与芳基锌的不对称偶联反应

Scheme 35 Nickel-catalyzed asymmetric coupling of racemic benzylic alcohols with aryl zinc reagents

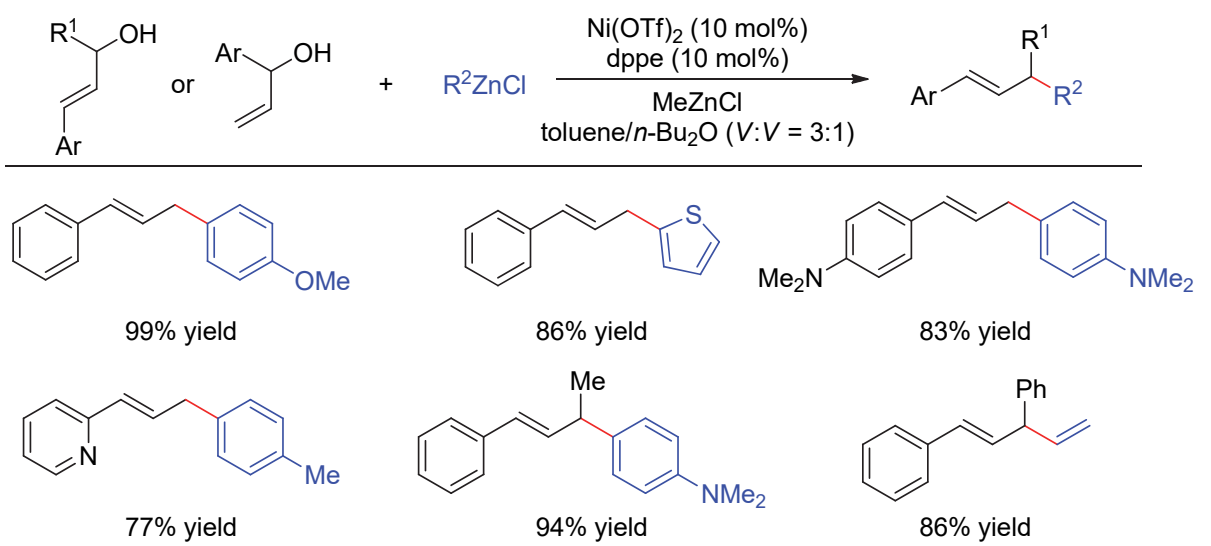

图式 36 镍催化烯丙醇与有机锌试剂的偶联反应

Scheme 36 Nickel-catalyzed coupling of allyl alcohols with organozinc reagents

报道了镍催化的 2-芳基环氧乙烷与芳基硼酸的开环 1,2芳基化反应. 推测的机理如下: 首先镍对环氧底物氧化 加成获得金属氧杂环丁烷 39, 随后开环再 $\beta$-H 消除, 镍 重新插入得到镍氧杂环丁烷中间体 40, 然后与芳基硓 酸转金属化，还原消除得到产物，同时释放出镍催化 剂[63] (Scheme 37).

2013 年, Jarvo 课题组 ${ }^{[64]}$ 开发了一例氨基甲酸茮酯 和新戊酸酯与芳基和杂芳基硼酸酯的立体专一性交叉 偶联反应，合成了一系列光学纯的三芳基甲烷类化合 物. 通过配体的调控, 反应可以选择性地得到亲电碳原 子上手性翻转或是手性保持产物. 当以三环己基膦为配 体时得到手性保持产物; 而以氮杂环卡宾为配体时得到 手性翻转产物. 控制实验和 DFT 计算表明, 氧化加成决 定了具有两个竞争性过渡态的立体选择性, 其中一个 $\mathrm{S}_{\mathrm{N}} 2$ 进攻过渡态的背面使茮基立体中心发生翻转, 另一
个是通过环状过渡态进行协同氧化加成使立体中心得 到保持. 两种过渡状态之间的主要区别在于底物-镍-配 体角度变化 ${ }^{[65]}$. 几乎在同一时期, Watson 课题组 ${ }^{[66]}$ 也报 道了类似的反应，在不加配体的条件下得到手性翻转产 物(Scheme 38).

与苯甲醇一样，手性的烯丙醇类衍生物也很容易制 备，此外这些产品还具有乙烯基官能团，易于修饰。这 些特性使其成为具有吸引力的用于立体专一性交叉偶 联的底物. 2000 年 Uemura 课题组 ${ }^{[67]}$ 首次报道了镍催化 环状烯丙基乙酸酯与芳基硣酸的不对称偶联反应，以良 好的收率和中等的对映选择性得到目标产物. 几乎在同 一时期 Deng 课题组 ${ }^{[68]}$ 同样利用镍催化剂促进了 1,3-二 取代碳酸烯丙酯与炔基硼酸酯的交叉偶联反应，遗憾的 是在对不对称催化进行研究后，最高只能获得 $13 \%$ 的 $e e$ 值. 利用手性烯丙醇衍生物为底物立体专一性地转化为 


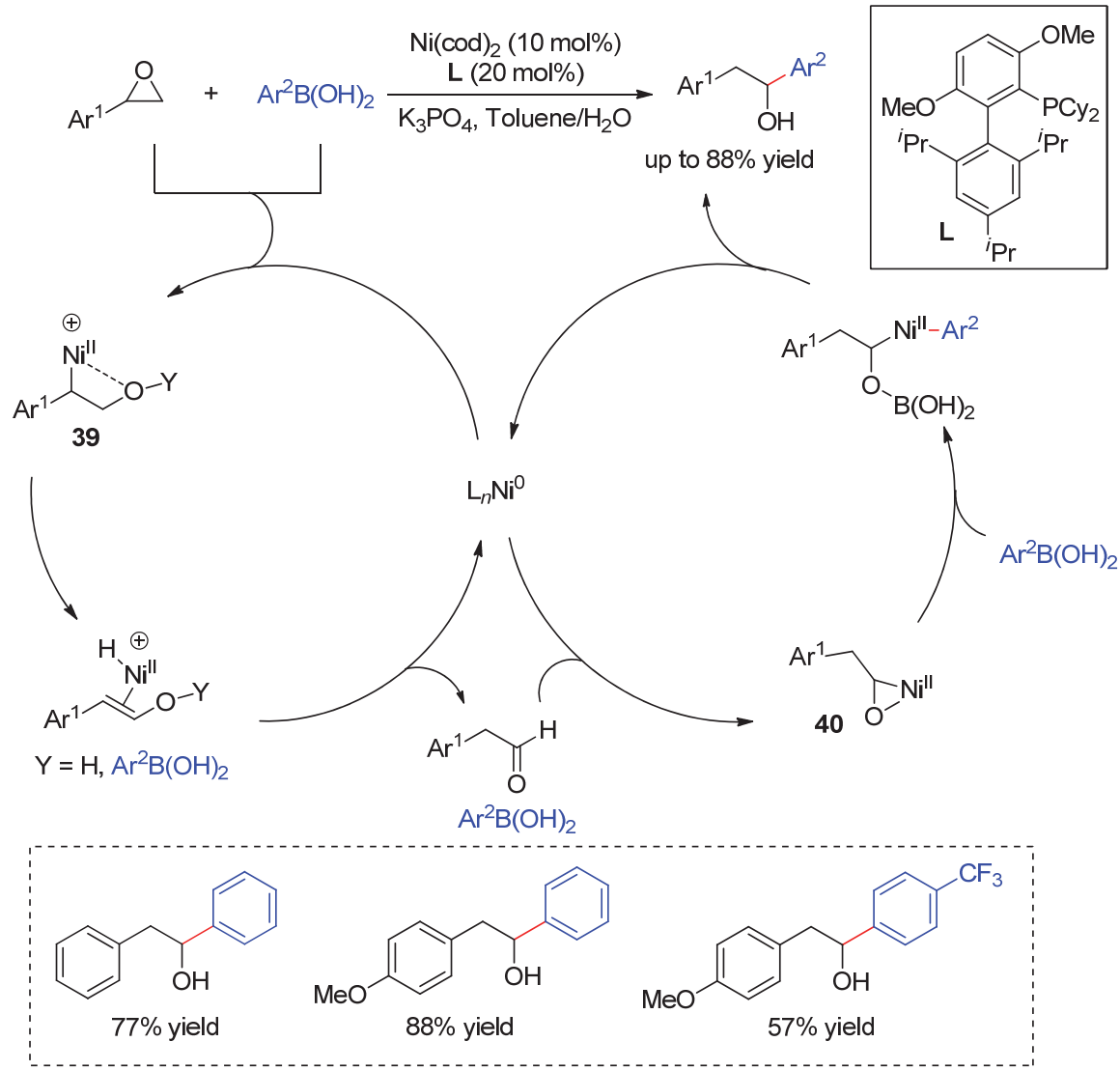

图式 37 镍催化环氧与有机嗍试剂的偶联反应及机理

Scheme 37 Nickel-catalyzed coupling of epoxides with organoboron reagents and mechanism

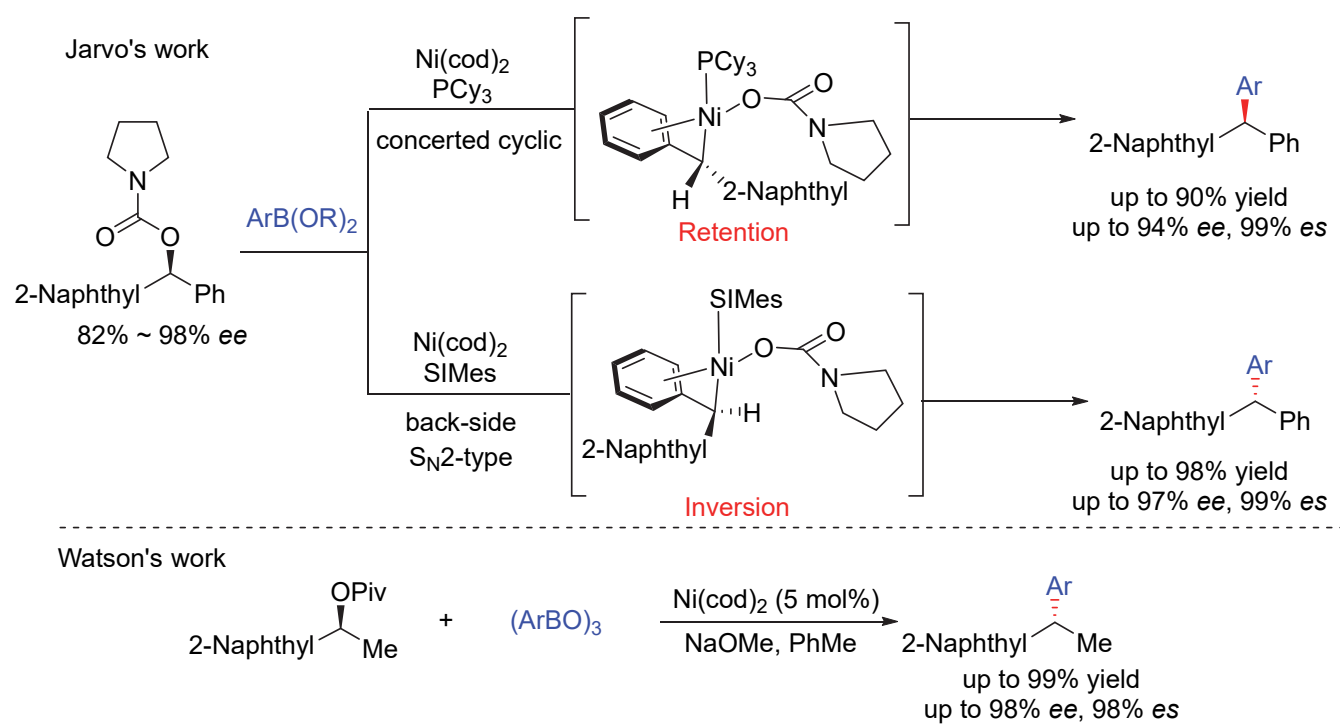

图式 38 立体专一性的镍催化氨基甲酸苄酯与有机硼试剂的偶联反应

Scheme 38 Stereospecific nickel-catalyzed coupling of benzylic carbamates with organoboron reagents

相应手性产物的最早案例是 Kobayashi 课题组 ${ }^{[69]}$ 报道的 镍催化的嗍酸盐对手性烯丙基乙酸酯的立体专一性反 应(Scheme 39).

随后 Watson 课题组 ${ }^{[70]}$ 开发了温和条件下镍催化对
映体富集的新戊酸烯丙酯的 Suzuki-Miyaura 交叉偶联反 应. 该反应的机理与新戊酸茮酯相似, 通过一个 $\pi$-烯丙 基镍物种进行，导致立体翻转. 为了验证这一假设，该 小组利用标准底物 41 的另一个异构体 42 作为反应原 
Enatioselective (Uemura's work)

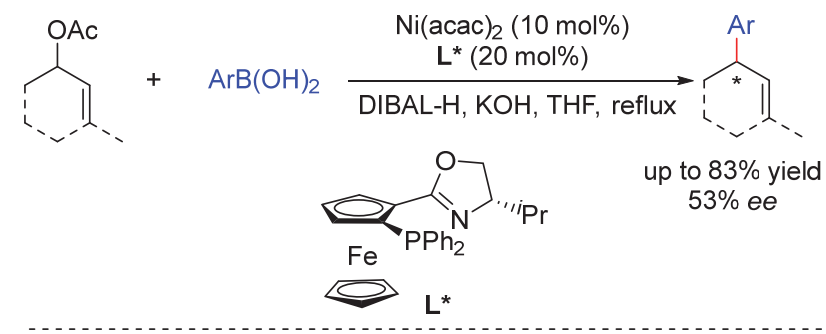

Enatioselective (Deng's work)
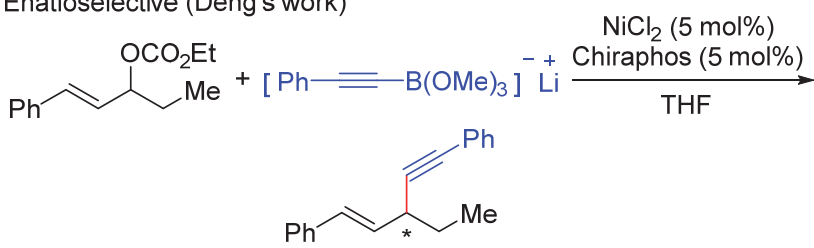

$67 \%$ yield, $13 \%$ ee

Enantiospecific (Kobayashi's work)

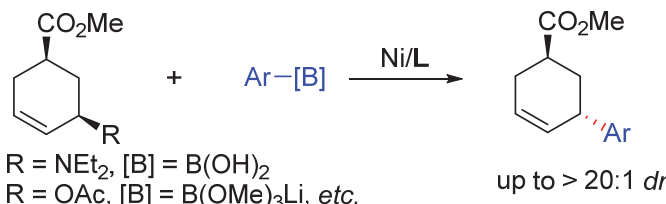

图式 39 几例镍催化烯丙醇衍生物与有机硼试剂的偶联反应 Scheme 39 Several cases of nickel-catalyzed coupling of allyl alcohol derivatives with organoboron reagents

料, 在标准条件下进行反应能够得到与标准底物同样的 产物. 值得注意的是, 与苄基衍生物相比, 这些反应性 更高的烯丙基底物能够在较低的温度和较低的催化剂 用量下进行偶联. 然而, 该反应的局限性在于只能高区 域选择性地获得苯乙烯基类产物(Scheme 40).

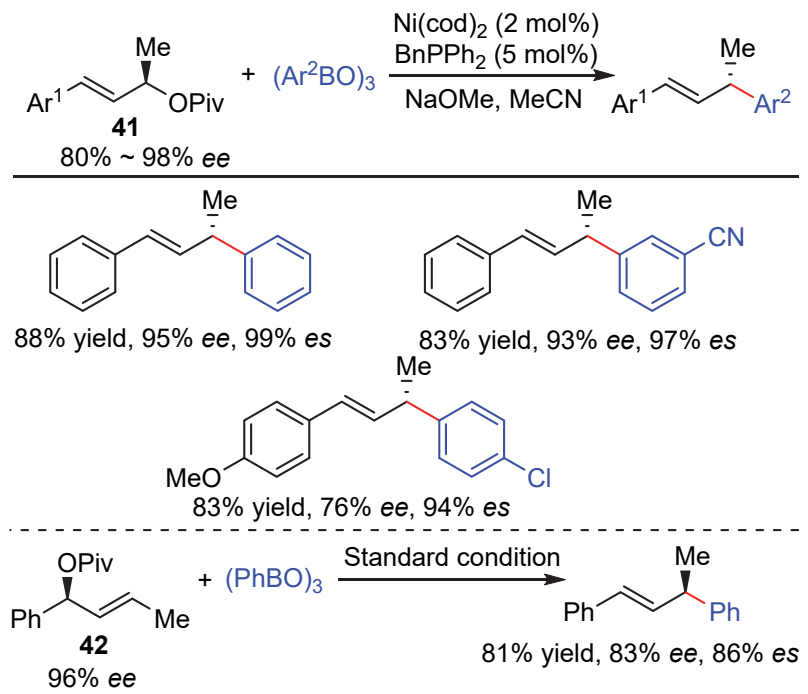

图式 40 立体专一性的镍催化新戊酸烯丙酯与有机嗍试剂的 偶联反应

Scheme 40 Stereospecific nickel-catalyzed coupling of allylic pivalates with organoboron reagents

鉴于构建全碳手性中心的重要性和挑战, Watson 课
题组 ${ }^{[71]}$ 设计了一类烯烃端位二取代的新戊酸烯丙酯底 物，以 $\mathrm{NiCl}_{2} \cdot$ 乙二醇二甲醚(DME) 和 $2,2^{\prime}$-双 (二苯基膦基 甲基) $-1,1^{\prime}$-联苯(BISBI)为催化剂体系，实现了其与芳基 硼试剂的立体专一性交叉偶联反应，得到含全碳手性中 心的立体翻转产物. 该体系适用于含腈基、环氧丙烷等 基团的底物(Scheme 41).

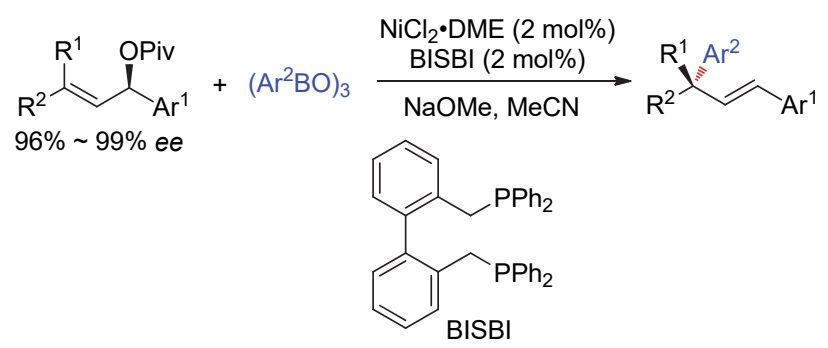

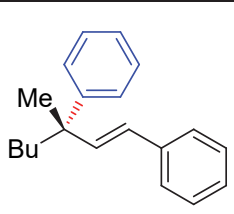

$87 \%$ yield, $94 \%$ ee, $96 \%$ es<smiles>Cn1ccc2cc(C(C)(C)C=Cc3ccccc3)ccc21</smiles>
$79 \%$ yield, $89 \%$ ee, $91 \%$ es<smiles>COc1cccc(/C=C/c2ccc(C#N)cc2)c1</smiles>

$68 \%$ yield, $95 \%$ ee, $97 \%$ es

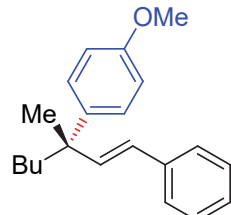

$87 \%$ yield, $93 \%$ ee, $93 \%$ es<smiles>COc1cccc(/C=C/C(C)(CBr)CBr)c1</smiles>

$91 \%$ yield, $86 \%$ ee, $88 \%$ es

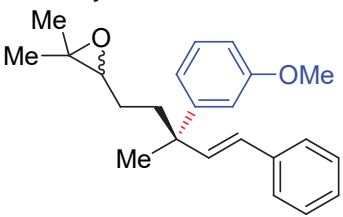

$90 \%$ yield, $82 \%$ ee, $84 \%$ es
图式 41 立体专一性的镍催化新戊酸烯丙酯的 Suzuki 偶联构 建手性季碳

Scheme 41 Stereospecific nickel-catalyzed Suzuki coupling of allylic pivalates to deliver quaternary stereocenters

\section{2 仲醇衍生物与有机卤化物等的还原偶联反应}

\subsection{1 酯类化合物作为仲烷基亲电试剂}

2016 年, Jarvo 课题组 ${ }^{[36]}$ 报道了苄基酯类衍生物的 分子内还原偶联反应，一系列杂环和官能团在反应条件 下都是可耐受的，最高获得 $90 \%$ 的收率. 2019 年，龚和 贵课题组 ${ }^{[72]}$ 在温和条件下实现了镍催化草酸酯基团修 饰的 $\alpha$-羟基羰基化合物与芳基卤化物的还原交叉偶联, 得到一系列 $\alpha$-芳基酯和酮产物. 初步机理研究表明, 该 反应在使用锌作为还原剂的条件下具有有效的 $\mathrm{C}-\mathrm{O}$ 键 断裂形成烷基自由基的能力，从而促进反应的进行. 同 年该小组 ${ }^{[37]}$ 在类似反应条件下实现了氯甲酸芐酯衍生 物与芳基碘化物的还原交叉偶联反应，以中等到优异的 收率得到二芳基甲烷类衍生物(Scheme 42). 


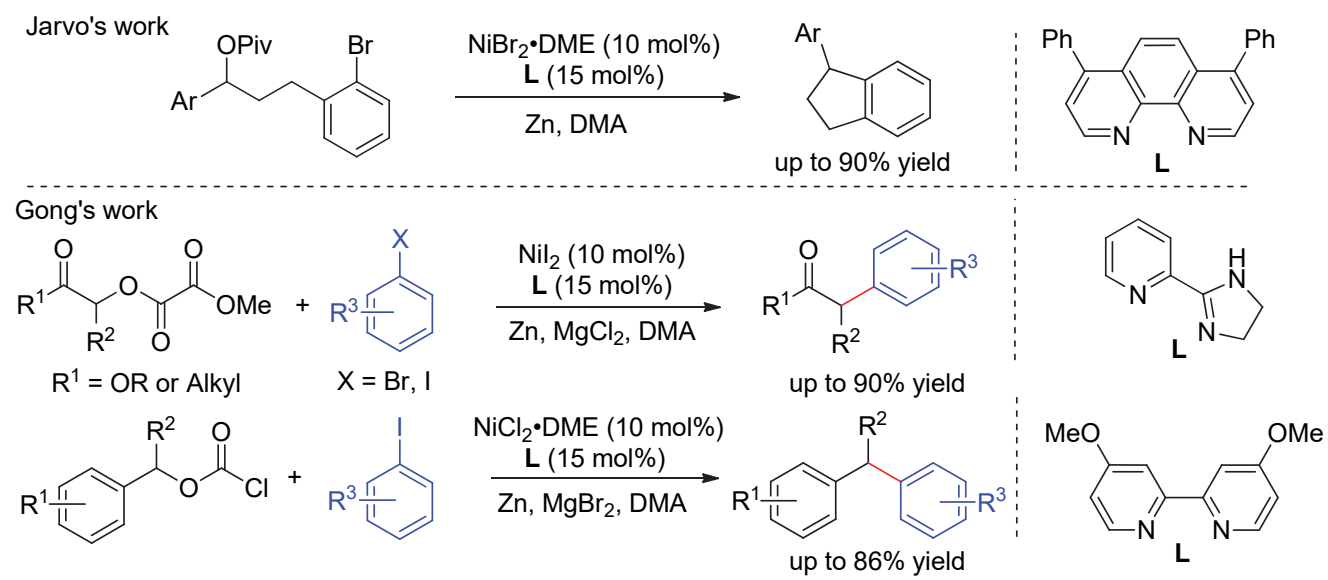

图式 42 几例镍催化酯类衍生物与有机卤化物的偶联反应

Scheme 42 Several cases of nickel-catalyzed coupling of ester derivatives with organic halides

2020 年, 储玲玲课题组 ${ }^{[73]}$ 报道了可见光诱导的镍/ 光氧化还原双催化的烯丙基碳酸酯与乙烯基三氟甲磺 酸酯的立体发散型还原偶联反应, 通过条件的控制能够 分别得到 $E$ 式或者 $Z$ 式的 1,4-二烯衍生物. 值得注意的 是, 这种协同交叉亲电偶联的立体选择性可以通过具有 合适三线态能量的不同光催化剂进行调节, 为烯烃合成 提供了一类实用和立体发散的新策略(Scheme 43).

2016 年, MacMillan 课题组 ${ }^{[74]}$ 首次利用镍/铱/光实 现了简单醇化合物与芳基卤化物的交叉偶联反应. 在反 应过程中, 醇需要通过草酰氯现场制备成相应的草酸烷 基酯作为原料参与反应. 这一偶联成功应用于类固醇等 相关药物的高效合成. 作者推测了镍-光反应催化剂协 同催化反应机理; 首先在光氧化还原催化循环中, 三价 的光反应催化剂 IrIII 被光激发到高氧化性的激发态*IrIII, 随后对草酸烷基酯类底物进行单电子氧化, 光反应催化 剂还原到二价 $\mathrm{Ir}^{\mathrm{II}}$, 草酸烷基酯底物脱质子脱二氧化碳
得到烷基自由基 43; 在镍催化循环中, 零价镍物种 44 对芳基卤化物氧化加成得到二价镍物种 $\mathbf{4 5}$, 然后捕获 烷基自由基 43 得到三价镍物种 46, 随后发生还原消除 反应得到目标产物和一价镍物种 $\mathbf{4 7 , 4 7}$ 经二价光反应催 化剂 Ir ${ }^{\mathrm{II}}$ 还原生成零价镍物种 $\mathbf{4 4}$, 完成催化循环 (Scheme 44).

最近王川课题组 ${ }^{[75]}$ 报道了镍催化的含未活化烯烃 的芳基碘化物与烯丙醇衍生物的不对称交叉偶联反应. 值得注意的是，该反应以高线性/支化比、 $E / Z$ 比和对映 选择性得到各种含高烯丙基取代季碳立体中心的手性 狮满和二氢苯并呋喃类衍生物, 最高获得 $98 \%$ 的对映选 择性. 在该还原反应中, 可以避免使用预生成的有机金 属化合物, 从而使该过程具有良好的官能团耐受性和高 步骤经济性. 在之前文献的基础上，该小组提出了一个 合理的镍催化烯丙基化反应的机理 (Scheme 45). 从零 价 $\mathrm{Ni}^{0}$ 出发, 首先与含烯烃的芳基碘化物进行氧化加成,

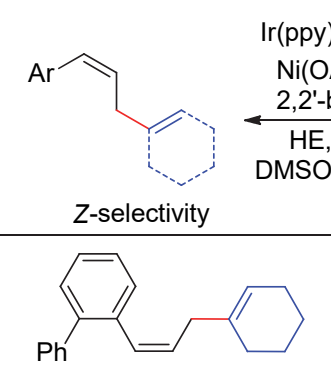

$80 \%$ yield, $Z / E=94: 6$

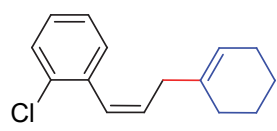

$69 \%$ yield, $Z / E=92: 8$

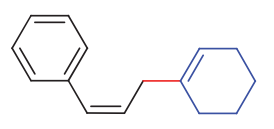

$70 \%$ yield, $Z / E=85: 15$
$\mathrm{Ru}(\mathrm{bpy})_{3}\left(\mathrm{PF}_{6}\right)_{2}$

$\mathrm{Ni}(\mathrm{OAc})_{2} \cdot 4 \mathrm{H}_{2} \mathrm{O}$
2,2 -bipyridine

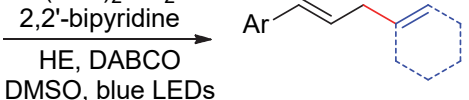

E-selectivity

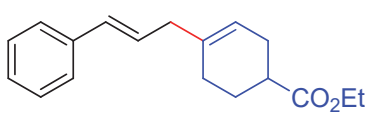

$78 \%$ yield, $E / Z=98: 2$

$86 \%$ yield, $E / Z>99: 1$

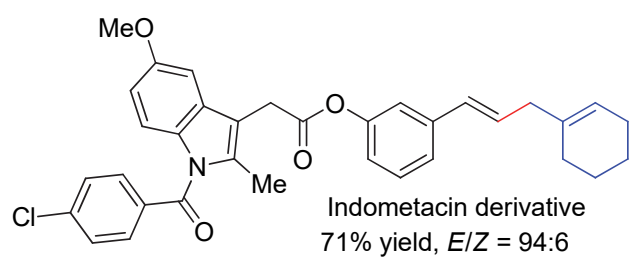

图式 43 镍催化烯丙基碳酸酯和乙烯基三氟甲磺酸酯的偶联反应

Scheme 43 Nickel-catalyzed coupling of allylic carbonates with vinyl triflates 


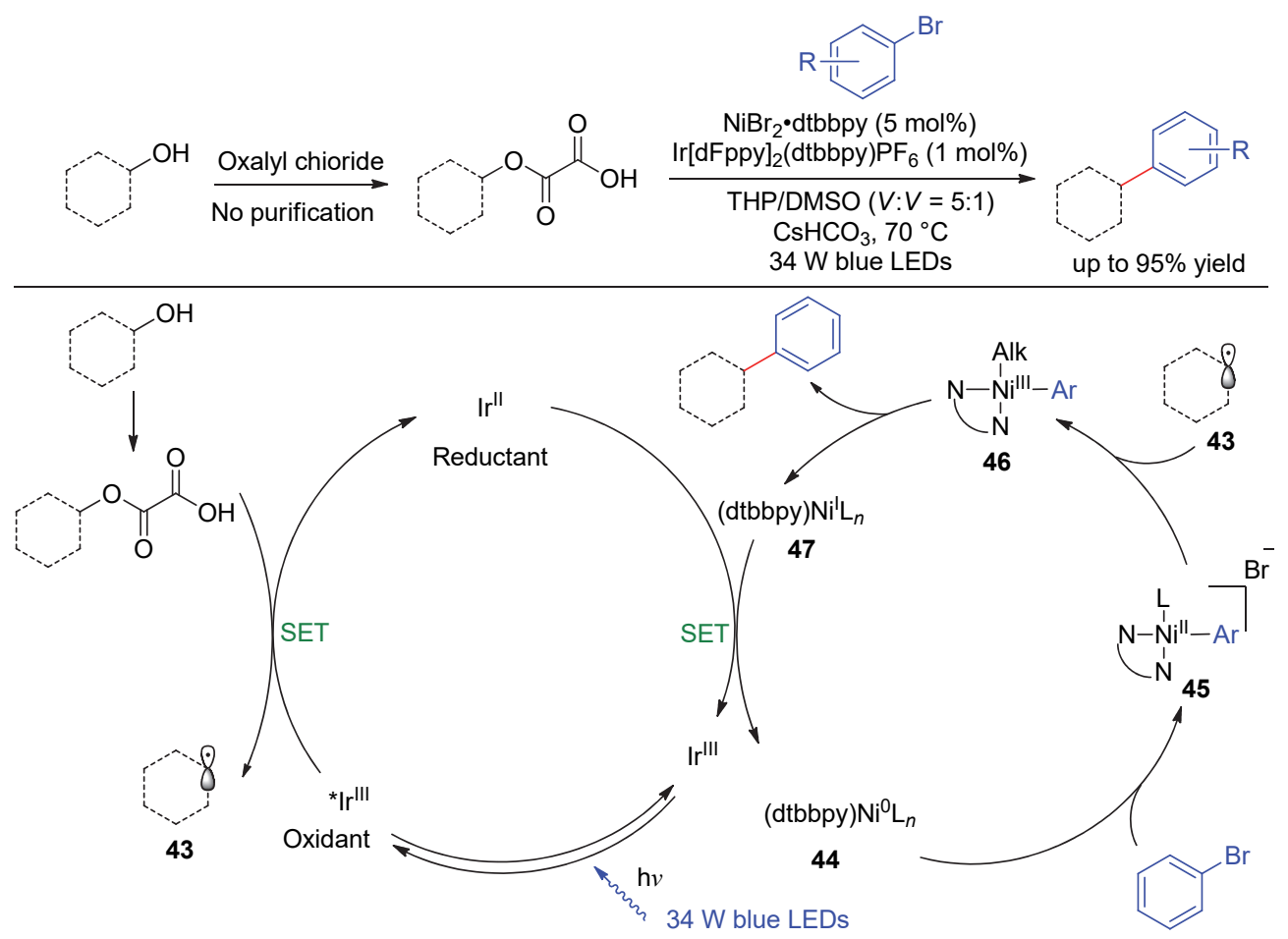

图式 44 镍/光氧化还原催化剂催化的醇衍生物与芳基溴化物的偶联反应及机理

Scheme 44 Nickel/photoredox-catalyzed coupling of alcohol derivatives with aryl bromides and mechanism
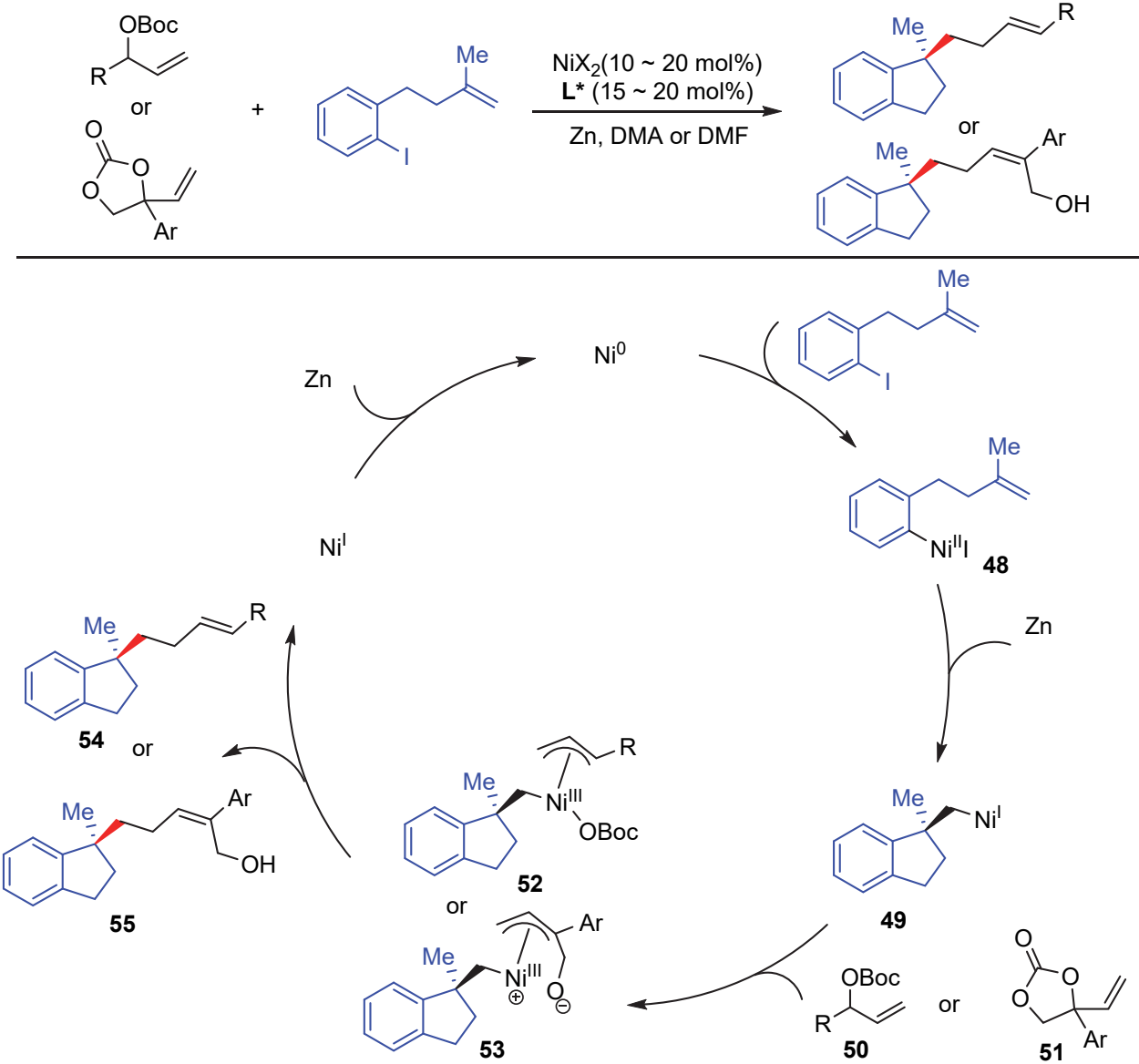

图式 45 镍催化含未活化烯烃的芳基碘化物与烯丙醇衍生物的偶联反应及机理

Scheme 45 Nickel-catalyzed coupling of aryl iodide-tethered unactivated alkenes with allyl alcohol derivatives and mechanism 
所得的 $\mathrm{Ni}^{\mathrm{II}}$ 物种 48 执行面选择性地分子内迁移插入到 侧链烯烃结构中, 再经 $\mathrm{Zn}$ 介导的还原得到含手性环境 的苯稠环中间体 49. 当烯丙基碳酸酯 50 为底物时, 通 过氧化加成得到中间体 $\mathbf{5 2}$, 最后还原消除得到线性芳 基烯丙基化产物 54, 同时释放出一价镍 $\mathrm{Ni}^{\mathrm{I}}$, 被 $\mathrm{Zn}$ 还原 得到零价 $\mathrm{Ni}^{0}$. 在环状碳酸烯丙酯 $\mathbf{5 1}$ 参与反应情况下, 需要经历氧化加成以及脱羒两个步骤后得到中间体 $\mathbf{5 3}$, 最后同样通过还原消除和 $\mathrm{Zn}$ 还原过程得到目标产物 $\mathbf{5 5}$.

\subsection{2 醚类化合物作为仲烷基亲电试剂}

2014 年, Weix 课题组 ${ }^{[76]}$ 报道了镍催化的 2-烷基环 氧乙烷与芳基溴化物的选择性开环偶联反应. 对于末端 环氧化物，区域选择性开环反应发生的位点取决于所用 的助催化剂. 当碘化物为助催化剂时, 通过碘代醇中间 体使环氧乙烷底物在位阻较小的位置开环得到末端加 成的直链产物. 当以茂铁为助催化剂时, 通过 $\mathrm{Ti}^{\mathrm{IV}}$ 自由 基中间体控制环氧乙烷底物在位阻较大的位置开环, 得 到内部加成的支链产物. 值得一提的是, 1,2-二取代的 环氧化物在两种情况下开环, 都得到以反式为主的开环 偶联产物(Scheme 46).

在之前工作的基础上, 2015 年 Weix 课题组 ${ }^{[77]}$ 首次 报道了 $\mathrm{NiCl}_{2}$ (bpy) 和手性茂钛这一组合催化剂促进的内 消旋环氧化物与芳基溴化物的不对称开环偶联反应. 高 对映选择性地得到反式- $\beta$-芳基环烷醇(up to $95 \% e e$ ). 反应的官能团容忍性优异, 5 元到 7 元环底物都能顺利 发生反应. 经过一系列控制实验, 提出了可能的催化循 环机理, 该反应的关键步骤是内消旋环氧化物对映选择
性地形成 $\beta$-钛氧碳自由基 56, 随后，该自由基对芳基镍 (II)氧化加成得到三价镍物种 $\mathbf{5 7}$, 还原消除得到目标产 物, 并释放出镍催化剂(Scheme 47).

2020 年, Doyle 课题组 ${ }^{[78]}$ 利用镍、钛和有机光氧化 还原催化剂体系，实现了环氧化物与芳基碘化物的交叉 偶联反应. 三种不同的环氧化合物: 苯乙烯环氧化物、 环状环氧化物和末端脂肪烷烃环氧化物都能以中等至 良好的收率和较高的区域选择性发生交叉偶联反应. 这 一反应展示出了有趣的配体效应, 不同类型的环氧底物 需要不同类型的氮配体促进反应. 值得注意的是, 苯乙 烯环氧化物参与反应, 能够选择性地得到支链偶联产 物; 末端脂肪烷烃环氧化物参与反应时, 能够选择性地 得到直链偶联产物. 机理研究表明, 苯乙烯环氧化物为 底物时，通过钛促进开环得到相应的伯醇类自由基中间 体，从而生成支链产物. 相反，对于末端脂肪烷烃环氧 化物，反应中会生成碘代醇中间体，随后通过卤原子㨘 取得到仲醇类自由基，从而得到直链产物(Scheme 48).

\section{3 镍催化叔醇衍生物参与的偶联反应}

季碳广泛存在于具有生物活性的分子和天然产物 中, 其中季碳中心对这些分子的生物活性有着重要的影 响. 季碳的存在同时也会影响分子的化学性质，例如 Thorpe-Ingold 效应，又被称为偕二甲基效应，当一个亚 甲基上的氢被两个甲基取代后就形成了一个偕二甲基 季碳，能够显著地加快成环反应的速率，因此被广泛用 于多环生物分子的合成中. 向候选药物中添加季碳中心

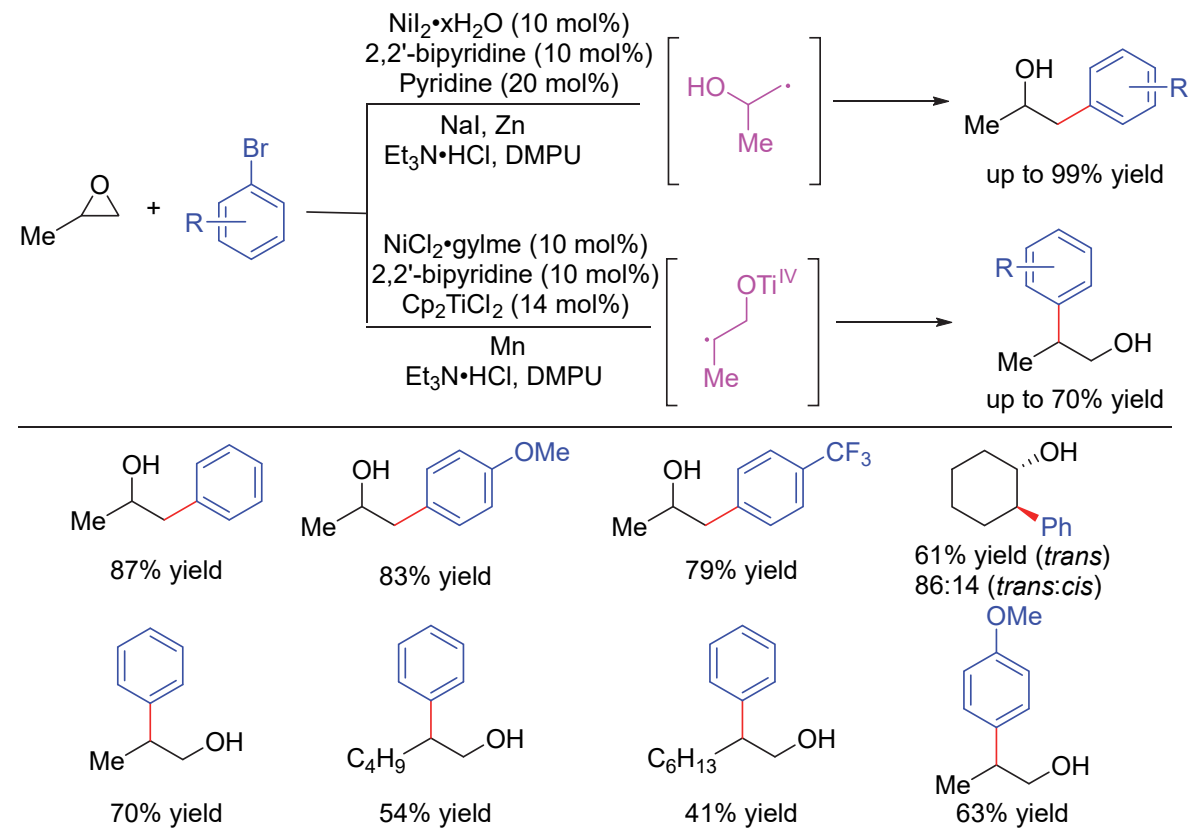

图式 46 镍催化环氧化合物的开环偶联反应

Scheme 46 Nickel-catalyzed ring-opening coupling of epoxides 

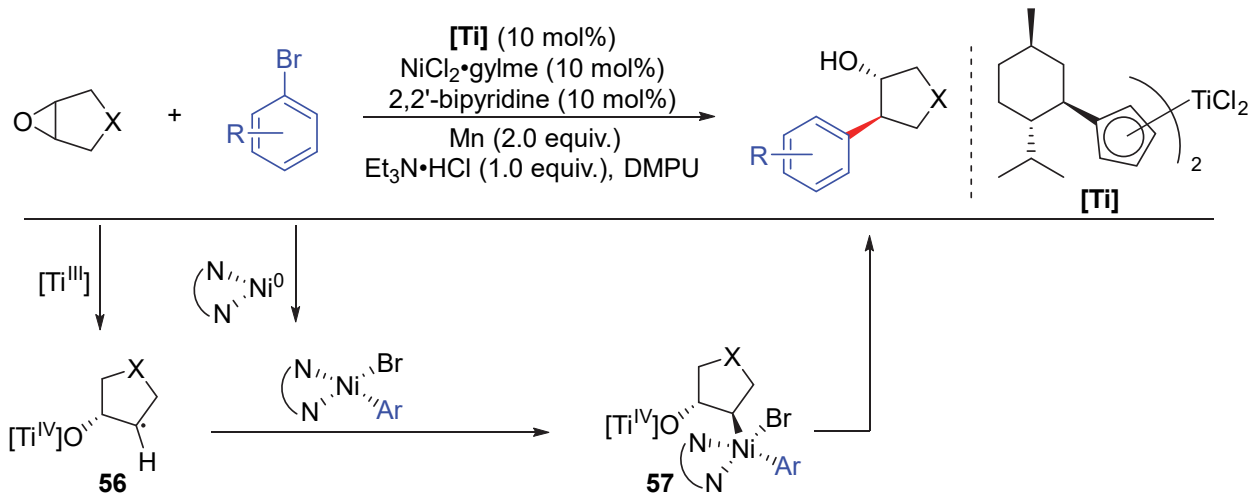

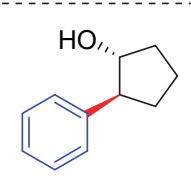

$89 \%$ yield, $87 \%$ ee

$\mathrm{HO}$,<smiles>COc1ccccc1[C@@H]1CCC[C@H]1O</smiles>

$85 \%$ yield, $86 \%$ ee

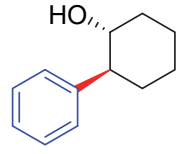

$93 \%$ yield, $80 \%$ ee

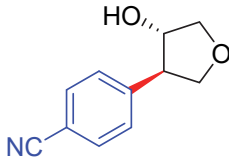

$80 \%$ yield, $94 \%$ ee

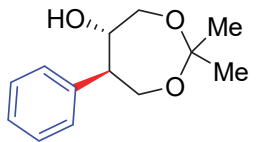

$82 \%$ yield, $91 \%$ ee

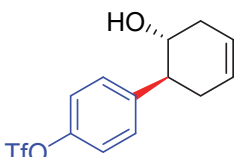

91\% yield, $94 \%$ ee

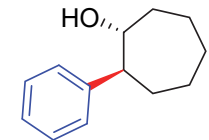

$72 \%$ yield, $86 \%$ ee

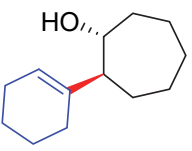

$64 \%$ yield, $78 \%$ ee

图式 47 镍催化环氧化合物与芳基溴化物的不对称开环偶联反应及机理

Scheme 47 Nickel-catalyzed asymmetric ring-opening coupling of epoxides with aryl bromides and mechanism
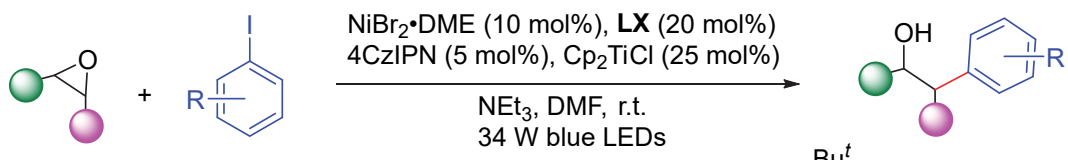<smiles>N=C(c1ccccn1)N1CCCCC1</smiles><smiles>c1ccc(-c2ccnc3c2ccc2c(-c4ccccc4)ccnc23)cc1</smiles>

L6<smiles>Brc1ccnc(-c2cc(Br)cc(-c3cc(Br)ccn3)n2)c1</smiles>

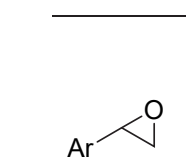

Styrene oxides with L5<smiles>C1CCC2OC2C1</smiles>

Cyclic epoxides with L6<smiles>[AlH2]C1CO1</smiles>

Aliphatic epoxides with L7
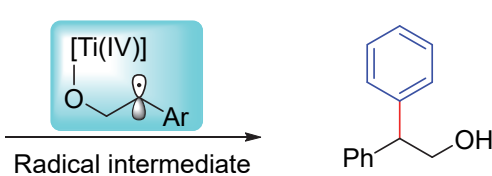

$88 \%$ yield

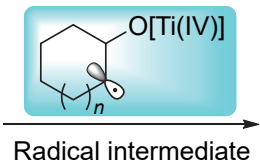

Radical intermediate

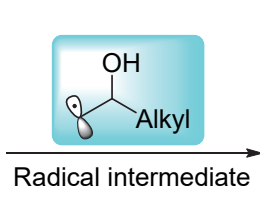

Radical intermediate

$\mathrm{C}_{10} \mathrm{H}_{2}$

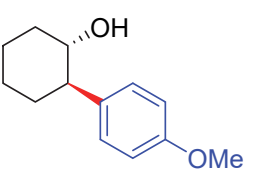

$94 \%$ yield

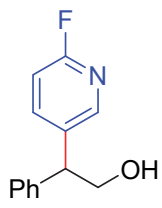

$39 \%$ yield

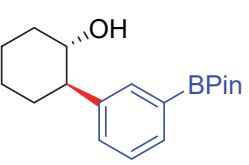

$66 \%$ yield

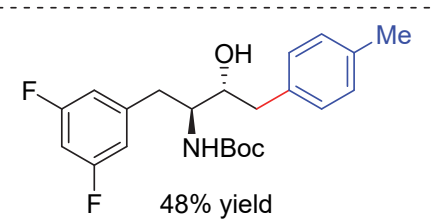

图式 48 镍/钛/光氧化还原催化剂催化的环氧化合物与芳基溴化物的偶联反应

Scheme $48 \mathrm{Ni} / \mathrm{Ti} /$ Photoredox-catalyzed coupling of epoxides with aryl bromides 
尤其是手性季碳中心, 可以增强其活性和代谢稳定 性 ${ }^{[79]}$. 然而, 由于叔烷基的位阻效应导致其参与的偶联 反应困难一直以来都是合成化学的巨大挑战, 镍催化偶 联反应为克服该难题提供了宝贵的途径. 近年来, 通过 镍催化的叔醇衍生物参与的交叉偶联反应来实现季碳 中心的高效构筑取得了显著成就.

2020 年, Rousseaux 课题组 ${ }^{[80]}$ 开发了镍催化的环丙 醇衍生物与芳基锌试剂的交叉偶联反应，以中等到优异 的收率得到一系列含季碳中心的环丙烷类衍生物. 该小 组通过不同氧化还原活性离去基团的设计和优化, 得到 不同的偶联产物. 在这一反应中, 环丙烷具有两电子和
单电子两种反应性, 在极性(2e) 条件下获得开环产物, 而在自由基(1e)条件下获得闭环的三元环产物. 随后在 这一工作的指导下，该小组实现了离去基团为对甲苯磺 酸根(2e)的环丙烷与芳基嗍酸的开环偶联反应，最高获 得 $89 \%$ 的收率 ${ }^{[81]}$ (Scheme 49).

2019 年, 龚和贵课题组 ${ }^{[82]}$ 报道了镍催化叔烷基草 酸酯与缺电子烯烃以及芳基卤化物的交叉偶联反应 (Scheme 50). 机理研究表明, 在镍催化剂存在下 $\mathrm{Zn}$ 和 $\mathrm{MgCl}_{2}$ 能够促进底物 $\mathrm{C}\left(\mathrm{sp}^{3}\right)-\mathrm{O}$ 键的断裂从而得到烷基 自由基，随后被缺电子烯烃或者芳基卤化物捕获，得到 目标产物. $\mathrm{MgCl}_{2}$ 和吡啶类添加剂在该过程中能够活化

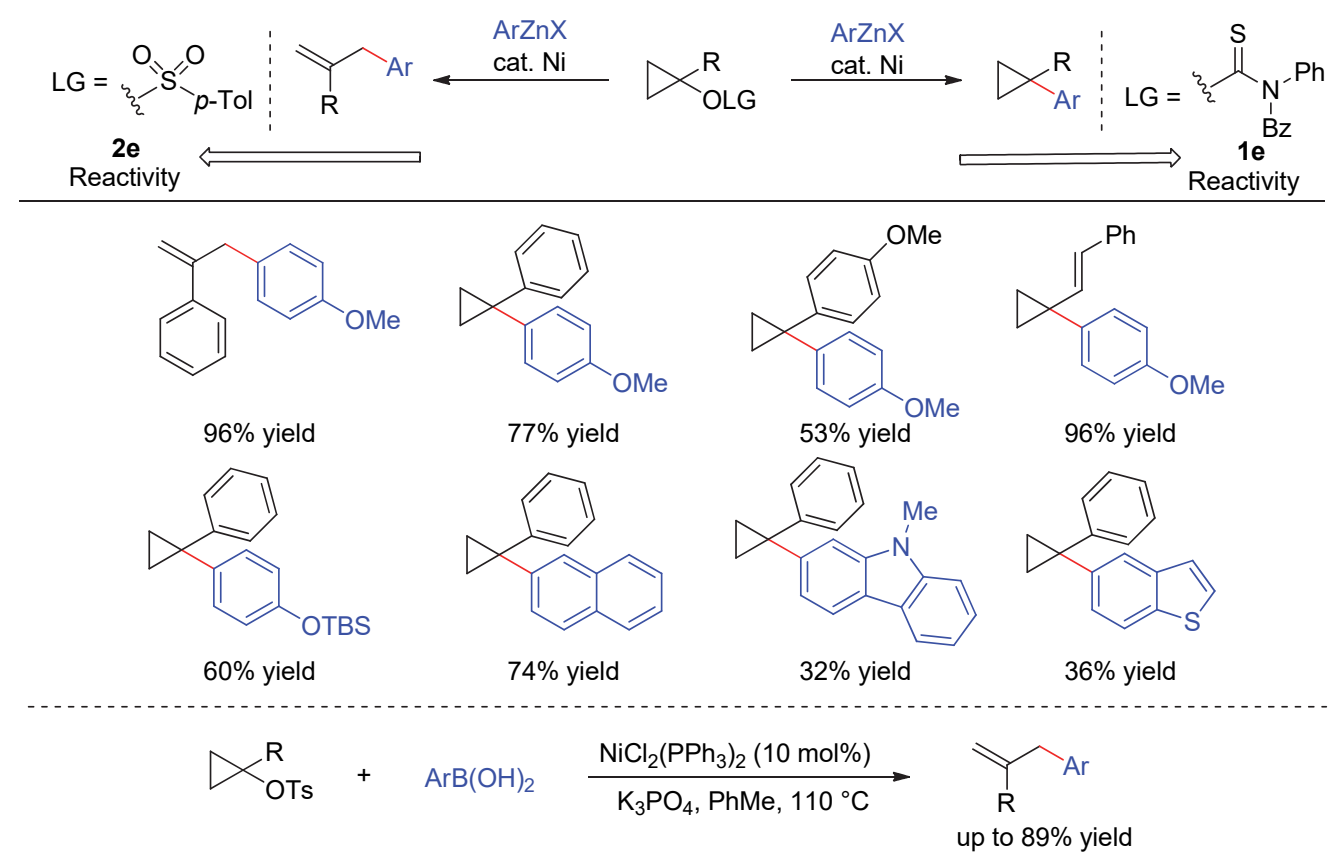

图式 49 镍催化环丙醇衍生物参与的偶联反应

Scheme 49 Nickel-catalyzed coupling reaction involving cyclopropanol derivatives
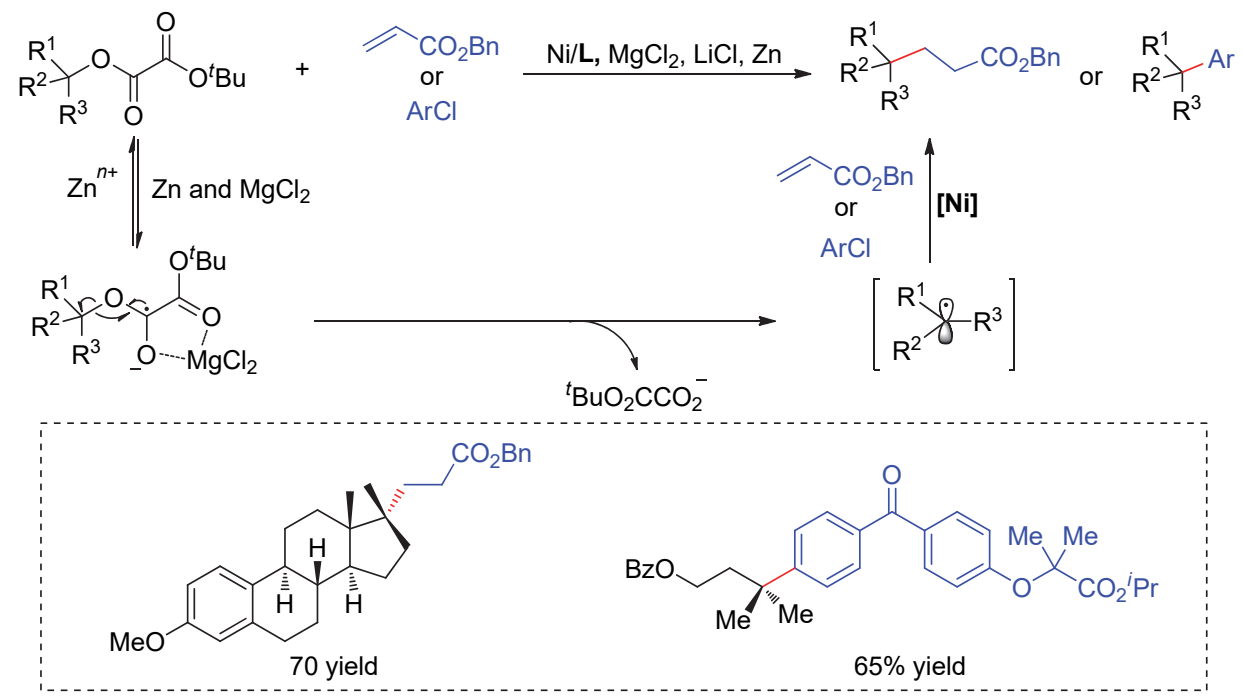

图式 50 镍催化叔烷基草酸酯与缺电子烯烃以及芳基卤化物的偶联反应

Scheme 50 Nickel-catalyzed coupling of tertiary alkyl oxalates with electron-deficient olefins and aryl halides 
$\mathrm{Zn}$ 和叔醇衍生的草酸二烷基酯底物, 同时稳定自由基 阴离子中间体.

在手性季碳中心的构建方面, 2016 年 Watson 课题 组 ${ }^{[83]}$ 开发了镍催化的对映体富集的叔苄醇类化合物与 芳基硼酸酯的立体专一性交叉偶联反应，构建了一系列 光学纯的季碳手性中心. 在最优条件下, 醇原料能够立 体保持地生成四取代产物. 因为在对底物进行氧化加成 的过程中, 需要形成 $\pi$-烯丙基-Ni 中间体, 因此大 $\pi$-共 轭的取代基, 例如䒺基或联苯基对于该转化至关重要 (Scheme 51).
最近 Watson 课题组 ${ }^{[84]}$ 又实现了镍催化无配体参与 的 Suzuki-Miyaura 乙烯基化反应，以高对映体富集的叔 芐基羧酸盐衍生物为原料, 高收率和高对映选择性地构 筑了一个季碳手性中心. 该方法第一次克服了在此类反 应中对苄基羒酸盐上的荎基的长期需求，可以使用简单 芳基底物就能实现反应(Scheme 52). 随后该小组 ${ }^{[85]}$ 利 用镍为金属催化剂, 简单的二苯乙烯为配体实现了叔茮 基羧酸盐衍生物与芳基硼试剂的立体专一性交叉偶联 反应，高效合成了具有挑战性的含全碳手性中心的二芳 基类化合物(Scheme 53).

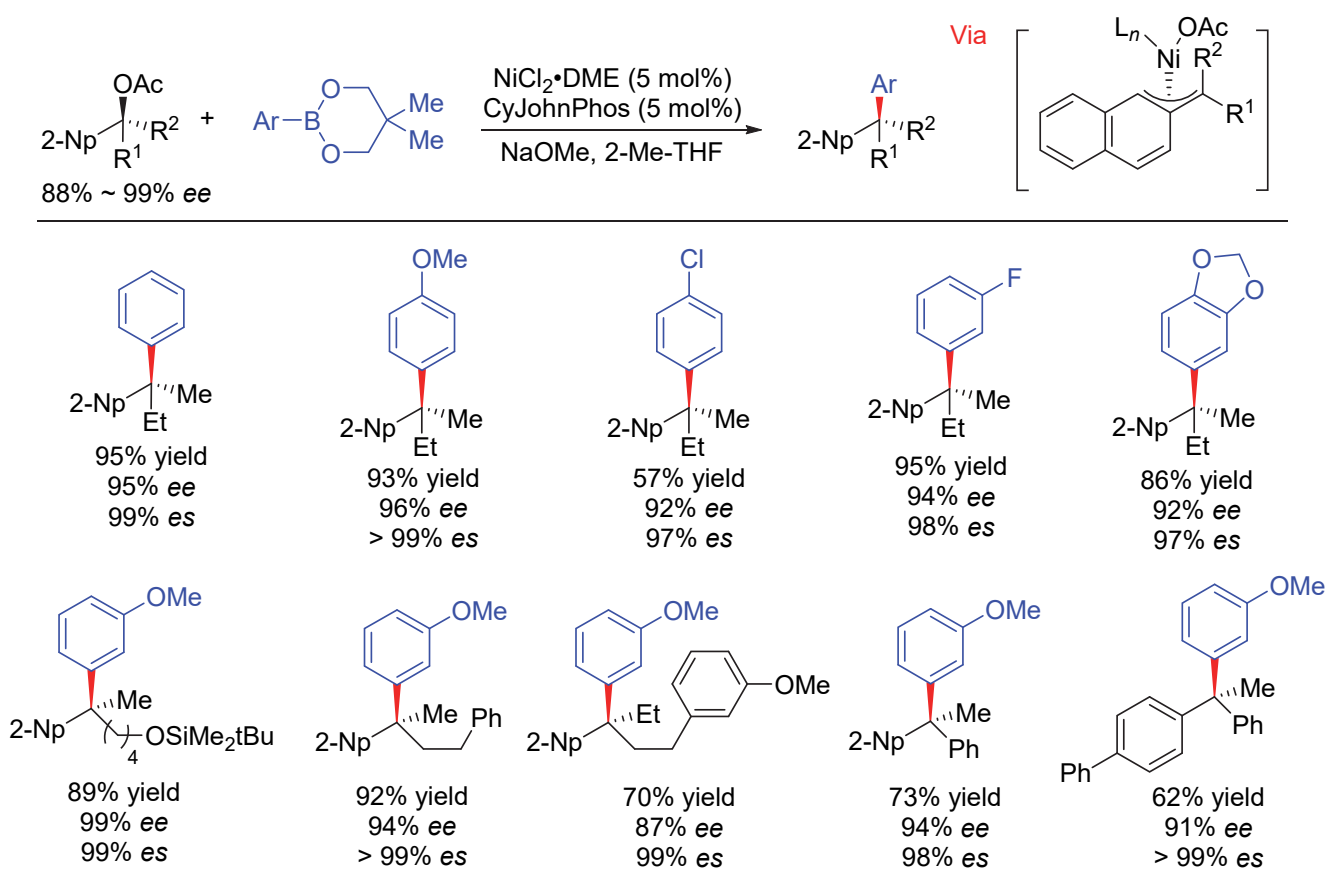

图式 51 立体专一性的镍催化叔乙酸苄酯与芳基硼试剂的偶联反应

Scheme 51 Stereospecific nickel-catalyzed coupling of tertiary benzylic acetates with aryl boron reagents

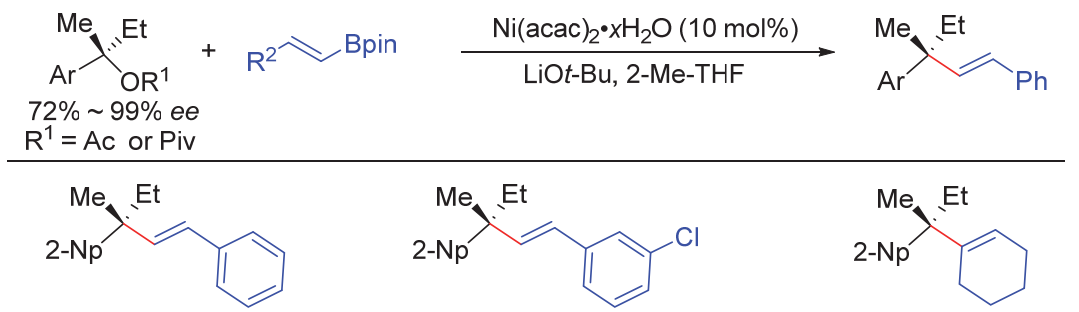

$98 \%$ yield, $96 \%$ ee, $>99 \%$ es

$78 \%$ yield, $96 \%$ ee, $99 \%$ es

$89 \%$ yield, $96 \%$ ee, $>99 \%$ es

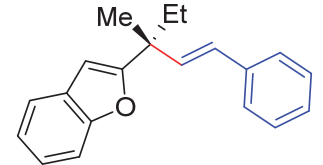

$66 \%$ yield, $72 \%$ ee, $>99 \%$ es<smiles>CCC(C)(/C=C/c1ccccc1)c1ccc(OC)cc1</smiles>

$89 \%$ yield, $90 \%$ ee, $99 \%$ es

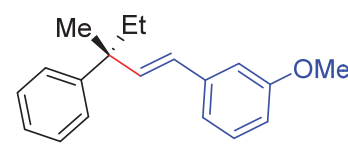

$79 \%$ yield, $95 \%$ ee, $>99 \%$ es

图式 52 立体专一性的镍催化叔苄基羧酸盐与烯基嗍试剂的偶联反应

Scheme 52 Stereospecific nickel-catalyzed coupling of tertiary benzylic carboxylates with alkenyl boron reagents 


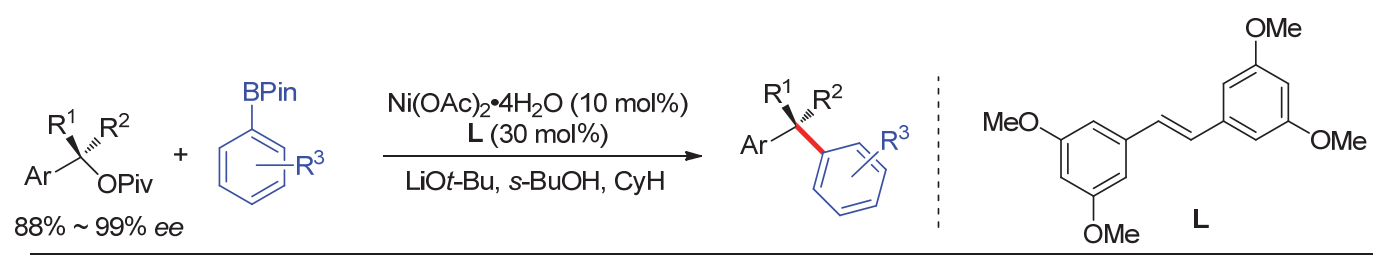

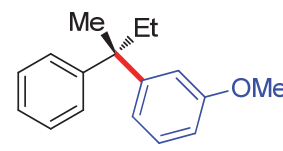

$77 \%$ yield, $96 \%$ ee, $>99 \%$ es

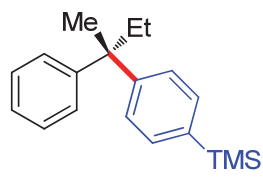

$83 \%$ yield, $96 \%$ ee, $>99 \%$ es

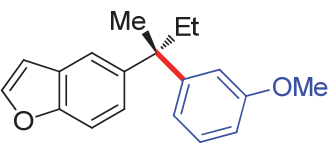

$93 \%$ yield, $92 \%$ ee, $>99 \%$ es

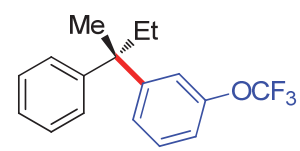

$73 \%$ yield, $95 \%$ ee, $99 \%$ es

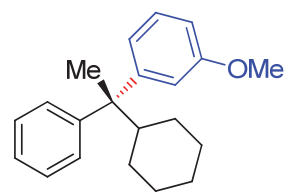

$54 \%$ yield, $95 \%$ ee, > $99 \%$ es

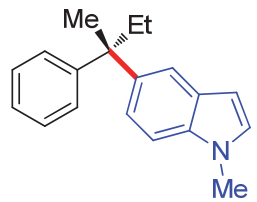

$73 \%$ yield, $96 \%$ ee, > $99 \%$ es

图式 53 立体专一性的镍催化叔苄基羧酸盐与芳基硼试剂的偶联反应

Scheme 53 Stereospecific nickel-catalyzed coupling of tertiary benzylic carboxylates with aryl boron reagents

手性汇聚的偶联反应能够将外消旋体直接高收率 和高对映选择性地转化为目标产物, 从而避免了立体专 一性偶联和动力学拆分的不足. 近几年来通过镍催化外 消旋烷基亲电试剂参与的手性汇聚不对称偶联反应来 构建手性中心的策略得到了越来越多的研究. 通常情况 下, 用于镍催化的不对称偶联反应的烷基亲电试剂仅限 于可产生手性叔碳立体中心的卤化物或类似物的仲烷 基亲电试剂, 而大位阻叔烷基亲电试剂参与的不对称偶 联反应构筑季碳手性中心却鲜有报道. 2018 年, $\mathrm{Fu}$ 课题 组 ${ }^{[86]}$ 发表了镍不对称催化偶联反应构筑手性季碳的研 究工作. 几乎与此同时, 张万斌课题组 ${ }^{[87]}$ 首次报道了镍
催化的叔醇衍生物为亲电试剂, 构建季碳手性中心的不 对称偶联反应, 利用镍/双膦体系催化了螺环环氧吲哚 酮与烯基硼酸的不对称开环偶联烯基化反应. 外消旋的 螺环环氧吲哚酮通过手性汇聚过程, 高收率和高对映选 择性地合成了含有季碳立体中心的手性高烯丙醇类化 合物(up to $98 \%$ yield, up to $95 \% e e$ ). 高烯丙基醇部分可 以高效地转化为手性四氢呋喃骨架，一步制备具有三个 手性中心的螺一呋喃一氧化吲哚结构. 该反应提供了镍催 化的叔烷基亲电试剂的对映选择性交叉偶联反应和外 消旋环氧化物的手性汇聚转化的罕见实例(Scheme 54).
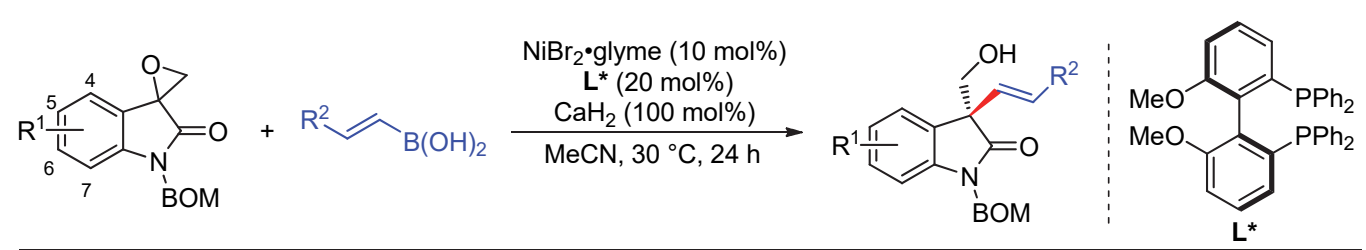

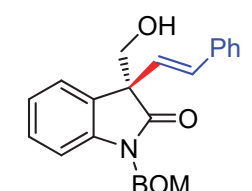

$86 \%$ yield, $87 \%$ ee<smiles>Cc1ccc(/C=C/[C@@]2(CO)C(=O)Nc3cccc(Cl)c32)cc1</smiles>

BOM

$94 \%$ yield, $95 \%$ ee<smiles>CC(=O)N1C(=O)[C@@](C=Cc2ccccc2)(CO)c2c(Cl)cccc21</smiles>

91\% yield, $93 \%$ ee

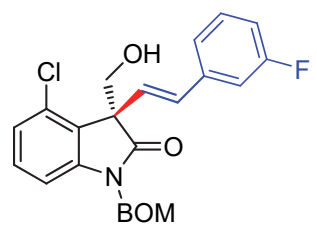

$89 \%$ yield, $92 \%$ ee<smiles>Cc1ccc2c(c1)[C@](C=Cc1ccccc1)(CO)C(=O)N2O</smiles>

BOM $90 \%$ yield, $88 \%$ ee<smiles>CC(=O)N1C(=O)[C@](C=Cc2ccsc2)(CO)c2c(Cl)cccc21</smiles>

$77 \%$ yield, $92 \%$ ee<smiles>COC(=O)N1C(=O)[C@](/C=C/c2ccccc2)(CO)c2ccc(Br)cc21</smiles>

$70 \%$ yield, $80 \%$ ee<smiles>CC(C)=CC[C@]1(CO)C(=O)N(c2cccc(Cl)c2)c2ccccc21</smiles>

$89 \%$ yield, $94 \%$ ee

图式 54 镍催化螺环环氧吲哚酮与烯基硼酸的不对称偶联反应

Scheme 54 Nickel-catalyzed asymmetric coupling of spiro-epoxyoxindoles with alkenylboronic acids 
该小组结合自由基捕获实验以及相关的立体化学 实验，更倾向于在氧化加成过程中生成稳定的叔碳自由 基中间体的单电子转移机理, 从而实现对映选择性的控 制. 首先镍对螺环环氧吲哚酮进行反应, 得到叔烷基亲 电自由基 58, 镍的价态升高一价. 接着手性的镍与自由 基碳键合从而诱导出手性的中间体 $\mathbf{5 9}$, 镍的价态再升 高一价. 然后与烯基硼酸进行转金属化得到中间体 60 . 最后还原消除得到开环偶联产物，镍的价态降低二价， 进入下一个催化循环. 另一种可能是先进行转金属化, 然后发生氧化加成(Scheme 55).

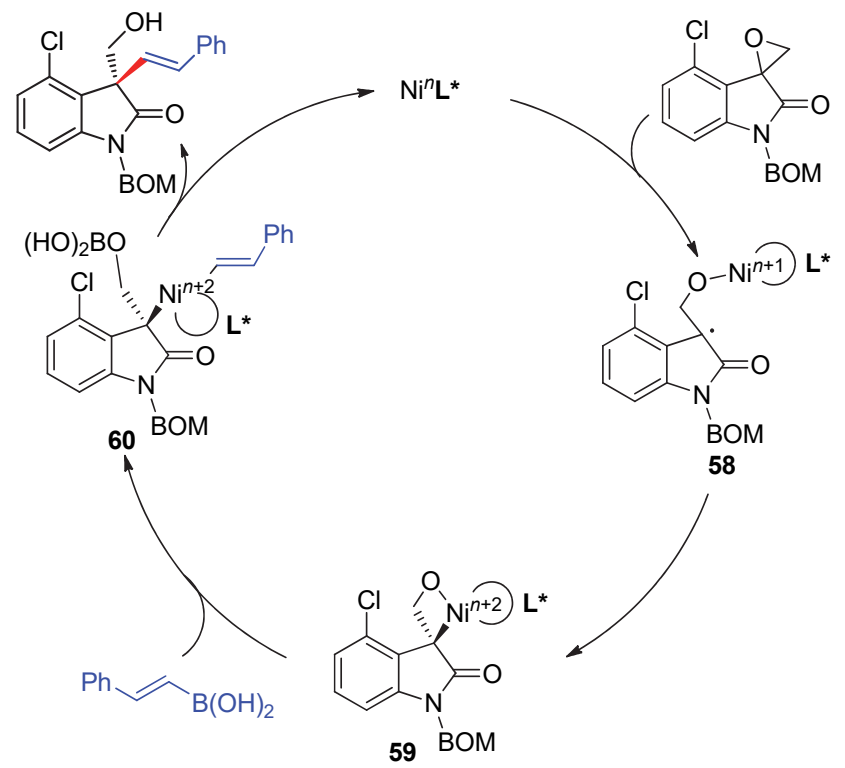

图式 55 镍催化不对称烯基化反应可能的机理 Scheme 55 Possible mechanism of nickel-catalyzed asymmetric alkenylation

\section{4 镍催化缩醛和 $N, O$-缩醛衍生物参与的偶联} 反应

1998 年 Hoveyda 课题组 ${ }^{88}$ 报道了一例镍催化不饱 和环状缩醛与有机镁试剂的不对称偶联反应. 在酸性条 件下处理后，以高收率和良好的对映选择性获得酮产 物. 令人意外的是, 非手性膦配体例如 $\mathrm{PPh}_{3}$ 的加入能够 提高产物的对映选择性(Scheme 56).
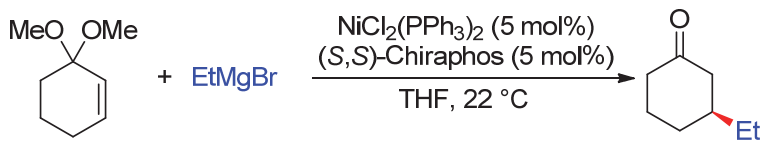

$90 \%$ yield, $85 \%$ ee

图式 56 镍催化环状缩醛与有机镁试剂的偶联反应 Scheme 56 Nickel-catalyzed coupling of cyclic acetals with organomagnesium reagents

2017 年, Doyle 课题组 ${ }^{[89]}$ 开创性地设计了一类 3,5位含有大体积基团的芳基烷基膦配体，与镍配位后共同 促进了缩酫衍生物与有机硼试剂的交叉偶联反应，得到 了一系列苄梄类化合物. 反应条件温和、底物范围广泛, 最高能够获得 $91 \%$ 的收率. 在研究过程中该小组通过使 用参数量化膦的空间和电子性质以及回归统计分析，确 定了配位模型，表明有效的膦具有较远的空间位阻，这 一概念可以指导未来针对镍进行的配体设计 (Scheme 57).

利用路易斯酸/还原剂的组合可以促进缩醛生成 $\alpha$ 甲氧基自由基，同时为了进一步扩大烷基交叉偶联反应 的合成范围. 2015 年, Doyle 课题组 ${ }^{[0]}$ 利用 $\mathrm{Ni} / \mathrm{Zn} / \mathrm{TMSCl}$ 体系，将缩醛激发原位生成自由基后与芳基卤化物偶 联，实现了碳-碳键的构筑，得到一系列二芳基醚类化 合物(Scheme 58).

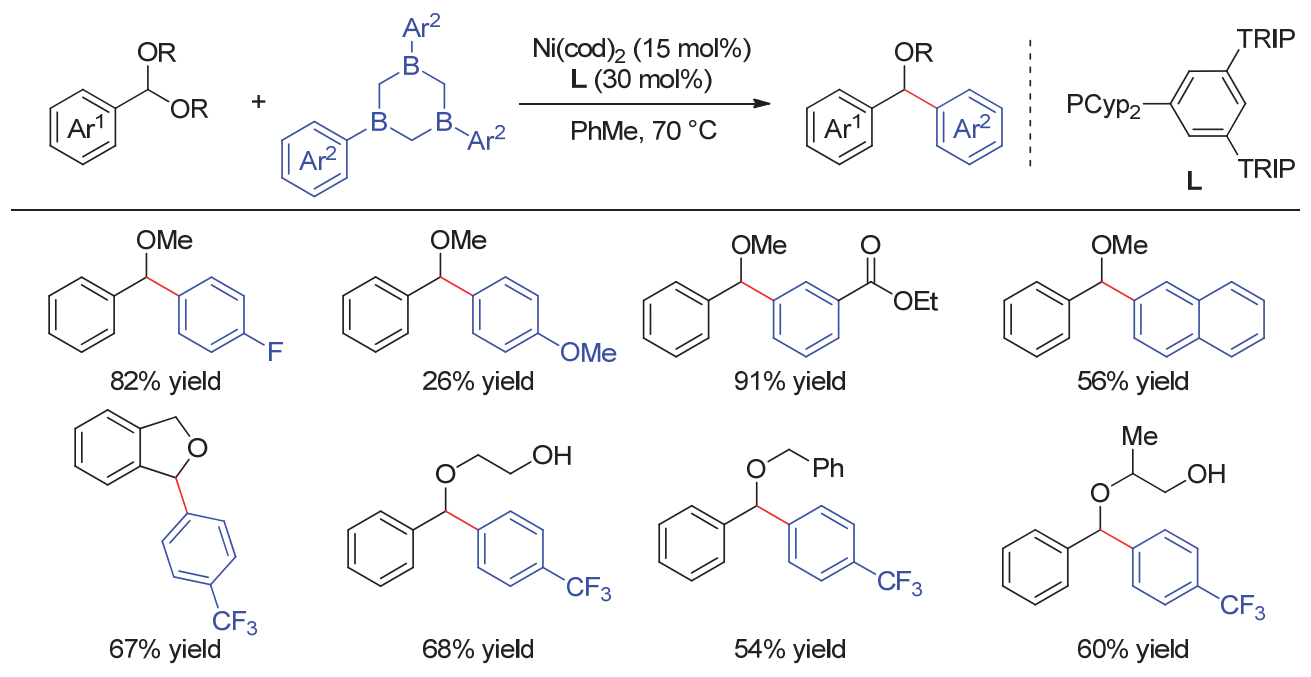

图式 57 镍催化茮基缩醛与有机硼试剂的偶联反应

Scheme 57 Nickel-catalyzed coupling of benzylic acetals with organoboron reagents 


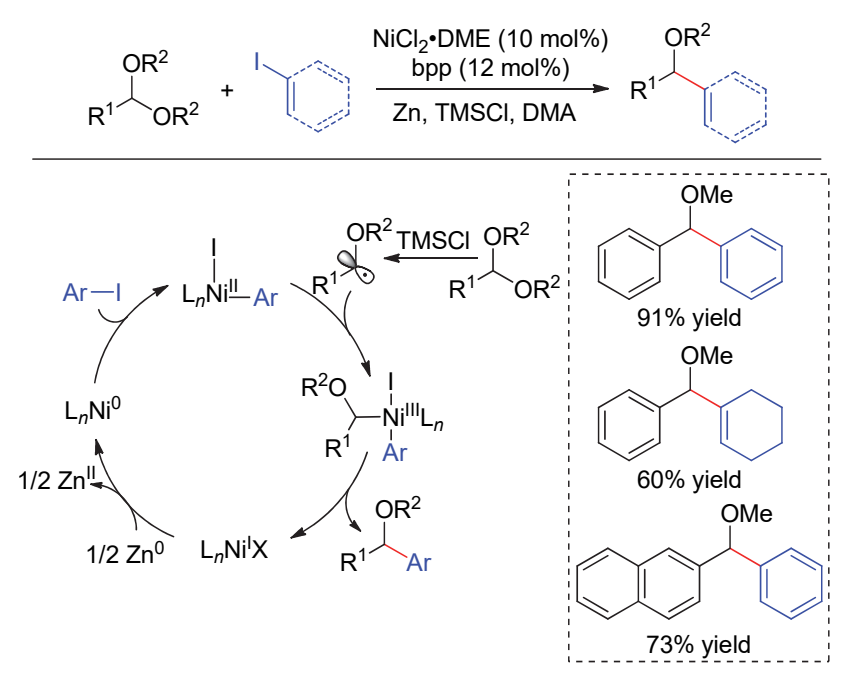

图式 58 镍催化缩醛与芳基碘化物的偶联反应及机理 Scheme 58 Nickel-catalyzed coupling of acetals with aryl iodides and mechanism

2019 年, 王川课题组 ${ }^{[91]}$ 利用 $\mathrm{Ni} /$ bipyridine-Zn$\mathrm{TMSCl}$ 催化体系促进 $\mathrm{C}-\mathrm{O}$ 和 $\mathrm{C}-\mathrm{F}$ 键裂解, 实现了缩 醛与 $\alpha$-三氟甲基烯烃的交叉偶联反应，合成了一系列烷 氧基取代的二氟烯烃类衍生物. 首先缩醛在 $\mathrm{TMSCl}$ 作 用下得到了重要的自由基中间体 61 , 随后与 $\alpha$-三氟甲 基烯烃反应得到自由基 62, 再与零价镍作用得到 63 ; 或 者 61 直接对双键加成得到中间体 63 , 再经过 $\beta-\mathrm{F}$ 消除 得到产物(Scheme 59).

2011 年, Doyle 课题组 ${ }^{[92]}$ 报道了一例镍催化芳基㸴 酸和含半缩胺醛结构的喹啉和异喹啉衍生物的交叉偶 联反应, 反应条件温和, 并且可以耐受常见的有机官能 团. 机理研究表明, 嗍酸在反应中作为 Lewis 酸活化 $N, O$-缩醛中的 $\mathrm{C}-\mathrm{O}$ 键, 促进了反应的进行. 随后该小
组 ${ }^{[93]}$ 对其不对称催化进行研究，通过镍盐、手性配体的 系统篮选实现了外消旋底物的对映选择性芳基化反应， 最高获得 90\%的 ee 值(Scheme 60).

2021 年, 龚和贵课题组 ${ }^{[94]}$ 报道了镍催化 $N$-羰基保 护的 $\alpha$-新戊酰氧基甘氨酸与乙烯基/芳基卤化物及三氟 甲磺酸酯的交叉偶联反应. $\alpha$-新戊酰氧基甘氨酸在偶联 反应中原位转化为低浓度的活性 $\alpha$-碘甘氨酸或亚胺酯, 再通过单电子还原或者卤化物篗取得到甘氨酰自由基, 然后与乙烯基/芳基 $-\mathrm{Ni}^{\mathrm{II}}$ 物种偶联，以中等到良好的收 率得到目标产物(Scheme 61).

\section{5 结论与展望}

如上所述, 镍催化醇衍生物的交叉偶联反应已经成 为构建 $\mathrm{C}\left(\mathrm{sp}^{3}\right)-\mathrm{C}$ 键的重要方法之一. 由于镍原子半径 较小, 具有几种可变的价态, 可以灵活地参与到氧化还 原中性交叉偶联以及还原性交叉偶联反应中. 在与有机 卤化物等的反应中, 镍催化剂通过自由基催化循环促进 烷基亲电试剂的活化，并抑制和/或控制 $\beta$ - $\mathrm{H}$ 消除反应. 在镍催化手性纯的仲醇或叔醇衍生物的立体专一性偶 联反应构建手性叔碳或季碳中心领域, Jarvo、Watson 等 课题组做出了许多重要的工作. 而此类反应的不对称催 化却鲜有报道，到目前为止仅有 Doyle、 $\mathrm{Fu}$ 以及张万斌 课题组开发的几例反应. 接下来, 开发相关不对称催化 反应，特别是构筑季碳的相关偶联反应，仍然是极具挑 战性的工作，这需要从底物的设计上以及开发结构上新 颖的手性配体等方面进行探索, 并与动力学分析和 DFT 计算等相结合进行深入研究和改进. 可以预见的是, 未 来将会有更多的醇衍生物作为烷基亲电试剂的镍催化 绿色偶联反应被创新性地开发出来, 并且找到更多潜在

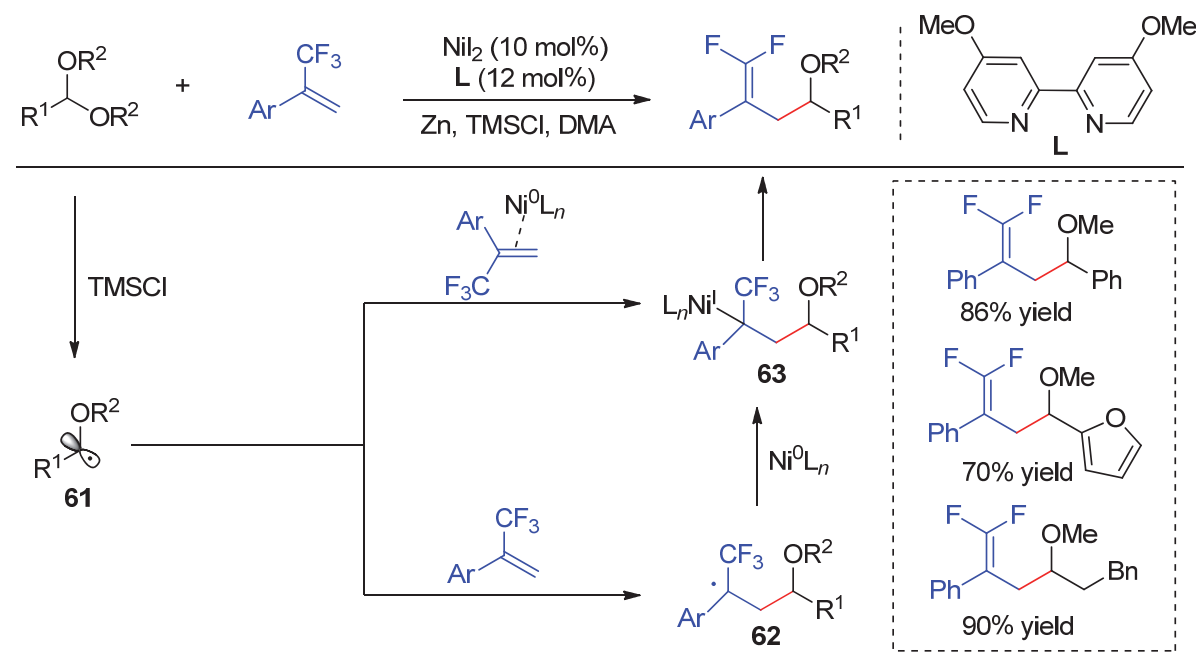

图式 59 镍催化缩醛与 $\alpha$-三氟甲基烯烃的偶联反应及机理

Scheme 59 Nickel-catalyzed coupling of acetals with $\alpha$-trifluoromethyl alkenes and mechanism 

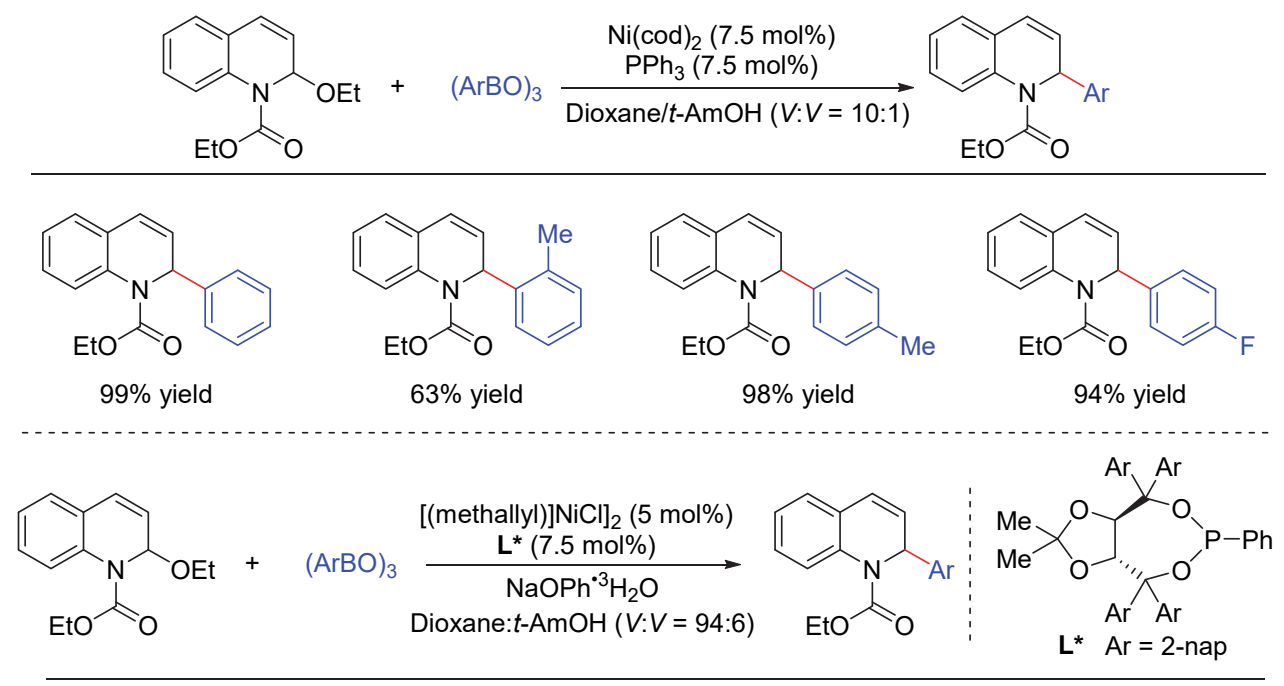<smiles>CCOC(=O)N1c2ccccc2C=C[C@H]1c1ccccc1</smiles>

$99 \%$ yield, $85 \%$ ee<smiles>CCOC(=O)N1c2ccccc2C=C[C@H]1c1ccccc1C</smiles>

$85 \%$ yield, $77 \%$ ee<smiles>CCOC(=O)N1c2ccccc2C=C[C@H]1c1ccc(C)cc1</smiles>

$85 \%$ yield, $87 \%$ ee

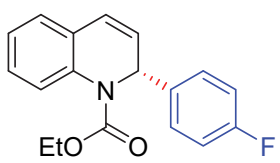

$96 \%$ yield, $83 \%$ ee

图式 60 镍催化喹啉衍生物与有机硼试剂的偶联反应

Scheme 60 Nickel-catalyzed coupling of quinolines derivatives with organoboron reagents

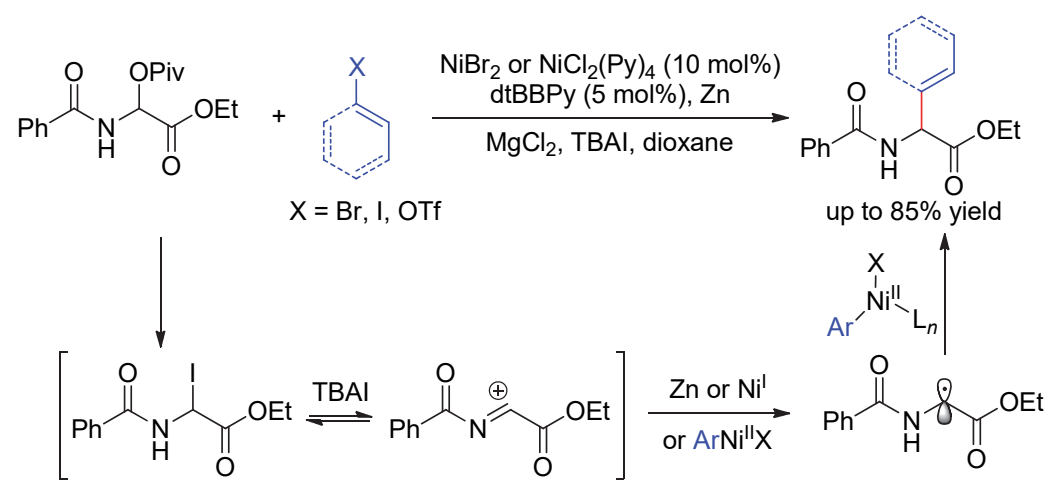

图式 61 镍催化 $\alpha$-新戊酰氧基甘氨酸与有机卤化物的偶联反应

Scheme 61 Nickel-catalyzed coupling of $\alpha$-pivaloyloxy glycine with organic halides

的应用, 从而有利于合成化学、药物化学和更广泛的科 学领域.

\section{References}

[1] (a) Fagnou, K.; Lautens, M. Chem. Rev. 2003, 103, 169. (b) Cherney, A. H.; Kadunce, N. T.; Reisman, S. E. Chem. Rev. 2015, 115, 9587.

[2] (a) Wu, X. F.; Anbarasan, P.; Neumann, H.; Beller, M. Angew. Chem., Int. Ed. 2010, 49, 9047.

(b) Hanna, L. E.; Jarvo, E. R. Angew. Chem., Int. Ed. 2015, 54, 15618.

(c) Li, Y.; Fan, Y.; Jia, Q. Chin. J. Org. Chem. 2019, 39, 350 (in Chinese).

(李娅琼, 范玉航, 贾乾发, 有机化学, 2019, 39, 350.)

[3] (a) Knappke, C. E. I.; Grupe, S.; Gärtner, D.; Corpet, M.; Gosmini, C.; von Wangelin, A. J. Chem.-Eur. J. 2014, 20, 6828.

(b) Moragas, T.; Correa, A.; Martin, R. Chem.-Eur. J. 2014, 20, 8242 .

(c) Weix, D. J. Acc. Chem. Res. 2015, 48, 1767. (d) Gu, J.; Wang, X.; Xue, W.; Gong, H. Org. Chem. Front. 2015, 2 , 1411 .

(e) Zhang, W.; Dai, J.; Xu, H. Chin. J. Org. Chem. 2015, 35, 1820 (in Chinese).

(张文曼, 戴建军, 许华建, 有机化学, 2015, 35, 1820.)

[4] (a) Quan, M.; Tang, L.; Shen, J.; Yang, G.; Zhang, W. Chem. Commun. 2017, 53, 609.

(b) Quan, M.; Wang, X.; Wu, L.; Gridnev, I. D.; Yang, G.; Zhang, W. Nat. Commun. 2018, 9, 2258.

(c) Wang, X.; Quan, M.; Xie, F.; Yang, G.; Zhang, W. Tetrahedron Lett. 2018, 59, 1573.

(d) Lv, X.-Y.; Fan, C.; Xiao, L.-J.; Xie, J.-H.; Zhou, Q.-L. CCS Chem. 2019, 1, 328.

(e) Zhang, Y.; He, J.; Song, P.; Wang, Y.; Zhu, S. CCS Chem. 2020, 2,2259

(f) Li, Z.; Wu, D.; Ding, C.; Yin, G. CCS Chem. 2020, 2, 576.

(g) Wang, Z.-C.; Gao, J.; Cai, Y.; Ye, X.; Shi, S.-L. CCS Chem. 2021, 3, 1445.

(h) You, C.; Li, X.; Gong, Q.; Wen, J.; Zhang, X. J. Am. Chem. Soc. 2019, 141, 14560 .

(i) Li, B.; Chen, J.; Zhang, Z.; Gridnev, I. D.; Zhang, W. Angew. 
Chem., Int. Ed. 2019, 58, 7329.

(j) Liu, D.; Li, B.; Chen, J.; Gridnev, I. D.; Yan. D.; Zhang, W. Nat. Commun. 2020, 11, 5935.

(k) Hu, Y.; Chen, J.; Li, B.; Zhang, Z.; Gridnev, I. D.; Zhang, W. Angew. Chem., Int. Ed. 2020, 59, 5371.

(1) Chen, J.; Zhang, W. Chin. J. Org. Chem. 2020, 40, 4372 (in Chinese).

(陈建中, 张万斌, 有机化学, 2020, 40, 4372.)

(m) Li, B.; Liu, D.; Hu, Y.; Chen, J.; Zhang, Z.; Zhang, W. Eur. J. Org. Chem. 2021, 3421.

(n) Zhu, C.; Yue, H.; Nikolaienko, P.; Rueping, M. CCS Chem. 2020, 2, 179.

(o) Han, X.-W.; Zhang, T.; Yao, W.-W.; Chen, H.; Ye, M. CCS Chem. 2020, 2, 955.

(p) Ding, D.; Dong, H.; Wang, C. CCS Chem. 2021, 3, 718.

(q) Zheng, Y.-L.; Ye, M. Chin. J. Chem. 2020, 38, 489.

(r) Li, Y.-Q.; Li, F.; Shi, S.-L. Chin. J. Chem. 2020, 38, 1035.

(s) Gan, Y.; Zhang, N.; Huang, S.; Liu, Y. Chin. J. Chem. 2020, 38, 1686 .

(t) Xiao, C.; Xiao, W. Chin. J. Org. Chem. 2020, 40, 3004 (in Chinese).

(肖聪，肖文精，有机化学， 2020, 40, 3004.)

(u) Xu, G.-L.; Liu, C.-Y.; Pang, X.; Liu, X.-Y.; Shu, X.-Z. CCS Chem. 2021, 3, 1147.

(v) Shao, P.; Yu, T.; Lu, H.; Xu, P.-F.; Wei, H. CCS Chem. 2020, 2, 1862.

(w) Shen, H.-C.; Chen, Y.; Zhang, Y.; Jiang, H.-M.; Zhang, W.-Q.; Li, W.-A.; Sayed, M.; Zhang, X.; Wu, Y.-D.; Gong, L.-Z. CCS Chem. 2021, 3, 421 .

(x) Zhang, H.; Jia, Y. Chin. J. Org. Chem. 2021, 41, 1749 (in Chinese).

(张晗月, 贾义霞, 有机化学, 2021, 41, 1749.)

[5] (a) Tamaru, Y. Modern Organonickel Chemistry, Wiley-VCH, Weinheim, 2005.

(b) Ogoshi, S. Nickel Catalysis in Organic Synthesis: Methods and Reactions, Wiley-VCH, Weinheim, 2020.

(c) Tasker, S. Z.; Standley, E. A.; Jamison, T. F. Nature 2014, 509, 299.

(d) Ananikov, V. P. ACS Catal. 2015, 5, 1964.

(e) Butt, N. A.; Zhang, W. Chem. Soc. Rev. 2015, 44, 7929.

(f) Choi, J.; Fu, G. C. Science 2017, 356, eaaf7230.

(g) Fu, G. C. ACS Cent. Sci. 2017, 3, 692.

(h) Ruan, L.; Dong, Z.; Chen, C.; Wu, S.; Sun, J. Chin. J. Org. Chem. 2017, 37, 2544 (in Chinese).

(阮利衡, 董振诚, 陈春欣, 吴爽, 孙京, 有机化学, 2017, 37, 2544.)

(i) Zhang, Z.; Butt, N. A.; Zhou, M.; Liu, D.; Zhang, W. Chin. J. Chem. 2018, 36, 443.

(j) Quan, M.; Wu, L.; Yang, G.; Zhang, W. Chem. Commun. 2018, 54, 10394.

(k) Liu, Y.; Bandini, M. Chin. J. Chem. 2019, 37, 431.

(1) Chen, J.; Butt, N. A.; Zhang, W. Res. Chem. Intermed. 2019, 45, 5959 .

(m) Fu, L.; Greßies, S.; Chen, P.; Liu, G. Chin. J. Chem. 2020, 38, 91.

(n) Liu, Y.-H.; Xia, Y.-N.; Shi, B.-F. Chin. J. Chem. 2020, 38, 635.

(o) Liu, Y.; Dong, X.-Q.; Zhang, X. Chin. J. Org. Chem. 2020, 40, 1096 (in Chinese).

(刘元华, 董秀琴, 张绪穆, 有机化学, 2020, 40, 1096.)

(p) Cheng, L.; Zhou, Q. Acta Chim. Sinica 2020, 78, 1017 (in Chinese).

(程磊，周其林，化学学报, 2020, 78, 1017.)

(q) Clevenger, A. L.; Stolley, R. M.; Aderibigbe, J.; Louie, J. Chem. Rev. 2020, 120, 6124.

(r) Li, Z. L.; Jin, J.; Huang, S. H. Chin. J. Org. Chem. 2020, 40, 563 (in Chinese).

(李祯龙, 金健, 黄莎华, 有机化学, 2020, 40, 563.)

(s) Dai, H.; Wu, F.; Bai, D. Chin. J. Org. Chem. 2020, 40, 1423 (in
Chinese).

(代洪雪, 吴芬, 白大昌, 有机化学, 2020, 40, 1423.)

(t) Chen, S.; Zhao, Y. Chin. J. Org. Chem. 2020, 40, 3078 (in Chinese).

(陈思, 赵延川, 有机化学, 2020, 40, 3078.)

(u) Luo, Y.-C.; Xu, C.; Zhang, X. Chin. J. Chem. 2020, 38, 1371.

(v) Xue, W.; Jia, X.; Wang, X.; Tao, X.; Yin, Z.; Gong, H. Chem. Soc. Rev. 2021, 50, 4162 .

(w) Xie, J.-Q.; Liang, R.-X.; Jia, Y.-X. Chin. J. Chem. 2021, 39, 710 .

[6] (a) Rosen, B. M.; Quasdorf, K. W.; Wilson, D. A.; Zhang, N.; Resmerita, A.-M.; Garg, N.; Percec, K. V. Chem. Rev. 2011, 111, 1346 .

(b) Cornella, J.; Zarate, C.; Martin, R. Chem. Soc. Rev. 2014, 43, 8081.

(c) Tobisu, M.; Chatani, N. Acc. Chem. Res. 2015, 48, 1717.

(d) Tollefson, E. J.; Hanna, L. E.; Jarvo, E. R. Acc. Chem. Res. 2015, 48, 2344.

(e) Su, B.; Cao, Z.-C.; Shi, Z.-J. Acc. Chem. Res. 2015, 48, 886.

(f) Zarate, C.; van Gemmeren, M.; Somerville, R. J.; Martin, R. Adv. Organomet. Chem. 2016, 66, 143.

(g) Pound, S. M.; Watson, M. P. Chem. Commun. 2018, 54, 12286.

(h) Liu, J.; Ye, Y.; Sessler, J. L.; Gong, H. Acc. Chem. Res. 2020, $53,1833$.

(i) Xu, J.; Bercher, O. P.; Talley, M. R.; Watson, M. P. ACS Catal. 2021, 11, 1604.

[7] (a) Trost, B. M.; Van Vranken, D. L. Chem. Rev. 1996, 96, 395.

(b) Trost, B. M.; Crawley, M. L. Chem. Rev. 2003, 103, 2921.

(c) Lu, Z.; Ma, S. Angew. Chem., Int. Ed. 2008, 47, 258.

(d) Diéguez, M.; Pàmies, O. Acc. Chem. Res. 2010, 43, 312.

(e) Weaver, J. D.; Recio, A.; Grenning, A. J.; Tunge, J. A. Chem Rev. 2011, 111, 1846.

(f) Huo, X.; Yang, G.; Liu, D.; Liu, Y.; Gridnev, I. D.; Zhang, W. Angew. Chem., Int. Ed. 2014, 53, 6776.

(g) Huo, X.; He, R.; Zhang, X.; Zhang, W. J. Am. Chem. Soc. 2016, 138, 11093.

(h) Tang, H.; Huo, X.; Meng, Q.; Zhang, W. Acta Chim. Sinica 2016, 74, 219 (in Chinese).

(汤溟淏, 霍小红, 孟庆华, 张万斌, 化学学报, 2016, 74, 219.)

(i) Huo, X.; He, R.; Fu, J.; Zhang, J.; Yang, G.; Zhang, W. J. Am. Chem. Soc. 2017, 139, 9819.

(j) Huo, X.; Zhang, J.; Fu, J.; Zhang, W. J. Am. Chem. Soc. 2018, 140,2080 .

(k) Zhang, M.-M.; Luo, Y.-Y.; Lu, L.-Q.; Xiao, W.-J. Acta Chim. Sinica 2018, 76, 838 (in Chinese).

(张毛毛, 骆元元, 陆良秋, 肖文精, 化学学报, 2018, 76, 838.)

(1) Li, Z.; Zheng, J.; Li, C.; Wu, W.; Jiang, H. Chin. J. Chem. 2019, 37,140

(m) Wang, R.; Luan, Y.; Ye, M. Chin. J. Chem. 2019, 37, 720.

(n) Yao, K.; Liu, H.; Yuan, Q.; Liu, Y.; Liu, D.; Zhang, W. Acta Chim. Sinica 2019, 77, 993 (in Chinese).

(姚坤, 刘浩, 袁乾家, 刘燕刚, 刘德龙, 张万斌, 化学学报, 2019, 77, 993.)

(o) Zhang, H.-H.; Yu, S. Acta Chim. Sinica 2019, 77, 832 (in Chinese).

(张洪浩, 俞寿云, 化学学报, 2019, 77, 832.)

(p) Zhang, H.; Gu, Q.; You, S. Chin. J. Org. Chem. 2019, 39, 15 (in Chinese).

(张慧君，顾庆，游书力，有机化学, 2019, 39, 15.)

(q) Huang, L.; Cai, Y.; Zhang, H.-J.; Zheng, C.; Dai, L.-X.; You, S.-L. CCS Chem. 2019, 1, 106.

(r) Wang, R.-Q.; Shen, C.; Cheng, X.; Wang, Z.-F.; Tao, H.-Y.; Dong, X.-Q.; Wang, C.-J. Chin. J. Chem. 2020, 38, 807.

(s) He, R.; Huo, X.; Zhao, L.; Wang, F.; Jiang, L.; Liao, J.; Zhang, W. J. Am. Chem. Soc. 2020, 142, 8097.

(t) Wang, Y.; Luo, S. Chin. J. Org. Chem. 2020, 40, 2161 (in Chinese).

(王娅宁，罗三中，有机化学, 2020, 40, 2161.) 
(u) Ju, C.; Wu, Z.; Li, Y.; Zhang, W. Chin. J. Org. Chem. 2020, 40, 3925 (in Chinese)

(居辰阳, 吴正兴, 李云艺, 张万斌, 有机化学, 2020, 40, 3925.)

(v) Li, G.; Huo, X.; Jiang, X.; Zhang, W. Chem. Soc. Rev. 2020, 49, 2060

(w) Ma, X.; Yu, J.; Wang, Z.; Zhang, Y.; Zhou, Q. Chin. J. Org. Chem. 2020, 40, 2669 (in Chinese).

(马献涛, 于静, 王子龙, 张牮, 周秋菊, 有机化学, 2020, 40, 2669.)

(x) Tian, F.; Zhang, J.; Yang, W.; Deng, W. Chin. J. Org. Chem. 2020, 40, 3262 (in Chinese)

(田飞, 张键, 杨武林, 邓卫平, 有机化学, 2020, 40, 3262.)

(y) Huo, X.; Zhao, L.; Luo, Y.; Wu, Y.; Sun, Y.; Li, G.; Gridneva, T.; Zhang, J.; Ye, Y.; Zhang, W. CCS Chem. 2021, 3, 1933.

(z) Xiao, J.; Xu, H.; Huo, X.; Zhang, W.; Ma, S. Chin. J. Chem. 2021, 39, 1958

[8] Yanagisawa, A.; Nomura, N.; Habaue, S.; Yamamoto, H. Tetrahedron Lett. 1989, 30, 6409.

[9] Nagel, U.; Nedden, H. G. Inorg. Chim. Acta 1998, 269, 34

[10] (a) Novak, A.; Fryatt, R.; Woodward, S. C. R. Chim. 2007, 10, 206. (b) Novak, A.; Calhorda, M. J.; Costa, P. J.; Woodward, S. Eur. J. Org. Chem. 2009, 898.

[11] Sumida, Y.; Hayashi, S.; Hirano, K.; Yorimitsu, H.; Oshima, K. Org. Lett. 2008, 10, 1629.

[12] Matsubara, R.; Jamison, T. F. J. Am. Chem. Soc. 2010, 132, 6880

[13] Ho, C.-Y.; Jamison, T. F. Angew. Chem., Int. Ed. 2007, 46, 782.

[14] Wang, Z.-J.; Zheng, S.; Romero, E.; Matsui, J. K.; Molander, G. A. Org. Lett. 2019, 21, 6543.

[15] Tran, V. T.; Li, Z.-Q.; Gallagher, T. J.; Derosa, J.; Liu, P.; Engle, K. M. Angew. Chem., Int. Ed. 2020, 59, 7029.

[16] Eno, M. S.; Lu, A.; Morken, J. P. J. Am. Chem. Soc. 2016, 138, 7824.

[17] Guan, B.-T.; Xiang, S.-K.; Wang, B.-Q.; Sun, Z.-P.; Wang, Y.; Zhao, K.-Q.; Shi, Z.-J. J. Am. Chem. Soc. 2008, 130, 3268

[18] Yu, D.-G.; Wang, X.; Zhu, R.-Y.; Luo, S.; Zhang, X.-B.; Wang, B.-Q.; Wang, L.; Shi, Z.-J. J. Am. Chem. Soc. 2012, 134, 14638.

[19] Huang, Y. K.; Li, G.; Huang, W.-P.; Yu, D.-G.; Shi, Z.-J. Chem. Commun. 2011, 47, 7224.

[20] Barreiro, E. J.; Kümmerle, A. E.; Fraga, C. A. M. Chem. Rev. 2011, 111,5215 .

[21] Liang, Z.; Xue, W.; Lin, K.; Gong, H. Org. Lett. 2014, 16, 5620.

[22] Xu, H.; Zhao, C.; Qian, Q.; Deng, W.; Gong, H. Chem. Sci. 2013, 4, 4022.

[23] Wang, J.; Zhao, J.; Gong, H. Chem. Commun. 2017, 53, 10180.

[24] Komeyama, K.; Michiyuki, T.; Osaka, I. ACS Catal. 2019, 9, 9285.

[25] Smith, R. T.; Zhang, X.; Rincon, J. A.; Agejas, J.; Mateos, C.; Barberis, M.; García-Cerrada, S.; de Frutos, O.; MacMillan, D. W. C. J. Am. Chem. Soc. 2018, 140, 17433.

[26] Le, C.; Chen, T. Q.; Liang, T.; Zhang, P.; MacMillan, D. W. C. Science 2018, 360, 1010.

[27] (a) Chatgilialoglu, C. Acc. Chem. Res. 1992, 25, 188. (b) Chatgilialoglu, C.; Ferreri, C.; Landais, Y.; Timokhin, V. I. Chem. Rev. 2018, 118, 6516.

[28] Durandetti, M.; Devaud, M.; Perichon, J. New J. Chem. 1996, 20, 659

[29] Gutierrez, O.; Tellis, J. C.; Primer, D. N.; Molander, G. A.; Kozlowski, M. C. J. Am. Chem. Soc. 2015, 137, 4896.

[30] (a) Lin, X.; Phillips, D. L. J. Org. Chem. 2008, 73, 3680.

(b) Breitenfeld, J.; Ruiz, J.; Wodrich, M. D.; Hu, X. J. Am. Chem. Soc. 2013, 135, 12004.

[31] Dai, Y.; Wu, F.; Zang, Z.; You, H.; Gong, H. Chem.-Eur. J. 2012, 18,808 .

[32] Moragas, T.; Cornella, J.; Martin, R. J. Am. Chem. Soc. 2014, 136, 17702 .

[33] Chen, H.; Jia, X.; Yu, Y.; Qian, Q.; Gong, H. Angew. Chem., Int. Ed. 2017, 56, 13103.

[34] Ackerman, L. K. G.; Anka-Lufford, L. L.; Naodovic, M.; Weix, D. J. Chem. Sci. 2015, 6, 1115 .
[35] Yan, X.-B.; Li, C.-L.; Jin, W.-J.; Guo, P.; Shu, X.-Z. Chem. Sci. 2018, 9, 4529 .

[36] Konev, M. O.; Hanna, L. E.; Jarvo, E. R. Angew. Chem., Int. Ed. 2016, 55, 6730.

[37] Pan, Y.; Gong, Y.; Song, Y.; Tong, W.; Gong, H. Org. Biomol. Chem. 2019, 17, 4230.

[38] Guo, P.; Wang, K.; Jin, W.-J.; Xie, H.; Qi, L.; Liu, X.-Y.; Shu, X.-Z J. Am. Chem. Soc. 2021, 143, 513.

[39] (a) Diccianni, J. B.; Diao, T. Trends Chem. 2019, 1, 830. (b) Everson, D. A.; Weix, D. J. J. Org. Chem. 2014, 79, 4793.

[40] Kariofillis, S. K.; Shields, B. J.; Tekle-Smith, M. A.; Zacuto, M. J.; Doyle, A. G. J. Am. Chem. Soc. 2020, 142, 7683.

[41] Suga, T.; Ukaji, Y. Org. Lett. 2018, 20, 7846.

[42] (a) Biswas, S.; Weix, D. J. J. Am. Chem. Soc. 2013, 135, 16192. (b) Gutierrez, O.; Tellis, J. C.; Primer, D. N.; Molander, G. A.; Kozlowski, M. C. J. Am. Chem. Soc. 2015, 137, 4896.

(c)Wang, X.; Ma, G.; Peng, Y.; Pitsch, C. E.; Moll, B. J.; Ly, T. D.; Wang, X.; Gong, H. J. Am. Chem. Soc. 2018, 140, 14490.

[43] Chenniappan, V. K.; Peck, D.; Rahaim, R. Tetrahedron Lett. 2020 , 61,151729 .

[44] Jia, X.-G.; Guo, P.; Duan, J.; Shu, X.-Z. Chem. Sci. 2018, 9, 640

[45] van Gemmeren, M.; Börjesson, M.; Tortajada, A.; Sun, S.-Z.; Okura, K.; Martin, R. Angew. Chem., Int. Ed. 2017, 56, 6558.

[46] Consiglio, G.; Morandini, F.; Piccolo, O. Helv. Chim. Acta 1980, 63, 987.

[47] (a) Consiglio, G.; Morandini, F.; Piccolo, O. J. Chem. Soc., Chem. Commun. 1983, 112.

(b) Consiglio, G.; Piccolo, O.; Roncetti, L.; Morandini, F. Tetrahedron 1986, 42, 2043

(c) Indolese, A. F.; Consiglio, G. Organometallics 1994, 13, 2230. (d) Consiglio, G.; Indolese, A. Organometallics 1991, 10, 3425.

[48] Chung, K.-G.; Miyake, Y.; Uemura, S. J. Chem. Soc., Perkin Trans. $12000,2725$.

[49] Hiyama, T.; Wakasa, N. Tetrahedron Lett. 1985, 26, 3259.

[50] Nomura, N.; RajanBabu, T. V. Tetrahedron Lett. 1997, 38, 1713.

[51] Didiuk, M. T.; Morken, J. P.; Hoveyda, A. H. Tetrahedron 1998, 54, 1117.

[52] (a) Eliel, E. L.; Wilen, S. H. Stereochemistry of Organic Compounds, John Wiley \& Sons, New York, 1994.

(b) Walsh, P. J.; Kowzlowski, M. C. Fundamentals of Asymmetric Catalysis, University Science Books, Sausalito, CA, 2009.

[53] Taylor, B. L. H.; Swift, E. C.; Waetzig, J. D.; Jarvo, E. R. J. Am Chem. Soc. 2011, 133, 389

[54] Yonova, I. M.; Johnson, A. G.; Osborne, C. A.; Moore, C. E.; Morrissette, N. S.; Jarvo, E. R. Angew. Chem., Int. Ed. 2014, 53, 2422.

[55] (a) Greene, M. A.; Yonova, I. M.; Williams, F. J.; Jarvo, E. R. Org. Lett. 2012, 14, 4293.

(b) Taylor, B. L. H.; Harris, M. R.; Jarvo, E. R. Angew. Chem., Int. Ed. 2012, 51, 7790 .

[56] Tollefson, E. J.; Dawson, D. D.; Osborne, C. A.; Jarvo, E. R. J. Am Chem. Soc. 2014, 136, 14951.

[57] Dawson, D. D.; Jarvo, E. R. Org. Process Res. Dev. 2015, 19, 1356.

[58] (a) Chen, P.-P.; Lucas, E. L.; Greene, M. A.; Zhang, S.-Q.; Tollefson, E. J.; Erickson, L. W.; Taylor, B. L. H.; Jarvo, E. R.; Hong, X. J. Am. Chem. Soc. 2019, 141, 5835.

(b) Dawson, D. D.; Oswald, V. F.; Borovik, A. S.; Jarvo, E. R. Chem.-Eur. J. 2020, 26, 3044.

[59] Wisniewska, H. M.; Swift, E. C.; Jarvo, E. R. J. Am. Chem. Soc 2013, 135, 9083

[60] Do, H.-Q.; Chandrashekar, E. R. R., Fu, G. C. J. Am. Chem. Soc. 2013, 135, 16288

[61] Yang, B.; Wang, Z.-X. J. Org. Chem. 2017, 82, 4542.

[62] Nielsen, D. K.; Doyle, A. G. Angew. Chem., Int. Ed. 2011, 50, 6056.

[63] (a) Jørgensen, K. A.; Schioett, B. Chem. Rev. 1990, 90, 1483.

(b) de Bruin, B.; Budzelaar, P. H. M.; Gal, A. W. Angew. Chem., Int. Ed. 2004, 43, 4142.

(c) Lenarda, M.; Pahor, N. B.; Calligaris, M.; Graziani, M.; Randaccio, L. J. Chem. Soc., Dalton Trans. 1978, 279. 
(d) Schlodder, R.; Ibers, J.; Lenarda, M.; Graziani, M. J. Am. Chem. Soc. 1974, 96, 6893.

(e) Molinaro, C.; Jamison, T. J. Am. Chem. Soc. 2003, 125, 8076.

[64] Harris, M. R.; Hanna, L. E.; Greene, M. A.; Moore, C. E.; Jarvo, E. R. J. Am. Chem. Soc. 2013, 135, 3303.

[65] Zhang, S.-Q.; Taylor, B. L. H.; Ji, C.-L.; Gao, Y.; Harris, M. R.; Hanna, L. E.; Jarvo, E. R.; Houk, K. N.; Hong, X. J. Am. Chem. Soc. 2017, 139, 12994.

[66] Zhou, Q.; Srinivas, H. D.; Dasgupta, S.; Watson, M. P. J. Am. Chem. Soc. 2013, 135, 3307.

[67] Chung, K.-G.; Miyake, Y.; Uemura, S. J. Chem. Soc., Perkin Trans. $12000,15$.

[68] Chen, H.; Deng, M.-Z. J. Organomet. Chem. 2000, 603, 189.

[69] (a) Kobayashi, Y.; Tokoro, Y.; Watatani, K. Tetrahedron Lett. 1998, 39, 7537.

(b) Kobayashi, Y.; Mizojiri, R.; Ikeda, E. J. Org. Chem. 1996, 61, 5391.

(c) Kobayashi, Y.; Watatani, K.; Kikori, Y.; Mizojiri, R. Tetrahedron Lett. 1996, 37, 6125.

(d) Kobayashi, Y.; Takahisa, E.; Usmani, S. B. Tetrahedron Lett. 1998, 39, 597 .

(e) Kobayashi, Y.; Tokoro, Y.; Watatani, K. Eur. J. Org. Chem. 2000, 3825 .

[70] Srinivas, H. D.; Zhou, Q.; Watson, M. P. Org. Lett. 2014, 16, 3596.

[71] Cobb, K. M.; Rabb-Lynch, J. M.; Hoerrner, M. E.; Manders, A.; Zhou, Q.; Watson, M. P. Org. Lett. 2017, 19, 4355.

[72] Gao, M.; Sun, D.; Gong, H. Org. Lett. 2019, 21, 1645.

[73] Song, F.; Wang, F.; Guo, L.; Feng, X.; Zhang, Y.; Chu, L. Angew. Chem., Int. Ed. 2020, 59, 177.

[74] Zhang, X.; MacMillan, D. W. C. J. Am. Chem. Soc. 2016, 138, 13862.

[75] Lin, Z.; Jin, Y.; Hu, W.; Wang, C. Chem. Sci. 2021, 12, 6712.
[76] Zhao, Y.; Weix, D. J. J. Am. Chem. Soc. 2014, 136, 48.

[77] Zhao, Y.; Weix, D. J. J. Am. Chem. Soc. 2015, 137, 3237.

[78] Parasram, M.; Shields, B. J.; Ahmad, O.; Knauber, T.; Doyle, A. G ACS Catal. 2020, 10, 5821.

[79] Hu, P.; Chi, H. M.; DeBacker, K. C.; Gong, X.; Keim, J. H.; Hsu, I. T.; Snyder, S. A. Nature 2019, 569, 703.

[80] Mills, L. R.; Monteith, J. J.; dos Passos Gomes, G.; Aspuru-Guzik, A.; Rousseaux, S. A. L. J. Am. Chem. Soc. 2020, 142, 13246.

[81] Mills, L. R.; Monteith, J. J.; Rousseaux, S. A. L. Chem. Commun. 2020, 56, 12538 .

[82] Ye, Y.; Chen, H.; Sessler, J. L.; Gong, H. J. Am. Chem. Soc. 2019, $141,820$.

[83] Zhou, Q.; Cobb, K. M.; Tan, T.; Watson, M. P. J. Am. Chem. Soc. 2016, 138, 12057.

[84] Xu, J.; Pound, S. M.; Basch, C. H.; Duke, A. D.; Watson, M. P. ChemRxiv DOI: 10.26434/chemrxiv.14403302.v1.

[85] Xu, J.; Bercher, O. P.; Watson, M. P. J. Am. Chem. Soc. 2021, 143, 8608.

[86] Wang, Z.; Yin, H.; Fu, G. C. Nature 2018, 563, 379.

[87] Wu, L.; Yang, G.; Zhang, W. CCS Chem. 2019, 1, 623.

[88] Gomez-Bengoa, E.; Heron, N. M.; Didiuk, M. T.; Luchaco, C. A.; Hoveyda, A. H. J. Am. Chem. Soc. 1998, 120, 7649.

[89] Wu, K.; Doyle, A. G. Nat. Chem. 2017, 9, 779.

[90] Arendt, K. M.; Doyle, A. G. Angew. Chem., Int. Ed. 2015, 54, 9876.

[91] Lin, Z.; Lan, Y.; Wang, C. ACS Catal. 2019, 9, 775.

[92] Graham, T. J. A.; Shields, J. D.; Doyle, A. G. Chem. Sci. 2011, 2, 980.

[93] Shields, J. D.; Ahneman, D. T.; Graham, T. J. A.; Doyle, A. G. Org. Lett. 2014, 16, 142.

[94] Tao, X.; Chen, Y.; Guo, J.; Wang, X.; Gong, H. Chem. Sci. 2021, $12,220$. 